\title{
Beyond prejudice: Are negative evaluations the problem and is getting us to like one another more the solution?
}

\author{
John Dixon \\ Department of Psychology, Open University, Milton Keynes MK7 6AA, \\ United Kingdom

\begin{abstract}
For most of the history of prejudice research, negativity has been treated as its emotional and cognitive signature, a conception that continues to dominate work on the topic. By this definition, prejudice occurs when we dislike or derogate members of other groups. Recent research, however, has highlighted the need for a more nuanced and "inclusive" (Eagly 2004) perspective on the role of intergroup emotions and beliefs in sustaining discrimination. On the one hand, several independent lines of research have shown that unequal intergroup relations are often marked by attitudinal complexity, with positive responses such as affection and admiration mingling with negative responses such as contempt and resentment. Simple antipathy is the exception rather than the rule. On the other hand, there is mounting evidence that nurturing bonds of affection between the advantaged and the disadvantaged sometimes entrenches rather than disrupts wider patterns of discrimination. Notably, prejudice reduction interventions may have ironic effects on the political attitudes of the historically disadvantaged, decreasing their perceptions of injustice and willingness to engage in collective action to transform social inequalities.

These developments raise a number of important questions. Has the time come to challenge the assumption that negative evaluations are inevitably the cognitive and affective hallmarks of discrimination? Is the orthodox concept of prejudice in danger of side-tracking, if not obstructing, progress towards social justice in a fuller sense? What are the prospects for reconciling a prejudice reduction model of change, designed to get people to like one another more, with a collective action model of change, designed to ignite struggles to achieve intergroup equality?
\end{abstract}

Keywords: contact; collective action; intergroup relations; prejudice; prejudice reduction social change

\section{Introduction}

Over the past century, the concept of prejudice has become increasingly central to scientific thinking about relations between groups, marking a profound moral and political, as well as a conceptual shift. During the late nineteenth and early twentieth centuries, many scholars favoured conceptual frameworks based around notions of group differences, hierarchy, and biological inheritance (e.g., see Goldberg 1993; Haller 1971). By rooting the causes of 
ethnic and racial hostility in the supposed characteristics of its targets, these scholars upheld the traditional doctrine of the "well-deserved reputation" (Zawadzki 1948). Between the 1920s and 1940s, however, an "abrupt reversal" (Samelson 1978) occurred in scientific thinking. Rather than crediting it to the inherited deficiencies of minorities, social disharmony was attributed increasingly to the bigotry of majority group members. ${ }^{1}$ In the years following the end of World War II, the concept of prejudice became central to the explanation of a range of social problems, including problems of discrimination, inequality, ideological extremism, and genocide. By the 1950s, prejudice research had "spread like a flood both in social psychology and in

John Dixon is a professor of Social Psychology at the Open University in the United Kingdom. He has published extensively around themes of prejudice, inequality, and social change. His research has appeared in journals such as American Psychologist, Psychological Science, Current Directions in Psychological Science, the Journal of Social Issues, Political Psychology, the British Journal of Social Psychology, and the European Journal of Social Psychology. He is currently co-editor (with Jolanda Jetten) of the British Journal of Social Psychology and is co-author (with Kevin Durrheim) of Racial Encounter: The Social Psychology of Contact and Desegregation (Routledge).

Mark Levine is a professor of Social Psychology at the University of Exeter in the United Kingdom. His research explores the impact of group processes in pro-social and anti-social behaviour, with a particular focus in the role of third parties in regulating aggressive and violent behaviour. He has published in journals such as Psychological Science, American Psychologist, Journal of Personality and Social Psychology, Personality and Social Psychology Bulletin, and British Journal of Social Psychology. He is co-editor (with John Dixon) of the 2012 book Beyond Prejudice: Extending the Social Psychology of Intergroup Conflict, Inequality and Social Change (Cambridge University Press).

Stephen Reicher is a professor of Psychology at the University of St. Andrews, Fellow of the Royal Society of Edinburgh, Academician of the Social Sciences, past editor of the British Journal of Social Psychology and scientific consultant to Scientific American Mind. He works on the relationship between social identity and collective action and covers such topics as crowd behaviour, nationalism, leadership, intergroup hatred, and the psychology of tyranny. His recent books are The New Psychology of Leadership (2010, with Alex Haslam and Michael Platow) and Mad Mobs and Englishmen?: Myths and Realities of the 2011 Riots (2011, with Clifford Stott).

Kevin Durrheim is a professor of Psychology at the University of KwaZulu-Natal, where he teaches social psychology and research methods. He writes on topics related to racism, segregation, and social change. He has co-authored Race Trouble (Durrheim, Mtose \& Brown, 2011, Lexington Press) and Racial Encounter (Durrheim \& Dixon, 2005, Routledge); and is coeditor of Research in Practice (1999, 2006, UCT Press) and Numbers, Hypotheses and Conclusions (2002, UCT Press). adjacent social sciences" (Allport 1951, p. 4). The deluge continued in subsequent decades, and prejudice rapidly became a fundamental concept within research on intergroup relations.

Yet what is prejudice? The modern roots of the term lie in the eighteenth century with enlightenment liberalism, which distinguished opinions based on religious authority and tradition from opinions based on reason and scientific rationality (Billig 1988). The legacy of this ideological heritance has been prominent in modern research, which often treats prejudice as a form of thinking that distorts social reality, leading us to judge "a specific person on the basis of preconceived notions, without bothering to verify our beliefs or examine the merits of our judgements" (Saenger 1953, p. 3).

However, prejudice has seldom been treated purely as a matter of irrational beliefs. It has also been widely characterized as a negative evaluation ${ }^{2}$ of others made on the basis of their group membership (see Table 1). The nature of the relationship between the cognitive and affective dimensions of this kind of evaluation has, of course, generated considerable debate. For some researchers, prejudice should be regarded as an indissoluble combination of both; for others, emotional antipathy lies at the core of the problem, with concepts such as stereotyping being treated as empirically related but analytically distinct (e.g., see Duckitt 1992, pp. 11-13). Likewise, although most researchers have conceived prejudice as a generic negative response to members of another group, others have attempted to differentiate emotional subcategories. Kramer (1949) was an early advocate of this approach. His work prefigured recent developments in research on intergroup emotions, evolutionary psychology, and social neuroscience, which has increasingly focused on target-specific reactions such as fear, anger, and disgust and on the evolutionary and neurological mechanisms that underpin such reactions (e.g., see Cottrell \& Neuberg 2005; Harris \& Fiske 2006; Neuberg et al. 2011; Phelps et al. 2000).

The underlying causes of our negative evaluations of others have also been subject to considerable debate, and theoretical accounts have shifted over time. Explanations of prejudice have been grounded variously in personality

\section{Table 1. Some definitions of prejudice}

"feelings of intergroup hostility" (Allport \& Kramer 1946, p. 9)

"an antipathy based upon a faulty and inflexible generalization" (Allport 1954, p. 10)

"a negative attitude towards members of a minority group" (Levin \& Levin 1982, p. 66)

"a negative attitude towards members of socially defined groups" (Stephan 1983, p. 417)

"the holding of derogatory social attitudes or cognitive beliefs, the expression of negative affect or the display of hostile or discriminatory behaviour towards members of a group on account of their membership of that group" (Brown 1995, p. 8) "an unjustified, usually negative, attitude directed towards others because of their social category or group membership" (Sampson 1999, p. 4)

"the human individual's psychological tendency to make unfavorable evaluations about members of other social groups" (Ibanez et al. 2009, p. 81) 
Dixon et al.: Beyond prejudice

development, socialization, social cognition, evolutionary psychology, and neuroscience, as well as in sociological theories of normative and instrumental conflict (for overviews, see Brown 1995; Dovidio 2001; Dovidio et al. 2005; Duckitt 1992; Nelson 2009; Neuberg \& Cottrell 2006; Quillian 2006; Wetherell \& Potter 1992). Moreover, whereas earlier theories focused on "hot," direct, and explicit forms of prejudice (e.g., Adorno et al. 1950; Dollard et al. 1939; Sherif et al. 1961), modern theories often prioritize "cool," indirect, and implicit evaluations (e.g., Dovidio \& Gaertner 2004; Kinder \& Sears 1981; Pettigrew \& Meertens 1995). Notwithstanding this historical and conceptual complexity, at the heart of most prejudice research is a deceptively simple question: Why don't we like one another?

This question also underlies a closely related body of research on prejudice reduction, which encompasses work on interventions such as reeducation, perspective taking, cooperative learning, common identification, empathy arousal, and intergroup contact (e.g., Aronson \& Patnoe 1997; Lilienfeld et al. 2009; Pettigrew \& Tropp 2006; Stephan \& Finlay 1999). Although evidence of their effectiveness has been challenged (Paluck \& Green 2009), such interventions are typically portrayed as a shining example-perhaps the shining example-of how social science research on intergroup relations can promote a better society (e.g., see Brewer 1997). To be sure, in meeting the challenge of prejudice reduction, researchers have adopted varying theoretical perspectives, with varying implications for how processes of change are formulated. Perspectives treating prejudice as the outcome of deep-seated personality dynamics, for example, have constructed the problem of change differently than perspectives treating it as the outcome of more tractable forces such as social norms (e.g., Long 1951). Likewise, perspectives treating prejudice as a consciously held attitude have constructed change differently than perspectives treating it as an automatic and implicit process (e.g., Olson \& Fazio 2006; Wheeler \& Fiske 2005). By and large, however, advocates of prejudice reduction have united around a central imperative, which has become an interdisciplinary rallying call: How can we get individuals to think more positive thoughts about, and hold more positive feelings towards, members of other groups? In short, how can we get people to like each other?

The point of the present article is not to devalue research on prejudice or to deny its profound historical significance. Rather, we wish to explore the limits of the orthodox conception of prejudice as negative evaluation. What has this conception contributed to knowledge about relations between groups and what has it obscured? How effective or ineffective has it been in guiding attempts to improve such relations? This article has two main sections. The first section presents some critical alternatives to, or substantive elaborations of, the traditional concept of prejudice. We capitalize in particular on developments in research on paternalistic ideology, ambivalent sexism, infra-humanization, common identification, and intergroup helping. The second section interrogates the related process of prejudice reduction, focusing on emerging research on the paradoxical consequences of intergroup contact. We argue that it is especially in the arena of social change that the traditional concept of prejudice falls short, and developing this theme, we discuss the tensions between prejudice reduction and collective action models of change. The article's conclusion outlines directions for future research and recommends some ways in which researchers might move "beyond prejudice."

\section{Limits of a concept of prejudice as negative evaluation}

\subsection{The "velvet glove" of benign discrimination}

Sherif's Summer Camp studies are amongst the most influential studies ever conducted on prejudice (Sherif et al. 1961). They are rightly heralded as classics in the psychological and sociological literature. By creating an experimental context in which groups of boys competed for scarce resources, Sherif and his collaborators famously manufactured forms of intergroup hostility that echoed all too starkly the violence of intergroup conflict in the real world. They demonstrated that ordinary children with no prior history of animosity or special inclination towards bigotry - could rapidly develop many of the hallmarks of extreme prejudice if placed under the right structural conditions, including negative stereotyping, voluntary segregation, and verbal and physical aggression.

In a fascinating thought experiment, however, Mary Jackman (1994) asks us to consider how events might have unfolded in these studies had the following conditions prevailed: (1) relations were protracted in time; (2) one group of boys achieved stable dominance over the other in terms of the commandeering of valued resources; and (3) that this dominance depended on their securing an ongoing transfer of benefits from the subordinate group. Such conditions, of course, mirror real relations of class, race, and gender more faithfully than the brief, equal status, zero sum competition engineered by Sherif. Jackman argues that these conditions also yield a very different pattern of intergroup responses than that evidenced by the Summer Camp studies.

The point of her thought experiment is not to discredit Sherif's contribution. Instead, Jackman wants to highlight the contextual specificity of the Summer Camp findings and to challenge the assumption that negative reactions typify everyday relations in historically unequal societies. To the contrary, she argues, real relations of domination and subordination are marked by emotional complexity and ambivalence, with positive responses such as affection and admiration mingling with negative responses such as contempt and resentment. Sherifs work constitutes the exception rather than the rule. According to Jackman (1994; 2005), it also captures a wider tendency for researchers to overemphasize the role of antipathy within discriminatory relations between groups.

Jackman's (1994) landmark book, The Velvet Glove, addresses this problem, exposing the insidious role of positive intergroup emotions in the reproduction of systems of inequality. Under conditions of long-term, stable inequality, she contends, it is neither functional nor feasible for members of dominant groups to maintain uniformly negative attitudes towards subordinates. Given that dominants are dependent on subordinates' cooperation in order to sustain a smooth transfer of benefits (e.g., in the form of labour and services), the ideal social system is one of paternalism. Within paternalistic systems, role differentiation allows dominants to define the ideal characteristics of 
subordinates in ways that sustain the status quo and then to reward those who display these characteristics with affirmation, admiration, and even love. Such systems sugar-coat the harsh realities of inequality by framing social relations in more palatable terms for both dominant and subordinate group members. For dominants, exploitation is transformed into paternalistic regard. For subordinates, exploitation becomes more difficult to recognize and to resist. The bonds of connection fostered by paternalistic institutions encourage subordinates to identify with the very roles on which their subordination is founded. They nurture positive feelings for the dominant group and decrease the motivation to challenge the status quo, a point elaborated later in the article (sects. 3.1, 3.2, 4).

Gender relations provide the clearest illustration of paternalistic influences on intergroup attitudes, exposing the limits of a concept of prejudice based solely around negative evaluation. Such relations were largely ignored in early work in the field, when the foundations of prejudice research were laid. Yet few commentators would nowadays dispute that gender discrimination remains pervasive or that men are often its complicit beneficiaries. At the same time, evidence suggests that many men express warm emotional attitudes towards women. Indeed, they tend to like them more than they like other men, a phenomenon that is sometimes labeled, not a little ironically, the "women are wonderful effect" (Eagly \& Mladinic 1989; 1993). If men behave in ways that maintain gender inequality and discriminate against women, then it is not because they feel some sort of generic hostility towards them. The traditional concept of prejudice as "unalloyed antipathy" (Glick \& Fiske 2001, p. 109) does not seem to fit well.

\subsection{Ambivalent sexism (and racism)}

This paradox has been investigated recently by researchers working within the theoretical framework of Ambivalent Sexism developed by Peter Glick and Susan Fiske. According to Glick \& Fiske (2001), sexist attitudes come in two forms. Hostile Sexism (HS) refers to attitudes of overt "hostility towards women who challenge male power" (Glick et al. 2004, p. 715), and this concept is broadly consistent with an approach that treats prejudice as negative evaluation. Benevolent Sexism (BS), by contrast, refers to attitudes that seem supportive towards women, treating them as "wonderful fragile creatures who ought to be protected and provided for by men" (Glick et al. 2004, p. 715), but also as creatures who lack agency and independence.

HS and BS are manifest in all cultures and, according to Glick, Fiske, and others, their ubiquity expresses a fundamental ambivalence in attitudes towards women. On the one hand, as a subordinate group, women must be kept in their "proper place." This encourages the derogation of those who threaten (the legitimacy of) male advantage. On the other hand, men are dependent on women for, among other benefits, the provision of emotional support, child care, and sexual gratification. This encourages the veneration of women who "know their place," whose conformity to traditional gender roles inspires admiration, idealization, sacrifice, and protectiveness. In everyday situations, of course, the expression of these hostile or benevolent attitudes is highly flexible, varying, for example, according to whether female targets are perceived as undermining (e.g., “career woman”) or supporting (e.g., "homemaker") the wider gender hierarchy (see also Eagly 2004).

Ambivalent sexism theory is relevant to our argument here because it directly challenges the assumption that intergroup prejudice - and associated forms of discrimination - operates primarily via attitudinal negativity. The point of the theory is not simply to explain how men express and reconcile their polarized attitudes towards women, but also to highlight the broader ideological role of $\mathrm{HS}$ and BS in maintaining gender inequality. A number of issues are worth flagging here.

First, BS is associated with a range of discriminatory beliefs, attributions, and behaviours (e.g., see Abrams et al. 2003; Chapleau et al. 2007; Rye \& Meaney 2010). Yet because of its veneer of affectionate regard for (certain types of) women, BS is less readily perceived as sexist as HS (Barreto \& Ellemers 2005). It is hence a defensible ideology in societies where gender equality is a social ideal. Second and related, as well as shaping men's gender attitudes, BS plays a powerful role in structuring women's attitudes towards other women. Longitudinal research indicates, for example, that women who score high on BS are more likely to express hostile attitudes towards their own gender in the future (Sibley et al. 2007). They are also more likely to judge women who transgress traditional gender roles harshly and to support female behaviour that affirms these roles, such as the use of beauty products (e.g., Forbes et al. 2006). Third, it is important to appreciate how hostile and benevolent attitudes act in tandem to sustain the status quo. Cross-national research suggests that individuals' scores on measures of BS and HS tend to be positively correlated and that national averages for both forms of sexism are elevated in societies with higher levels of gender inequality (Glick \& Fiske 2001).

As this brief review illustrates, emerging research on Ambivalent Sexism has gone some way to answering Jackman's (2005, p. 89) call for researchers to "dethrone hostility" as the affective hallmark of discriminatory relations. To what extent, however, can work on attitudes in the field of gender relations be generalized to other kinds of intergroup relations?

Doubtless, gender relations are in several senses a "special case," involving unusually intense forms of intimacy and interdependency (see also Glick \& Fiske 1996). Even so, there is growing evidence that other kinds of intergroup relations may be characterized by a similar blend of positive and negative elements. Recent research on stereotype content demonstrates, for example, that groups other than women (e.g., the elderly) evoke paternalistic prejudices, which combine positive attributions of emotional warmth with negative attributions of intellectual incompetence. Conversely, other groups (e.g., Jews) evoke so-called "envious" prejudices, which combine attributions of intellectual competence with attributions of emotional coldness (see Cuddy et al. 2008).

Along similar lines, Jackman $(1994 ; 2005)$ holds that systems of domination other than patriarchy rely on a combination of negative and paternalistic attitudes, a claim supported by an array of historical evidence. Consider, for example, the history of slavery in the United States. In their monumental study of the mind of Southern slaveholders, Elizabeth Fox-Genovese and Eugene Genovese (2005) point out that enslaved people were widely viewed 
Dixon et al.: Beyond prejudice

as a sacred trust to whom the owners owed paternal care. As an illustration, they cite one such slaveholder, John Hartwell Cocke, who insisted that dutiful slaves should be treated with "kindness, and even sometimes with indulgence" (p. 370) and condemned the whipping of a slave out of passion or malice as "absolutely mean and unmanly" ( $p$. 370). In stark contrast, however, harsh measures to deal with undutiful slaves - those who malingered, stole, or absconded - were deemed not only permissible, but also necessary by slaveholders. As William Elliot told members of the State Agricultural Society of South Carolina in 1849, "against insubordination alone, we are severe" (p. 368, emphasis in the original).

This ambivalent alliance between paternalistic care and punitive aggression mirrors Glick and Fiske's (2001) distinction between benevolent forms of sexism (expressed towards women who accept their dependency) and hostile forms (expressed towards those who challenge it). What Fox-Genovese \& Genovese's (2005) analysis also confirms is that benevolence towards enslaved people was not associated with opposition to slavery. Rather, it was quite the opposite. By subscribing to a code of chivalry, slaveholders sought to depict slavery as "a system of organic social relations that, unlike the market relations of the free-labor system, created a bond of interest that encouraged Christian behaviour" (p. 368). After all, only if one was nice to one's chattel could one sustain the legitimizing myth that slavery was "a blessing to both master and slave" (p. 515).

Although slavery has long been abolished, Jackman (1994) suggests that there remains a complex set of interrelations between benevolence, hostility, and racial inequality in our own times. Using national survey data on race attitudes in the United States, for example, she has shown that many white Americans (39\%) who express inclusive feelings towards African Americans also express conservative or reactionary attitudes towards policies designed to create racial equality in the domains of housing, employment, and education. Positive intergroup emotions, in other words, happily coexist with rejection of race-targeted interventions, as depicted by the "paternalistic" quadrant of Figure 1. Of course, interpreting the implications of such findings is not straightforward, and resistance to interventions such as affirmative action in the workplace does not necessarily equate to racial discrimination. Moreover, Jackman's findings do not refute the claim that negative evaluations play a key role in maintaining ethnic and racial inequality in many contexts. Indeed, her analysis also shows that only a small percentage of white respondents (7\%) who feel emotionally estranged from black people support race-targeted policies (the "tolerant" quadrant in Fig. 1), whereas a high percentage (39\%) espouse either conservative or reactionary policy attitudes (the "conflictive" quadrant in Fig. 1). Nevertheless, her findings do indicate that antipathy is not the whole story of racial and ethnic discrimination, a theme that is being developed in other areas of research.

\subsection{The spectrum of dehumanization: From genocidal hatred to loving condescension}

As the term suggests, dehumanization is a process through which other people become perceived as "less than human." This process has been associated historically
Feelings towards disadvantaged group

\begin{tabular}{|l|l|l|l|}
\hline & & Inclusive & Estranged \\
\cline { 2 - 4 } & $\begin{array}{l}\text { Affirmative } \\
\text { Change }\end{array}$ & REVISIONIST & TOLERANT \\
\hline $\begin{array}{l}\text { Policy } \\
\text { attitudes }\end{array}$ & $\begin{array}{l}\text { Conservative or } \\
\text { Reactionary }\end{array}$ & PATERNALISTIC & CONFLICTIVE \\
\cline { 2 - 4 } & & & \\
\hline
\end{tabular}

Figure 1. Configurations of interracial feelings and attitudes towards race-targeted policies, based on Jackman (1994, p. 280). Respondents were classified as having Inclusive Feelings when their attitudes towards the out-group were similar to, or more positive than, their attitudes towards the in-group. Estranged Feelings were defined as feelings where the in-group was favoured over the out-group. Policy attitudes were classified as Affirmative when respondents' ratings suggested they believed the government should be doing more to promote racial equality in the areas of housing, employment, and education than they were currently doing. They were classified as Conservative or Reactionary when respondents' ratings indicated that the government was already doing enough or too much, respectively, to promote racial equality.

with some of the most degrading expressions of prejudice. Indeed, it is difficult to imagine a more negative reaction than one that likens others to animals, filth, or disease, relegates them beyond the scope of justice (Opotow 1990), or targets them for mass extermination (Staub 1989). Such brutal expressions of prejudice concerned researchers in the period following World War II and continue to blight relations in many societies. They are undoubtedly linked to powerful negative emotions such as hatred and disgust (e.g., Goff et al. 2008; Harris \& Fiske 2006). As the most recent wave of research illustrates, however, dehumanization also assumes subtler forms that are irreducible to affective and cognitive negativity (see Haslam 2006; Leyens et al. 2007 for overviews). In some circumstances, dehumanization expresses the kind of "benign" condescension of which Jackman (1994; 2005) and Glick and Fiske (2001) have written.

Advances in this aspect of our understanding of dehumanization have been inspired by the work of Leyens and his colleagues, who identified a subtype of dehumanization now widely known as infra-humanization. In their seminal work, this research group demonstrated that individuals attribute "secondary emotions" (e.g., empathy, remorse) more readily to members of the in-group than to members of the out-group, but that no such difference occurs for the attribution of primary emotions (e.g., anger, happiness) (Leyens et al. 2001; 2003). Subsequent research has suggested that this process may occur both within our controlled and conscious judgments of others (Explicit Infra-humanization) and also within our uncontrolled and unconscious associations (Implicit Infra-humanization). Using sequential priming techniques, for example, Boccato et al. (2007) found that respondents react more quickly to in-group/secondary emotion associations than to out-group/secondary emotion associations, supporting the claim that infra-humanization has an automatic component. 
Many commentators have interpreted infra-humanization as a form of prejudice. After all, primary emotions are generally perceived as being shared by human beings and animals, whereas secondary emotions implicate moral, civil, and aesthetic qualities that are somehow "uniquely human" (Leyens et al. 2001). To deny that outgroup members experience such emotions to the same degree as in-group members is thus to diminish their humanity. Infra-humanization and other forms of dehumanization often occur, however, in the absence of overt conflict between the groups involved (Leyens et al. 2007). Moreover, their expression is relatively independent of the negative evaluations highlighted by the traditional concept of prejudice: it is the nature of the emotional attributions (secondary versus primary) rather than their valence (negative versus positive) that is crucial to processes of infra-humanization.

Indeed, as Haslam and Loughnan (2012) have argued, even forms of dehumanization that are grounded in direct comparisons between people and animals do not necessarily entail antipathy. Saminaden et al. (2010) found that members of so-called "primitive" or "traditional" cultures were implicitly associated with animals but that this association was not accompanied by negative evaluations. To the contrary, primitives were actually evaluated somewhat more positively than the members of the ingroup. Haslam and Loughnan (2012) have suggested that such responses are congruent with idealised and superficially positive images of "the noble savage"-images in which members of "traditional" cultures are treated as authentic and innocent and thus in need of protection and "development." In other words, they illustrate how dehumanization may sustain relations of benevolent paternalism as much as it does relations of genocidal hatred, a contradiction that would surprise few historians of Western colonialism (e.g., Said 1993).

\subsection{Ironies of intergroup helping}

Unlike dehumanization, helping is generally conceived as a pro-social phenomenon, involving elevated emotions such as empathy, compassion, and consideration. Given that people are generally more inclined to assist in-group than out-group members (e.g., Levine \& Crowther 2008), helping across intergroup boundaries has been deemed an especially positive activity. As such, intergroup helping is sometimes used as a yardstick for judging the success of prejudice reduction interventions such as common identification. To cite one example: Nier et al. (2001) reported that white spectators at an American football game were significantly more helpful to a black confederate when he shared their university affiliation (indicated via clothing displays) than when he had a different university affiliation (see Fig. 2).

However, helping relations also involve an inherent inequality. The act of giving signifies the power of a donor to confer benefits to a (needy) beneficiary and may hence produce status differences between them. Moreover, at least delivered in certain forms, helping may foster long-term relations of dependency and inequality. To use Nadler et al.'s (2007, p. 4) terminology: "the continuous downward flow of assistance can be conceptualized as a social barter where the higher status group provides caring and assistance to the lower status group, which

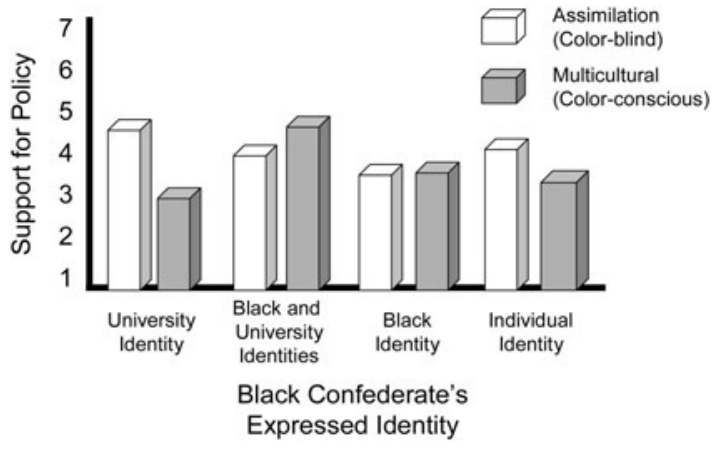

Figure 2. The relationship between the social identity displayed by a black confederate and support for assimilationist versus multicultural race-targeted policies (based on Dovidio et al. 2010).

reciprocates by accepting the social hierarchy and its place in it as legitimate."

Gender relations again provide the most obvious illustration of the political complexity of helping relationships. The ability to cater to women's needs (e.g., economic welfare) has served historically as an ideological cornerstone of patriarchal relations and, in so "benefitting," women have sacrificed power and autonomy. Over the past decade or so, however, Arie Nadler and his colleagues have identified analogous processes operating within other kinds of unequal intergroup relations (e.g., between Israeli Arabs and Jews) and have developed a general theoretical model of helping as a "status organizing process" (e.g., see Halabi et al. 2008; Nadler 2002; Nadler \& Halabi 2006). Their work has shown that intergroup helping relations may service relations of domination in varying ways, depending on the prevailing ideological conditions.

In societies with secure and stable status hierarchies, helping relations often serve to justify the status quo. When an advantaged group caters to the needs of a disadvantaged group, and this assistance is treated as desirable and necessary, then power relations become ideologically reconstructed as moral responsibility. In societies marked by insecure and unstable status hierarchies, by contrast, helping may be a mechanism for reestablishing threatened power differentials. Revealingly, under such conditions, research suggests dominants tend to favour the provision of chronic, dependency-oriented help, which allows them to reassert control and shore up the status hierarchy. By contrast, subordinates tend to favour the kind of help that allows them to retain collective autonomy and efficacy. They have misgivings about help that entrenches the status hierarchy by enabling others to intervene in their affairs or break down self-reliance (see Nadler 2010).

Helping relations, in sum, illustrate our broader point that superficially positive behavior can have discriminatory consequences, being implicated in wider power struggles in historically unequal societies. One is reminded here of the words of Albert Camus, who once wrote that "The welfare of the people has always been the alibi of tyrants, and it provides the further advantage of giving the servants of tyranny a good conscience" (Camus 1955/1961).

\subsection{Common identification: The darker side of "we"}

A similar kind of argument can be applied to processes of common identification. Proposed originally by Samuel 
Gaertner and Jack Dovidio, the so-called Common Identity Model holds that inducing members of different social groups (e.g., blacks and whites) to view one another as members of a shared in-group (e.g., Americans) tends to improve their intergroup attitudes, reducing intergroup bias and increasing positive responses such as liking and empathy (see Gaertner \& Dovidio 2000; 2009). Research on this model is now extensive and overwhelmingly supportive. Common identification is widely viewed as one of the most promising interventions to improve intergroup relations.

In an elaboration of their own model, however, Dovidio et al. (2009) have discussed the so-called "the darker side of we," exploring some of the unacknowledged consequences of social inclusion. First, they concede that the ideological terms of inclusion are often a site of intergroup struggle. Members of historically advantaged groups typically favour assimilative forms of inclusion (a "one-group" representation of common identity) that leave intact the existing status hierarchy, whereas members of disadvantaged groups prefer a dual-identity model, which tends to better protect their group interests (see also Dovidio et al. 2008). Second, although it reduces prejudice by encouraging us to like one another more, common identification does not necessarily lead to support for policies designed to produce structural change in historically unequal societies.

In a striking demonstration, Dovidio and colleagues exposed white students to a black "confederate" who displayed either a common category membership (University identity), a dual identity (black and a university identity), a black identity, or an individual identity (Dovidio et al. 2010). In line with the Common Identity Model, they found that levels of racial prejudice - both towards the confederate in particular and black people in general-were lowest amongst whites in the common category condition and levels of "empathic concern" were highest. However, they also found that this group showed least support for policies designed to encourage multiculturalism on campus and most support for assimilationist policies that effectively disregard "race" (see Fig. 2). To the extent that multicultural policies challenge the status quo more than assimilationist policies (e.g., by conferring selective benefits to black students) - and we concede that this is a controversial issue in its own right-then one could argue that perceived common identification had the ironic effect of increasing whites' resistance to meaningful social change.

Emerging research has also examined effects of common identification on the political attitudes of minority groups. Greenaway et al.'s (2011) study of the consequences of appeals to "common humanity" provides a revealing illustration. Although this kind of appeal may unite the victims and perpetrators of historical atrocities, increasing "forgiveness" of perpetrators, Greenaway et al. argue that it may also reduce victims' intentions to engage in collective action to transform enduring inequalities. Recognizing their shared humanity with others, in other words, may encourage victims to accept discrimination rather than to do something about it. We develop this theme in section 3.

\subsection{Summary and implications}

In sum, several independent strands of research have recently converged to challenge the traditional concept of prejudice as negative evaluation. Research on dehumanization has demonstrated how social perceptions that sustain intergroup hierarchies may operate in ways that are orthogonal to emotional valence. Dehumanization often occurs in absence of rancor. Indeed, we may deprive others of full human status whilst retaining indifference or even a mild, if condescending, affection towards them-as long, that is, as they accept their dependent place. If subordinate group members begin to contest their dependency, then that is often when negativity kicks in.

Research on common identification suggests that even when we are successful in creating more positive intergroup attitudes, encouraging people to evaluate one another more favourably, we may leave unaltered the conservative policy orientations of the historically advantaged. Viewing others as part of a shared in-group, it seems, does not necessarily promote support change in a structural or institutional sense. Moreover, members of dominant groups lean towards "assimilative" forms of inclusion that preserve rather than challenge social inequalities.

Perhaps most worrying, research on paternalistic social relations has suggested that "benevolent" intergroup attitudes may not only coexist with social inequality, but also serve as a mechanism through which it is reproduced. Men generally express warm and protective, if not loving, attitudes towards women and reserve antipathy primarily for those who challenge the gender hierarchy. As work on Ambivalent Sexism (and also on racism) has evinced, however, patriarchal relations are sustained by the warmth as well as the antipathy. It is the former as much as the latter, for example, that encourages many women to "buy into" conventional forms of gender differentiation and indeed to take responsibility for policing their boundaries. In a similar way, attempts by dominant groups to "help" the disadvantaged - arguably the ultimate expression of pro-social sentiment-may carry consequences that entrench rather than challenge social inequalities. Although such interventions may be motivated by positive emotions (e.g., empathy for others) and carry other beneficial consequences, they may equally help to reproduce status differences between the advantaged and the disadvantaged. Helping is thus a double-edged sword.

\section{The limits of a prejudice reduction model of social change}

\subsection{Two routes to social change in historically unequal societies}

If negative evaluation of the disadvantaged is defined as the problem, then the emotional and cognitive rehabilitation of the advantaged becomes the solution. We need, by this logic, to get such people to like others more and to abandon their negative stereotypes. In due course, incidences of discrimination will decline, creating a more equitable society in which the potential for intergroup conflict wanes. The concept of prejudice, in short, implies a ready-made antidote, which is a model of social change grounded in the psychology of prejudice reduction (see Table 2, top panel).

The main level of analysis at which this model operates is the individual, the person whose negative feelings and thoughts need to be changed. Of course, if change remained hidden in the recesses of the individual mind, 
Dixon et al.: Beyond prejudice

Table 2. Two models of change in historically unequal societies

\begin{tabular}{|c|c|c|c|c|}
\hline Model of change & Main agents of change & Interventions & Psychological processes & Behavioural outcome \\
\hline $\begin{array}{l}\text { Prejudice reduction } \\
\text { model }\end{array}$ & $\begin{array}{l}\text { Members of historically } \\
\text { advantaged groups }\end{array}$ & $\begin{array}{l}\text { Intergroup contact } \\
\text { Cooperative } \\
\text { interdependence Re- } \\
\text { education Empathy } \\
\text { arousal }\end{array}$ & $\begin{array}{l}\text { Stereotype reduction } \\
\text { More positive affect } \\
\text { Decreased salience of } \\
\text { group boundaries and } \\
\text { identities }\end{array}$ & $\begin{array}{l}\text { Reduction of individual } \\
\text { acts of discrimination } \\
\text { Reductions of } \\
\text { intergroup conflict }\end{array}$ \\
\hline Collective action model & $\begin{array}{l}\text { Members of historically } \\
\text { disadvantaged groups }\end{array}$ & $\begin{array}{l}\text { Empowerment } \\
\text { Consciousness raising } \\
\text { Coalition building }\end{array}$ & $\begin{array}{l}\text { Sense of injustice } \\
\text { Collective anger } \\
\text { Collective efficacy } \\
\text { increased salience of } \\
\text { group boundaries and } \\
\text { identities }\end{array}$ & $\begin{array}{l}\text { Collective action to } \\
\text { change the status quo }\end{array}$ \\
\hline
\end{tabular}

then prejudice reduction interventions would have limited utility. Accordingly, most prejudice researchers presume that what happens inside our heads ultimately carries consequences at other levels of social reality. By changing individuals' prejudices, we also change how they relate to other people in their lives, and in turn this effect is believed to ripple outwards to shape wider patterns of intergroup conflict and discrimination. To be sure, the intermediate steps and processes through which this occurs are often underspecified. Nevertheless, we concur with Wright and Baray (2012), who claim that most researchers presume prejudice reduction interventions have positive consequences that flow from a micro (individual) to a meso (interpersonal encounters and relationships) to a macro (institutional and intergroup relationships) level of analysis in order to create a more peaceful and just society.

Over the course of its history, this model of change has been periodically challenged. Some critics have argued that it individualises the historical, structural, and political roots of intergroup discrimination (e.g., Blumer 1958; Henriques et al. 1984; Rose 1956; Wetherell \& Potter 1992). Others have worried about the implication, embedded in several conceptualizations of prejudice, that social change is inevitably circumscribed by certain universal and intractable features of human psychology (e.g., Hopkins et al. 1997). Still others have questioned the strength of its supporting evidence (e.g., Paluck \& Green 2009) or directly challenged its underlying assumptions (Reicher 2007). Nevertheless, prejudice reduction remains the most intensively researched and passionately advocated perspective on how to improve intergroup relations, and it is particularly influential within the discipline of psychology.

Prejudice reduction is not, however, the only perspective. Table 2 (bottom panel) depicts a second model of social change that has engaged psychologists (e.g., Dion 2002; Drury \& Reicher 2009; Klandermans 1997; van Zomeren et al. 2008), along with historians (Rude 1981; Thompson 1991; Tilly et al. 1975), political scientists (Ackerman \& Kruegler 1994; Piven \& Cloward 1979; Roberts \& Ash 2009; Ulfelder 2005), and sociologists (Smelser 1962; Tarrow 2011; Turner \& Killian 1987). According to this model, dominant group members rarely (if ever) give away their power and privileges. Rather, these must be wrested from them by members of subordinate groups. The analytic focus therefore shifts away from the goodwill of dominants towards the resistance of subordinates. More specifically, this model highlights the role of collective action in achieving social justice. Its guiding assumption is that social change is predicated upon mass mobilization, a process that typically brings representatives of historically disadvantaged groups (who stand to benefit from change) into conflict with representatives of historically advantaged groups (who stand to lose out from change). Its significance is captured by Frances Fox Piven's contention that the "great moments of equalizing reform in American political history" (2008, p. 21) have come about through the exercise of disruptive collective action.

To illustrate this alternative to a prejudice reduction model of social change, let us consider what are arguably the three greatest moments of racial equalization in modern history: the end of apartheid in South Africa, civil rights reforms in the United States, and the abolition of New World slavery. In the case of apartheid, there is some controversy over whether the violent struggles of the African National Congress' (ANC's) armed wing Unkhonto we Sizwe or the nonviolent struggles of civic organizations and trade unions had a greater role in overturning the system (Zunes 1999). Yet there is little disagreement that change was principally down to black collective action. To say this is not to downplay either the role of international solidarity through the boycott movement or the role of white radicals and business organisations in securing the transition to majority rule. (Particularly in the twilight years of apartheid, for example, corporations such as Consolidated Gold Fields played an important part in bringing the State and the ANC together in negotiations and ensuring a peaceful end to the old system.) Nevertheless, as Harvey (2003) relates in his book The Fall of Apartheid: "There can be no doubt that the black majority won South Africa's bitterly fought racial war," even if, equally, there can be no doubt that "white surrender was conditional and took place well before military considerations alone would have dictated" (p. 2).

The achievement of U.S. civil rights followed a similar trajectory. Of course, white politicians and white radicals played an important role. Yet, as Oppenheimer (1994 1995) asks: What happened between April 1, 1963, when Kennedy opposed the introduction of a Civil Rights Act, 
and May 20, when he directed the Department of Justice to draft just such an Act (which was signed into law on July 2, 1964, by Lyndon Johnson)? His answer is admirably terse: "In a word-Birmingham" (p. 646). He is referring, of course, to the massive desegregation campaign led by Martin Luther King, Jr., who arrived in Birmingham, Alabama, on April 2, 1963. The resulting legislative changes had profound effects in all areas of American life, not least in the political domain. In 1965, only 193 black people held elected office in the entire United States. By 1985 - when Barack Obama began working as a political organizer in Chicago - the figure stood at 6,016 (Sugrue 2010). And, of course, on November 4, 2008, Obama himself was elected as president. A popular slogan in the last days of his election campaign was "Rosa sat so Martin could walk/Martin walked so Obama could run/Obama is running so our children can fly" (cited in Sugrue 2010). Or, as Obama himself acknowledged in his Selma speech of March 4, 2007: "I'm here because somebody marched" (full text available at http://blogs.suntimes.com/sweet/ 2007/03/obamas_selma_speech_text_as_de.html).

Finally, let us consider how slavery was abolished. This is an area of furious controversy (see, e.g., the debate in Drescher \& Emmer 2010), and the controversy is complicated by the fact that different dynamics were at play in the British, French, Spanish, and American instances of abolition (Blackburn 2011). However, it is significant that the debate concerns the relative contribution of two different forms of collective action: on the one hand, the resistance of slaves themselves, and on the other, the agitation of the largely white-led abolitionist movement. In other words, it concerns the contribution of collective struggles both between and within the slave and "master" communities. What is not in question is: (a) that abolitionist movements were critical in rallying popular sentiment against slaveholding interests (Marques 2006; 2010b); (b) that the success of such movements was facilitated by crises or divisions in the slaveholding state (see Blackburn 2011); and (c) above all, that slave revolts - or the threat of slave revolts - were critical in inspiring abolitionist movements and in ensuring their ultimate success (Marques 2010a).

In all three examples, then, equality was won rather than given away. In all three, change was the result of sustained collective resistance rather than some kind of general improvement, whether incremental or dramatic, in intergroup attitudes. What is more, the examples illustrate that such collective resistance can occur at many levels. The struggle of the subordinate group against the dominant group - and hence the struggle to mobilise subordinate group members-often has a determining weight. However, the struggle within the dominant group should not be forgotten, a point to which we shall return in the conclusion of our article. For the rest of this section, though, we address the question of how the two traditions of research on social change depicted in Table 2 are interrelated.

Although these models have developed largely in isolation, in our experience most researchers presume that they are complementary to the broader project of improving relations between groups. Prejudice researchers concentrate on changing the hearts and minds of the advantaged; collective action researchers study how, when, and why the disadvantaged take political action to create more just societies. The models seem to fit together as different parts of the overall puzzle of social change.
Recent research indicates, however, that their interrelationship may be more complicated and more vexed.

According to Steve Wright and colleagues, the two models of social change entail psychological processes that actually work in opposing directions (Wright 2001; Wright \& Baray 2012; Wright \& Lubensky 2009). On the one hand, prejudice reduction diminishes our tendency to view the world in "us" versus "them" terms, encouraging us to view others either as individuals (e.g., Brewer \& Miller 1984), as part of a common in-group (e.g., Gaertner \& Dovidio 2009), or at least as people who share "crossed" category memberships (e.g., Crisp \& Hewstone 1999). Such interventions foster positive emotional responses towards others, such as empathy and trust, whilst decreasing negative responses such as anxiety and anger (e.g., Esses \& Dovidio 2002; Paolini et al. 2004; Pettigrew \& Tropp 2008; Stephan \& Finlay 1999). For the most part, they also encourage participants to view one another as equal in status and sometimes involve active attempts to establish such equality, at least within the immediate context of intervention (e.g., see Riordan 1978). The overarching objective of this model of social change is to reduce intergroup conflict in historically divided societies, producing more stable and peaceful societies.

On the other hand, collective action interventions are based on the assumption that group identification is a powerful motor of social change. Within this model of change, an "us" versus "them" mentality is generally construed as functional and strategic: It encourages members of disadvantaged groups to display in-group loyalty and commitment to the cause of changing society, to form coalitions with similar groups, and, crucially, to act together in their common interest (Craig \& Richeson 2012; Klandermans 1997; 2002; Tajfel \& Turner 1986; Wright \& Baray 2012). Collective action also generally requires the emergence of "negative" intergroup emotions and perceptions, including anger and a sense of relative deprivation (e.g., Barlow et al. 2012; Grant \& Brown 1995; van Zomeren et al. 2004), which encourage group members to recognize injustice and status disparities and thus strive to change the status quo. ${ }^{3}$ Its main goal is not to reduce but to instigate intergroup conflict in order to challenge institutional inequality. Conflict is viewed as the fire that fuels social change rather than as a threat to extinguish at the point of conflagration.

\subsection{Paradoxical effects of intergroup contact}

Recognition of the potentially contradictory relationship between these two models of social change has inspired research on the "ironic" effects of prejudice reduction on the psychology of the disadvantaged. This idea was originally mooted by Wright (2001), and other researchers are now developing some of his insights.

Emerging research has focused mainly on the impact of interventions to promote intergroup contact, extending work on the so-called contact hypothesis (Allport 1954). The contact hypothesis is the most important tradition of research on prejudice reduction, and it has generated a vast research literature that spans a wide spectrum of disciplines, including sociology, psychology, and political science (e.g., see Allport 1954; Brown \& Hewstone 2005; Forbes 1997; Pettigrew \& Tropp 2006; Sigelman \& Welch 1993). Its basic premise is simple. Interaction between members of different groups reduces intergroup 
prejudice, particularly when it occurs under favourable conditions (e.g., equality of status between participants). Evidence supporting this idea is extensive and, many believe, conclusive. Pettigrew \& Tropp's (2006) widely cited meta-analysis found that contact decreased prejudice in $94 \%$ of 515 studies reviewed. A follow-up analysis (Pettigrew \& Tropp 2008) suggested that this effect was largely explained by reductions in intergroup anxiety and increases in intergroup empathy, as well as by improvements in participants' knowledge about members of other groups.

Like most traditions of research on prejudice, research on the contact hypothesis has focused mainly on the reactions of members of historically advantaged groups. In some recent studies, however, the impact of contact on the psychology of the historically disadvantaged has been prioritized, with some provocative results.

Dixon, Durrheim, and colleagues conducted two national surveys of racial attitudes in South Africa (Dixon et al. 2007; 2010a). Their first survey explored the relationship between interracial contact and South Africans' support for race-targeted policies being implemented by the ANC government to redress the legacy of apartheid, including policies of land redistribution and affirmative action (Dixon et al. 2007). They identified a divergence in the results for white and black respondents. For whites, positive contact with blacks was positively correlated with support for government policies of redress; for blacks, positive contact with whites was negatively correlated with support for such policies. In other words, contact was associated with increases in whites' and decreases in blacks' support for social change. In their second survey, Dixon et al. (2010a) investigated the relationship between interracial contact and black South Africans' perceptions of racial discrimination in the post-apartheid era. They found that respondents who reported having favourable contact experiences with whites also perceived the racial discrimination faced by their group to be less severe. As Figure 3 conveys, this effect was mediated both by perceived personal discrimination and by blacks' racial attitudes. That is, the inverse relationship between contact and judgments of collective discrimination was partly explained by reductions in respondents' sense of being personally targeted for racial discrimination, as well as increases in their positive emotions towards whites.

In a more recent study, Cakal et al. (2011) provided a partial replication and extension of Dixon et al.'s (2007; 2010a) results. To simplify a more complex set of findings, they reported that contact had a so-called "sedative effective" on black South Africans' readiness to engage in collective action benefitting their in-group, which operated both

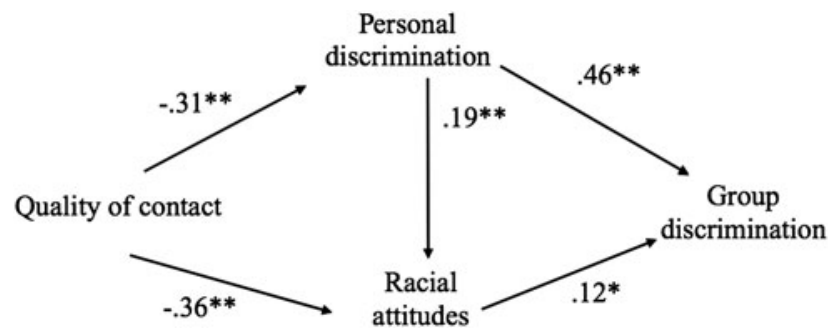

Figure 3. Indirect effects of contact quality on black South Africans' perceptions of group discrimination (taken from Dixon et al. 2010b). directly and indirectly. On the one hand, positive contact with whites was associated directly with a reduced inclination to participate in collective action. On the other hand, such contact exercised an indirect effect on collective action by moderating participants' sense of relative deprivation. That is, for participants who had comparatively little contact with whites, a sense of relative deprivation was positively associated with collective action tendencies. However, this relationship did not emerge for participants who had comparatively higher levels of contact with whites.

These effects are not unique to the South African situation. Wright and Lubensky (2009) reported that contact with white Americans reduced Africans' and Latin Americans' willingness to endorse group efforts to accomplish racial equality. Revealingly, as a collective action perspective would predict, this effect was mediated by shifts in their sense of identification with their respective ethnic groups. Similarly, in a longitudinal study conducted on a university campus in the United States, Tropp and colleagues found that making white friends tended to lower perceptions of racial discrimination and decrease support for ethnic activism amongst members of three minority groups (African American, Latin American, and Asian American) (Tropp et al. 2012). The effects were strongest for African Americans, the group that otherwise reported the highest levels of experienced discrimination and the greatest willingness to challenge such discrimination (e.g., through political demonstrations). Surveys conducted in Israel by Saguy et al. (2009, study 2) and in India by Tausch et al. (2009) have confirmed these "ironic" consequences of intergroup contact. In both studies, positive contact was associated with reduced perceptions of social injustice and lowered support for social change amongst members of disadvantaged groups (Arab Israelis and Muslims). In both studies, too, such effects were indirect, being mediated by respondents' attitudes towards the out-group in question (Jewish Israelis and Hindus).

Saguy et al. (2009, study 1) and Glasford and Calcagno (2011) have provided laboratory confirmation of these survey-based data, laying the foundations for a program of experimental work that warrants further development. Saguy et al. (2009, study 1) created an experimental paradigm in which higher and lower power groups interacted under conditions that emphasized either their differences (less positive contact) or their commonality (more positive contact). Higher-power group members were then asked to distribute a series of rewards across the two groups, whilst lower-power group members estimated the nature of the resulting distribution. The results provided a stark demonstration of the "darker side" of both common identification and positive contact - two preeminent techniques of prejudice reduction. Participants in the low-power/commonidentity/positive-contact cell consistently overestimated the extent to which higher-power participants would distribute rewards equitably. (In reality, the powerful group displayed a predictable pattern of in-group favouritism.) This study thus highlights the potential problem of nurturing positive intergroup evaluations whilst creating false expectations of equality amongst the disadvantaged.

Glasford and Calcagno (2012) investigated the interrelations between commonality, intergroup contact, and political solidarity amongst members of historically disadvantaged groups. As research on both collective action and common identification would predict, their study 
showed that cueing a sense of common identity amongst members of black and Latin American communities in the United States increased their political solidarity; that is, their readiness to work together to improve the status of both groups. However, this effect was moderated by contact with members of the historically advantaged white community. Specifically, the more intergroup contact Latin Americans had with whites, the less effective the commonality intervention was in fostering their sense of political solidarity with blacks. Once again, notwithstanding its beneficial effects on intergroup attitudes and stereotypes, contact exercised a potentially counterproductive impact on the political consciousness of the disadvantaged. As Glasford and Calcagno (2012) summarize: "The conflict of harmonious intergroup contact may lie in the fact that despite harmony leading to increased positive attitudes (Pettigrew \& Tropp 2006), it also has the potential to decrease a variety of social-change oriented responses among minority group members.” (p. 227).

\subsection{Summary and implications}

In this section, we have contrasted a prejudice reduction model of social change (based around getting dominant group members to like subordinate group members) with a collective action model (based around getting subordinate groups members to challenge dominant group advantage). Building on the work of Wright and colleagues, we have suggested that these models of change entail different, and potentially contradictory, psychological processes, as illustrated by recent research on the consequences of intergroup contact.

Such research indicates that contact with members of historically advantaged groups may improve the intergroup attitudes of the historically disadvantaged, but also, paradoxically, reduce the extent to which they acknowledge and challenge wider forms of social injustice or display solidarity with other disadvantaged communities. From a prejudice reduction perspective, we have a resounding success; from a collective action perspective, a dismal failure. Further, this work shows that the very processes that underpin prejudice reduction also help to explain the "ironic" impacts of intergroup contact on political attitudes. Perhaps most significant, several studies suggest that it is precisely because contact improves intergroup attitudes (prejudice reduction) that it also decreases perceptions of discrimination, support for race-targeted policies, and readiness to engage in collective action. When the disadvantaged come to like the advantaged, when they assume they are trustworthy and good human beings, when their personal experiences suggest that the collective discrimination might not be so bad after all, then they become more likely to abandon the project of collective action to change inequitable societies. Jackman's (1994; 2005) warning reverberates here. Inequality is maintained not only through emotional negativity and the exercise of repressive force, but also through the "coercive embrace" of an affectionate but conditional sense of inclusion.

\section{Conclusions and future directions}

For most of the history of prejudice research, negativity has been treated as its emotional and cognitive signature, a conception that continues to dominate work on the topic. ${ }^{4}$ By this definition, prejudice occurs when we dislike or derogate members of other groups. We do not dispute that research in this tradition has focused attention on processes that are essential to understanding the nature of intergroup discrimination. Recent work, however, has complicated the idea that prejudice consists exclusively of negative evaluations, highlighting the need to develop what Eagly (2004) calls an "inclusive" conception of the role of intergroup emotions and beliefs in sustaining discrimination. A common theme in this research is its functionalist emphasis on the social and psychological processes that serve to reproduce unequal social relations, an emphasis that resonates with Rose's (1956, p. 5) early definition of prejudice as a "set of attitudes which causes, supports or justifies discrimination." What is clear from evidence on topics such as paternalism, Ambivalent Sexism, common identification, intergroup contact, and intergroup helping is that "positive" evaluations of others may play as a central role within such processes as negative evaluations.

By necessity, our coverage of relevant literature has been selective. We have not had space to review, for example, emerging research on the "differentiated" nature of intergroup emotions (e.g., Mackie \& Smith 2002) and stereotype content (Cuddy et al. 2008) or on the broader factors that foster acceptance of unjust social systems amongst the historically disadvantaged (Jost et al. 2004). Nevertheless, taken collectively, the research discussed in this article offers a compelling challenge both to the orthodox conception of prejudice as negative evaluation and to the assumption that getting us to like one another more is some kind of sine qua non for promoting social change. Although evidence has accumulated steadily for several years, it is perhaps only in the domain of gender research that this emerging perspective has had a substantial impact, notably through work on Ambivalent Sexism. However, the significance of the subtler forms of discrimination discussed in this article extends beyond gender relations. Paternalistic ideology pervades other forms of intergroup relations. It is perhaps in the arena of social change that the limitations of the traditional concept of prejudice as negative evaluation become most apparent.

\subsection{Prejudice reduction and social change revisited: Some suggested parameters and future directions}

The question of change has troubled us most whilst preparing this article. An enduring strength of work on prejudice, as noted in our introduction, is that it shifted the target of social science research on intergroup relations. The study of immutable and hierarchical differences between groups became recast as the study of dominant group bigotry; and in the wake of this paradigmatic "reversal" (Samelson 1978), a rich tradition of research on prejudice reduction was born. The latter stages of our article, however, have complicated this optimistic view of the contribution of prejudice reduction interventions. As it turns out, there is mounting evidence that nurturing bonds of affection between the advantaged and the disadvantaged sometimes entrenches rather than disrupts wider patterns of discrimination.

In this closing section, we offer some general reflections on possible routes forward. To begin with, we advocate three ways in which research on the consequences of 
prejudice reduction should be extended, which concern the importance of acknowledging: (a) the relational nature of intergroup attitudes and perceptions, (b) the political, as well as the emotional and cognitive, effects of prejudice reduction, and (c) the complex relationship between harmony and conflict in the transformation of historically unequal societies. To conclude, we then revisit the question of how, if at all, prejudice reduction and collective action models of social change might be reconciled.

4.1.1. Recovering the relational character of intergroup attitudes. Research on prejudice has generally focused on the attitudes of the historically advantaged. This pattern was established by formative work on the topic, which sought to redress the problems of racism and anti-Semitism in the United States. It shone a harsh spotlight on the bigotry of the white, Protestant majority. Yet it often left the reactions of blacks, Jews, and other minority groups in the shadows, implicitly casting them as passive targets of bigotry. Of course, this early work had admirable objectives. As an unintended consequence, however, it established a lacuna that has persisted to the present day: a failure to acknowledge, sufficiently, how intergroup attitudes emerge in and through the relational dynamics of interaction between groups, with the actions of members of one group (e.g., blacks) forming the context in which the reactions of the other (e.g., whites) take shape and find expression, and vice versa (see also Shelton 2000; Shelton \& Richeson 2006).

This neglect must be borne in mind when evaluating research on the consequences of prejudice reduction interventions. Typically, such interventions shape the experiences of members of both historically advantaged and disadvantaged groups (e.g., by fostering more frequent intergroup contact). Moreover, they shape not only the intergroup attitudes of each group independently, but also the overall nature of the relationship between them (e.g., by encouraging recategorization so that "us" and "them" become "we"). For much of the history of research on prejudice reduction, however, scholars have prioritized its effects on the responses of the historically advantaged and have left its effects on the psychology of the disadvantaged comparatively underspecified.

We recommend, then, that the relational implications of prejudice reduction be brought to the forefront of future research. If this is done, then we anticipate that the ironic consequences highlighted in the present article will become increasingly apparent. We also recommend that researchers move beyond a simple, dualistic, "dominant" versus "subordinate" group model in order to explore other kinds of relatedness. Building on Glasford and Calcagno's (2012) study, for example, one might hypothesize that interventions designed to improve a subordinate group's attitudes towards a dominant group (e.g., by creating new forms of inclusion) may have unintended effects on its members' attitudes towards other subordinate groups. Not only may such interventions increase horizontal hostility (White \& Langer 1999), but also they may decrease the willingness of members of different subordinate groups to act collectively in their shared interest. This attitudinal pattern is prevalent in post-colonial societies in Africa and the near East, where the "divide and rule" strategies of colonial authorities were designed precisely to prevent the formation of rebellious alliances that might challenge the status quo.

4.1.2. Broadening the conception of a successful intervention "outcome.". Researchers have employed varying indices when evaluating the success of prejudice reduction interventions, which have become more sophisticated over time. Indices of blatant and controlled intergroup attitudes have been complemented by indices of indirect and automatic attitudes. Self-report indices have been complemented by behavioral and physiological indices. Scales measuring generic antipathy have been complemented by scales measuring specific intergroup emotions and associated action tendencies. By and large, however, the definition of a successful intervention outcome has remained within the boundaries of a concept of prejudice as negative evaluation. As its benchmark, prejudice reduction research continues to track shifts in emotional antipathy and pejorative stereotyping (or close proxies).

This emphasis on the cognitive and emotional rehabilitation of the bigoted individual has led to an underutilization of other, equally important, measures of outcome. For one thing, it has downplayed the role of positive (or ambivalent) emotions in sustaining relations of discrimination and inequality, a possibility raised by the work reviewed in our article, as well as by other functionalist research on how intergroup attitudes and beliefs serve to reproduce status and power relations. ${ }^{5}$ For another thing, it has submerged the political dimension of intergroup attitudes and perceptions of social reality. As Wright and Lubensky (2009, p. 18) remarked: "When efforts to reduce prejudice focus exclusively on getting dominant group members to think nicer thoughts and feel positive emotions about the disadvantaged group, they may not necessarily increase support for broader structural and institutional changes."

Consider, as an instructive example, research on whites' support for policies designed to promote racial equality. Several researchers have argued that such support declines as policies come to threaten the racial hierarchy more directly (e.g., see Bobo \& Kluegel 1993; Dixon et al. 2007; Schuman et al. 1997; Sears et al. 1997; Tuch \& Hughes 1996). Along these lines, for example, proponents of the Blumerian tradition of sociological research on prejudice have highlighted the evolution of what Bobo et al. (1997) have called a "kinder, gentler, anti-black ideology" in the United States, a set of political beliefs that justify racial inequality not in terms of the overt bigotry of "Jim Crow" racism, but in terms that are more defensible in the modern era. A key, and seemingly paradoxical, feature of this emerging ideology is that widespread acceptance of the principles of equality, integration, and anti-discrimination is offset by widespread resistance to their concrete implementation.

According to Jackman and Crane (1986), this kind of attitudinal pattern is unlikely to be eradicated by traditional techniques of prejudice reduction, which put "parochial negativism" rather than political attitudes at the heart of the problem of social change. In their analysis of national survey data gathered in the United States, for example, they reported that interracial contact led whites to espouse greater emotional warmth towards blacks, but had little impact on their acceptance of government interventions to address racial injustice. Likewise, as we have discussed, common identification-another prominent 
technique of prejudice reduction - may increase dominant group members' emotional acceptance of minorities without increasing their willingness to embrace institutional change (Dovidio et al. 2010).

Our general point here is not that support for structural change is unaffected by prejudice reduction. It is that prejudice researchers need to adopt a broader conception of the ideal outcomes of intervention. In particular, we need to know more about the relationship between prejudice reduction and the political attitudes that sustain the institutional core of disadvantage in historically unequal societies, justifying an unequal distribution of wealth, opportunity, and political power. How, for example, does prejudice reduction shape dominant and subordinate group members' attributions about the causes of group differences in wealth and opportunity? How does it affect acceptance of ideological belief systems that either justify or challenge the status quo (see also Jost et al. 2004)? Over the history of prejudice research, the goal of getting individuals to like one another has drawn attention away from these equally, if not more, important outcomes.

\subsubsection{Acknowledging the complexities of harmony and} conflict. The promotion of intergroup harmony has always been a cardinal objective of research on prejudice, and understandably so. Research on prejudice gathered impetus as a way of explaining the mass violence of World War II, and subsequent bloodshed throughout the twentieth and early twenty-first centuries did little to allay social scientists' concerns about "the toll in death, suffering and displacement caused by large-scale conflicts caused by groups defined by ethnicity, nationality, religion or other social identities" (Eidelson \& Eidelson 2003, p. 183). In the face of such events, the promotion of harmonious relations became an unquestioned moral imperative for many researchers.

However, the relationship among intergroup harmony, conflict, and social change is more complex than it first appears. On the one hand, harmony has a negative face, which our article has revealed. To borrow Jost et al.'s (2004) terminology, it carries insidious, often unacknowledged, "system-justifying" consequences. Seemingly tolerant and inclusive intergroup attitudes not only coexist with gross injustices, but also they can serve as a mechanism through which they are reproduced. On the other hand, if the unquestioned acceptance of intergroup harmony as an "absolute good" is simplistic, then so is the unquestioned rejection of intergroup conflict as an "absolute bad." Unlike harmony, whose meaning is often taken for granted by social scientists, conflict has been intensely scrutinized and condemned as a social problem. By implication, the diffusion of intergroup tensions has become the cardinal principle of prejudice reduction interventions. Whatever other contributions it has made, this approach has entrenched the assumption that conflict between groups is inherently pathological, disconnected from human rationality, and without social value. It has quietly obscured the possibility that such conflict is also "a normal and perfectly healthy aspect of the political process that is social life." (Oakes 2001, p. 16). Its psychological correlates of anger, strong social identification, recognition of status disparities, and sense of injustice do not sit easily with a prejudice reduction model of social change; however, in fueling collective resistance, conflict may improve intergroup relations in a structural and institutional sense.

The latter point raises several challenging, and perhaps troubling, questions for proponents of a prejudice reduction model of social change. What are the dangers of employing interventions that seek, above all else, to quell, contain, and dissipate intergroup tensions? ${ }^{6}$ In addition to combating negative stereotypes and emotions, should we be seeking to promote "positive" conflict; that is, conflict designed to confront not only the direct violence of overt discrimination, but also the indirect violence of structural inequality? How might such interventions fit with the broader project of reducing prejudice? What form might they take?

Our argument here is similar to that made by Georg Sorensen (1992) in his discussion of the field of international peace studies. Sorenson criticized researchers' tendency to extol the core value of "peace" whilst leaving its fundamental contradictions unexamined. More specifically, he railed against a utopian perspective in which inconvenient questions are ignored-questions, for example, about the apparent ineffectiveness of exclusively nonviolent solutions to problems of structural oppression in some societies and, conversely, about the apparent effectiveness of short-term "developmental violence" in establishing longer-term peace in others (cf., Fanon 1965). We believe a comparable problem afflicts much research on prejudice reduction. Social harmony has become an unquestioned ideal to be promoted, social conflict an unquestioned evil to be vanquished. Breaking with this approach, we advocate greater openness amongst prejudice researchers to interrogating the complex relationship between conflict and harmony as it unfolds within processes of social change in historically unequal societies.

\subsection{Reconciling prejudice reduction and collective action models of social change?}

The most important question that our article has left hanging is this: What are the prospects of reconciling a prejudice reduction model of social change, designed to help people get along better, with a collective action model of change, designed to ignite struggles to achieve social justice? There are a number of possible positions in this debate. One pole of the argument might assert that the two forms of social change are fundamentally complementary-that is, that getting people to like one another more will ultimately lead to social justice in a deeper sense. The other pole might assert that the two forms of social change are fundamentally incommensurable and that the drive for prejudice reduction has for too long marginalized, if not obstructed, more pressing concerns about core distributive justice (e.g., justice based on the fair distribution of resources such as wealth, jobs, and health). As readers will have gathered, we sympathize with the latter position, particularly when applied to the problem of improving intergroup relations in societies characterized by long-standing, systemic discrimination. ${ }^{7}$ To conclude, we revisit the question of whether or not the two models of social change can be reconciled with the goal of opening up a wider dialogue.

Thomas Pettigrew and his colleagues have presented the outline of a case for reconciliation, as part of a discussion of recent criticisms of research on the contact hypothesis (Pettigrew 2010; Pettigrew et al. 2011). Their case rests on two 
broad claims. First, they argue that intergroup contact has beneficial effects beyond the reduction of negative emotions and beliefs. Not only does it improve relations on moral and social indices such as trust and forgiveness, but also it can motivate political activism amongst members of historically advantaged groups and this may in turn facilitate change at a structural, as well as a psychological level. For example, Surace and Seeman (1968) studied Americans' engagement in civil rights activities in the 1960s and found that equal status contact was a better predictor of white activism than factors such as political liberalism and status concern. We might infer from such evidence that prejudice reduction can serve as a psychological mechanism through which members of privileged groups become enlisted within oppositional struggles to improve the situation of the disadvantaged, a process about which we still know comparatively little (though see Mallett et al. 2008; Nepstad 2007). Second, Pettigrew and colleagues (2011) contend that the argument that contact-and by implication other prejudice reduction interventions - inevitably diminishes the collective action orientation of members of historically disadvantaged groups is simplistic. Some research has shown, for example, that intergroup contact may sometimes heighten perceptions of injustice amongst the disadvantaged, encouraging them to make the kinds of "upwards" intergroup comparisons that foster a sense of relative deprivation (e.g., Poore et al. 2002). Similarly, it is possible to find evidence that common identification increases rather than decreases subordinate groups' concerns over injustice. Wenzel's (2001) longitudinal study of perceptions of entitlement and social injustice amongst East Germans in the post-unification era provides an interesting case in point. In light of this sort of evidence, Pettigrew and colleagues (2011) have insisted that although contact can sometimes reduce a minority's motivation for protest, this is an

incomplete description of the complex relationship between intergroup contact and efforts for social change....As with most social phenomena, the two approaches are intricately entwined. Some contact outcomes further mobilization, others counter it. And mobilization itself will in turn influence intergroup contact increasing it with outgroup allies and decreasing it with outgroup opponents (Pettigrew et al. 2011, p. 278).

At one level, we see this general line of argument as an important development. Indeed, it takes us back to a point we left hanging earlier in our discussion of slavery and other historical instances of change in unequal intergroup relations, where we argued that processes of change involve not only struggles between dominant and subordinate groups, but also struggles within each group. Certainly, we accept that it is important to examine the processes that lead some dominant group members to oppose the in-group's repression of others, to pave the way for subordinate group resistance, or even to agitate for an end to dominance themselves. We also accept, as Pettigrew and colleagues (2011) argue, that contact and similar interventions may play a role in these processes (see also, e.g., Dixon et al. 2010b; Mallett et al. 2008).

At another level, however, we believe that it is vital not to diminish the challenge posed by the collective action critique of contact research (Dixon et al. 2010c; Wright \& Lubensky 2009), which is addressed at its underlying model of social change. In our view, we cannot simply tack together a prejudice reduction with a collective action perspective whilst ignoring their incommensurable assumptions about the mechanisms through which change occurs (or is inhibited). In saying this, we are not dismissing studies that report a positive relationship between contact and political activism. However, we are broadening the terms of the debate and prioritizing a set of questions that have not featured prominently either in contact research or in prejudice reduction research more generally. How, when, and why do particular kinds of interventions lead to collective mobilization to challenge institutional discrimination? Crucially, what are the underlying mechanisms involved? Do they involve the creation of positive thoughts/feelings about others or alternative mechanisms such as, for example, the recognition of the illegitimacy of dominant group advantages or the realization that the oppression of others is a violation of core in-group norms (e.g., "it is un-Christian to oppress as we do"-see Brown 2006)? Do they involve encouraging subordinate group members to view the dominant group in more positive terms or opening their eyes to everyday inequities between groups and motivating them do something about them?

Viewed from this broader perspective, we believe that confidence in the long-term efficacy of contact and similar prejudice reduction interventions must be qualified in a number of ways. First, as we have seen, when power relations are bound up with paternalistic ideologies and associated institutional structures, then the promotion of positive evaluations of others is by no means antithetical with conservative political orientations. Witness the gulf between men's feelings towards women and their willingness to support militant feminism. Second, the extent to which reducing dominant group members' prejudice translates into effective political action remains open to question. Not only has research revealed a predictably modest relationship between prejudice and discriminatory behaviour (e.g., Talaska et al. 2008), but also it has suggested that reducing prejudice may not result in transformation at an institutional level. Kalev et al.'s (2006) recent study of the shifting racial composition of 708 American organizations, for example, found that interventions to reduce managers' racial biases were comparatively ineffective as a means of implementing racial diversity. (A more effective strategy was to create institutional structures that delineated clear lines of responsibility and accountability for change in the workplace.)

Third, and most important, historical evidence suggests that social inequality is eradicated more through the collective will of the disadvantaged than through the wellintentioned reforms of the advantaged, a point that returns us to the key question of how prejudice reduction affects the responses of subordinate group members. Again, we accept Pettigrew et al.'s (2011) claim that it is possible to find studies where intergroup contact has increased rather than decreased the collective action orientation of subordinate group members. In the majority of recent research, however, contact has been found to correlate negatively with members' perceptions of discrimination, sense of solidarity with other disadvantaged groups, support for policies designed to promote social change, and willingness to engage in collective protest (see Dixon et al. 2007; 2010c; Glasford \& Calcagno 2012; Saguy et al. 2009; Tausch et al. 2009; Wright \& Lubensky 2009). Moreover, although this line of research remains in its infancy, the data produced so far support Wright and Lubensky's (2009) claim that the prejudice reduction and collective action involve opposing psychological 
processes. That is, prejudice reduction decreases the likelihood of collective action precisely because it reduces subordinate group members' sense of collective identity and sense of being targeted for discrimination, whilst increasing their positive evaluation of the dominant group.

Our bottom line, then, is this. An array of evidence indicates that sociopolitical change often requires the disadvantaged to take action. However, such action is a rare occurrence in many societies. Numerous contextual, material, and psychological factors militate against its emergence (e.g., see Klandermans 1997; 2002) and, for this reason, the disadvantaged all too often acquiesce in their own subordination, whether existing in a state of serene acceptance or one of resigned tolerance. As Wright (2001) notes, once entrenched, the "tranquility" of inequitable relations between groups is notoriously difficult to disturb. In so far as prejudice reduction undermines the already tenuous possibility that subordinate group members will develop the kind of insurgent consciousness that fuels resistance to inequality, it may ultimately reproduce rather than disrupt the status quo. We believe that it is time to reevaluate this model of social change. We need to ask ourselves if prejudice reduction deserves its status as the preeminent framework through which we approach the problem of "improving" relations between groups within historically unequal societies. What might we see if we did not look at intergroup relations through a lens coloured so strongly by the concept of prejudice as negative evaluation? In particular, how might we rethink the problem of change?

\section{NOTES}

1. As Montagu remarked in his 1949 paper on the "pathognomic mythology" of race, "It is the discriminators, not the discriminated, the prejudiced, not those against whom prejudice is exhibited, who are the problem" (p. 176).

2. Hence, setting out the concept of prejudice that guided his influential overview of the field, Rupert Brown remarked:

Of course, logically, prejudice can take both positive and negative forms. I, for example, am particularly favourably disposed towards all things Italian: I love Italian food, Italian cinema, and lose no opportunity to try out my execrable Italian on anyone who will listen (much to the embarrassment of my friends and family). However, such harmless infatuations hardly constitute a major social problem worthy of our attention as social scientists. Rather, the kind of prejudice that besets so many societies in the world today and which so urgently requires our understanding is the negative variety: the wary, fearful, suspicious, derogatory, hostile or ultimately murderous treatment of one group of people by another. (Brown 1995, p. 7)

3. The emotional underpinnings of collective protest movements are, of course, far more complex than this brief discussion conveys and involve reactions other than anger and outrage (see Jasper 2011 for a detailed discussion). However, our argument here is simply that such "negative" emotional reactions are often crucial in motivating individuals to participate in collective action.

4. As Quillian (2006, p. 300) notes in a recent review, "Despite the changing nature of prejudice in modern society, most contemporary social science use of the term is highly consistent with Allport's (1954) early definition of prejudice as "antipathy based on a faulty or inflexible generalization."

5. This research includes the work of Eagly (2004) on the relationship among intergroup attitudes, structural role differentiation, and power relations, and Jost et al. (2004) on the role of intergroup emotions and beliefs in systems justification processes.

6. Maoz (2011) has illustrated one such danger in her recent review of research on the consequences of reconciliation encounters between Arab Israelis and Jewish Israelis. The primary model for such encounters is the so-called Coexistence Model (which critics have also disparagingly branded the "Hummus and Falafel Model"). Drawing its rationale from work on the contact hypothesis, this model is based around the goal of creating dialogue that emphasizes intergroup commonalities and similarities, while downplaying intergroup differences and points of dissension. Although it has been successful in building more positive attitudes, particularly amongst members of the advantaged Israeli Jewish group, it has also arguably neglected the political dimension of the Arab-Israeli conflict. As Maoz warns, such reconciliation encounters thus tend to "perpetuate existing asymmetrical power relations by focusing on changing individual-level prejudices while ignoring the need to address collective and institutionalized bases of discrimination" (p. 118).

7. We accept fully that, under conditions of social equality and justice, prejudice reduction remains an important ideal in its own right. Our focus in this conclusion, and in the rest of the article, is on social relations defined by long-standing inequality and discrimination.

\section{Open Peer Commentary}

\section{Prejudice reduction, collective action, and then what?}

\author{
doi:10.1017/S0140525X12001136
}

Dominic Abrams, Milica Vasiljevic, and Hazel M. Wardrop

Centre for the Study of Group Processes, University of Kent, Canterbury, Kent CT2 7NP, United Kingdom.

d.abrams@kent.ac.uk

http://www.kent.ac.uk/psychology/people/abramsd/

mdv@kent.ac.uk hmw32@kent.ac.uk

Abstract: Despite downsides, it must, on balance, be good to reduce prejudice. Despite upsides, collective action can also have destructive outcomes. Improving intergroup relations requires multiple levels of analysis involving a broader approach to prejudice reduction, awareness of potential conflict escalation, development of intergroup understanding, and promotion of a wider human rights perspective.

Dixon et al. contrast promotion of cross-group liking (prejudice reduction - $\mathrm{PR}$ ) with collective action $(\mathrm{CA})$ to promote structural change. This important point echoes social identity theory's distinction between social mobility and social change belief structures, the latter involving "antagonism between dominant and subordinate groups provided that the latter group rejects its previously accepted and consensually negative image, and with it the status quo" (Tajfel \& Turner 1979 , p. 38). PR and CA are both important but are neither mutually exclusive nor exhaustive options. A more extensive conceptual framework is needed to deal with prejudice and intergroup relations because no single approach to PR is likely to work across all intergroup relationships (Abrams 2010).

The benefits of "getting people to like each other" should not be underestimated. Modifying prejudices, particularly those held by members of powerful groups, can surely only be helpful. Even if use of social cognitive techniques to override categorical simplicity in social perception reduces pressure on the status quo, it can also create room for greater harmony in society by facilitating reconceptualization of relationships (Crisp \& Hewstone 2007; Crisp \& Turner 2011; Roccas \& Brewer 2002), perspective taking, empathy, and reciprocity (Brown \& Hewstone 2005). 
A further approach for improving intergroup relations is to develop better intergroup understanding. A shared intergroup reality involving consensual understanding of differences between groups can be a vehicle for facilitating communication, recognising inequality, and addressing it. PR may therefore actually highlight differences, such as inequality, and it may promote CA by members of either group to redress such inequality. For example, slavery and apartheid would not have been abolished without recognition by members of the advantaged groups that their group's perspective was incomplete and invalid. Wilberforce was a crucial advocate for the abolition of slavery, male members of parliament voted for universal suffrage, and English MPs voted to devolve power to Scotland and Wales (cf. Mallett et al. 2008).

We agree that intergroup inequalities and differences need to be tangible in order for them to be addressed. CA can highlight a group's consensual opposition to the status quo. However, CA need not entail violence and aggressive conflict. Collectives can represent themselves in multiple ways, including political mobilization and voting (Abrams \& Grant 2011). A just-so story can always be developed to argue that collective protest was a catalyst for eventual change. However, direct conflict and mass action may not offer the best, or only, means of eliminating paternalistic oppression. First, there are many examples of mass protests, strikes, or riots that have not resulted in successful outcomes for the protesters (e.g., in the United Kingdom: the miners' strike; opposition to the Iraq war; opposition to tuition fee increases). Second, members of a dominant group may respond to challenges by reasserting the status quo more vigorously, resulting in deeper and more dangerous conflict that may become entrenched (Bar-Tal 2007). Third, perpetual conflict based on a single intergroup axis is potentially dangerous, both because it can destabilise a social system and because it can overwhelm pressing needs that affect other groups and individuals (for example, organisations may lose productivity, communities may descend into anarchy). Finally, even if some disadvantaged groups see no prospect of improving their situation through conventional forms of protest and action, some forms of action are simply societally unacceptable in terms of the indiscriminate threat they pose to life (e.g., terrorism), and therefore it is incumbent upon social scientists and society to develop other means of resolving differences.

Dixon et al. focus on gender and white/black relations in the context of slavery. However, societies involve multiple groups in multiple cross-cutting relationships, organized both horizontally and hierarchically, resulting in multiple group memberships (Simmel 1955). It is important to sustain multiple levels of analysis to tackle multiple levels of social exclusion and disadvantage (Abrams \& Hogg 2004). Prejudices are manifested and held differently for different groups within the same society. For example, among a representative sample of nearly 3,000 people in the United Kingdom a higher percentage perceived that societal feelings towards Muslims involved fear and anger rather than disgust or pity, whereas relatively higher percentages perceived societal fear of black people, disgust towards homosexual people, and pity towards disabled people (Abrams \& Houston 2006; see Fig. 1). These emotions might result in very different societal responses to CA by each of these types of groups.

Moreover, proximal effects of PR and CA seem likely to bear on different (but connected) levels of outcome: social cognition and behaviour on the one hand, and legal and political structures on the other. In sum, rather than treating PR and CA as alternatives, it may be wise to consider effects of PR and CA separately, allowing conceptualisation of mutual influence, and outcomes at different levels of specificity.

The challenge is not just one of firefighting specific prejudices against specific groups, but fire prevention by promoting principles of justice and fairness while recognizing diversity across society (Vasiljevic \& Crisp 2010). The critical issue is how a

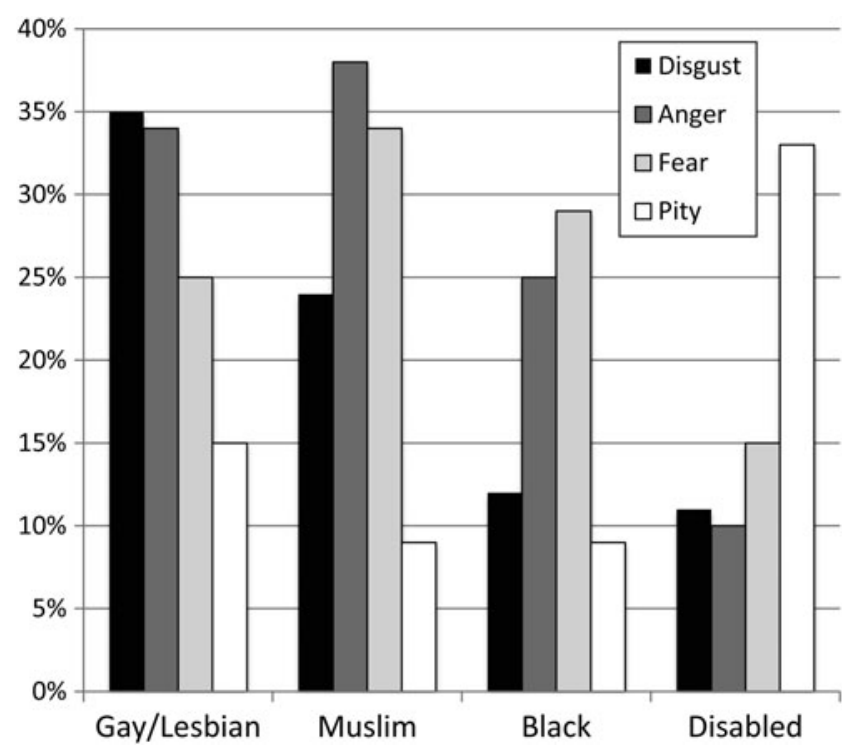

Figure 1 (Abrams et al.). Proportion perceiving different groups as evoking emotions "very much" or "extremely." (Adapted from Abrams \& Houston 2006)

society moves to a situation in which relationships are constructive and in which justice and fairness both among individuals and between groups are maximised (EHRC 2010). Engaging groups in conflict does not seem an optimal means of moving towards such a state. Propelling both groups and individuals towards a shared vision of human rights (Doise 1998) and moral responsibility (Zimmermann et al. 2011) offers a better prospect. This may well involve groups or systems beyond the groups in conflict. Improvement in many conflictual intergroup relationships has involved the influence or intervention by external agents, sanctions, and diplomatic and political pressure, often backed by wider consensus (e.g., promoted by the United Nations or nongovernmental organizations [NGOs]) that legitimised progressive social change. Examples include Yugoslavia, Northern Ireland, the ending of apartheid, and slavery in the United States.

The situation of an isolated disadvantaged versus advantaged group is perhaps unusual. Prejudice and conflict are common problems in intergroup relations, regardless of whether the groups are unequal or not. To conclude, PR and CA are aspects of intergroup relations but are only part of a picture involving structural complexity, historical relationships, and the wider sociopolitical context.

\section{You say you want a revolution?}

doi:10.1017/S0140525X12001409

\section{Mark Alicke \\ Department of Psychology, Ohio University, Athens, $\mathrm{OH} 45701$. alicke@ohio.edu}

Abstract: I argue that Dixon et al. fail to maintain a careful distinction between the negative evaluation definition of "prejudice" and the implications of this definition for correcting the social ills that prejudice engenders. I also argue that they adduce little evidence to suggest that if prejudice were diminished, commensurate reductions in discrimination would not follow.

I could not decide between this title and another equally apt one inspired by the Liverpool lads: "All You Need Is Not Love." The target article is an elegantly written paper that advances the important view that traditional perspectives on prejudice emphasize social change by altering the hearts and minds of the 
intolerant while underplaying the importance of collective social action. If the authors are right, then rectifying problems of discrimination toward classes of people will be achieved not by attitude change campaigns, but only by the active, and often violent, resistance of the disadvantaged groups. There are, I think, two major problems with this analysis. The first is that the authors fail to maintain a careful distinction between the negative evaluation definition of "prejudice" and the implications of this definition for correcting the social ills that prejudice engenders. In essence, I think they are attacking a straw man in claiming that because psychologists define "prejudice" as a negative evaluation, most believe that eradicating this evaluation will eliminate or reduce prejudice. The second problem is that they adduce no evidence to suggest that if prejudice were diminished, commensurate reductions in discrimination would not follow.

It is true, of course, that "prejudice" is routinely defined as a negative attitude or evaluation of a class of individuals. And it is also true that attitudes by themselves do not pose nearly the social problem that is presented by discriminatory behavior and unfair institutional practices. In this regard, it can be said that the traditional distinction between prejudice and discrimination has been overplayed in that discrimination is what ultimately matters. Consider, for example, a prejudiced person who never discriminates and who, instead, promotes the welfare of the groups about whom she holds unfavorable attitudes. Or, someone who passes every implicit and explicit test of egalitarianism with flying colors but nevertheless engages routinely in harmful actions against select groups. An example of the former might be an individual whose religious beliefs commit her to the view that homosexuality is sinful but whose humanitarian instincts lead her to support gay marriage, equal job opportunity, and antidiscriminatory laws. Here, the negative attitude seems to pale in importance compared with her more laudable actions. Conversely, holding no particular animus toward homosexuals does not warrant much credit if an individual consistently behaves in ways that are injurious to gay men and women.

So in one sense, the authors' advocacy of changing the cultural institutions that promote and maintain discrimination is fully justified. What is more difficult to defend is the claim that there is widespread disagreement on this matter. The central thesis of the paper is that psychologists have argued, almost exclusively, that altering prejudicial attitudes is the best means for ameliorating discrimination. For example, the authors assert that "at the heart of most prejudice research is a deceptively simple question: Why don't we like one another?" (sect. 1 para. 4) And more to the point, in the next paragraph: "advocates of prejudice reduction have united around a central imperative ... How can we get individuals to think more positive thoughts about, and hold more positive feelings towards, members of other groups?" Here, I believe the authors have made an erroneous leap in attributing to most psychologists the belief that if prejudice is a negative evaluation, then the sole or primary way to reduce it is to make people think more favorably of others.

In fact, defining "prejudice" as a negative evaluation does not necessarily entail, or even imply, that the best way to rectify the social problems that prejudice fosters is by changing individual attitude and value systems. The complexity of the attitude-behavior relationship is so widely acknowledged in social-psychological theories as to preclude any naïve assumptions about a simple relationship between the two. None of the main extant theories of prejudice, including that groups compete for scarce resources (Jackson 1993), that people have stereotypic expectations for group members (Eagly \& Wood 1991), that in-groups are naturally favored over out-groups (Mullen et al. 1992), that outgroup members are perceived as homogeneous (Quattrone \& Jones 1980), that negative characteristics are overperceived in minority groups (Hamilton 1981), that social institutions favor majorities (Fiske 1993), that minority groups are scapegoated for declining economic conditions (Hovland \& Sears 1940), and that victims are blamed for their misfortunes (Lerner 1980), imply that attitude-changing campaigns are the sole, or even the best, route to rectify discriminatory practices.

The strength of the authors' argument is also vitiated by the failure to adduce evidence to support the claim that reductions in prejudice would not produce parallel changes in discrimination. The authors cannot be faulted much for this because the relationship between prejudice and discrimination has received little empirical attention. Anecdotally, their argument for the importance of collective action in reducing or eliminating discrimination is a strong one. But this argument does not diminish the concomitant need for reductions in prejudice. It is virtually impossible to identify any important cultural change that was not preceded or accompanied by a significant change in people's attitudes. In fact, collective social action is often the outgrowth of widespread attitude change. Although the revolutionary action of black South Africans played the major role in ending apartheid in South Africa, it is difficult to imagine this having been achieved without the global demand for a change in these practices.

The same can be said for the abolition of slavery in America and for the achievements of the civil rights movement. Abolitionism had a long history in America before the Civil War, and the publication of Harriet Beecher Stowe's Uncle Tom's Cabin had an enormous impact on northern white's attitudes about the institution of slavery (McPherson 2003). Slavery as a social and economic system was almost certainly destined to failure even if the Civil War had never been fought, but it also seems certain that it would have lasted longer without increasing recognition of the plight of the enslaved people.

\section{Traditional prejudice remains outside of the WEIRD world}

\author{
doi:10.1017/S0140525X12001148
}

\section{Michal Bilewicz}

Faculty of Psychology, University of Warsaw, Center for Research on Prejudice, University of Warsaw, 00-183 Warsaw, Poland.

bilewicz@psych.uw.edu.pl http://bilewicz.socialpsychology.org/

Abstract: Dixon et al. accurately describe subtle mechanisms of discrimination that inhibit minorities' collective action in modern democratic societies. This commentary suggests that in contemporary non-Western societies, where ethnic conflicts are more violent, traditional overt forms of prejudice still exist and predict discrimination of ethnic and racial minorities. Thus, prejudice reduction models should and do improve intergroup relations in such contexts.

"Erst kommt das fressen, dann kommt die Moral" ("First grub, then ethics") wrote Bertolt Brecht in his Threepenny Opera, expressing the preferences of disadvantaged groups. These preferences are seldom accurately understood by even the best intentioned members of advantaged groups.

Recently, social psychologists started addressing this problem by switching the focus from the perpetrators' (high status/advantaged/majority group) feelings, needs, and attitudes into the deeper study of the victims' (low status/disadvantaged/minority group members) perspective. This paradigmatic shift occurred simultaneously in studies of intergroup helping (Nadler 2002), reconciliation (Shnabel \& Nadler 2008), intergroup contact (Saguy et al. 2009), intergroup emotions (Imhoff et al. 2012), and collective action (Wright \& Lubensky 2008). All these lines of research suggest a divergence of goals between advantaged and disadvantaged groups. Dixon et al. declare that the prevalent psychological approach to prejudice - treating negative evaluations as hallmarks of discrimination-was based on researchers' narrow focus on majority groups. The modern psychology of intergroup relations, by addressing minority groups' needs, should rather focus on subtle biases and paradoxical 
discriminatory consequences of seemingly unprejudiced attitudes. Acknowledging the importance of such an approach in understanding the dynamics of discrimination in the West, this comment will suggest some cultural limitations of it.

The classic theories of prejudice and prejudice reduction (Allport 1954; Zawadzki 1948) were developed in countries where prejudiced attitudes were culturally accepted and sometimes even normatively supported by legal, political, and religious authorities of majority groups. Dixon et al. argue that current structures of oppression are more nuanced: modern discrimination sometimes has a "benevolent" expression, so traditional prejudice reduction strategies (e.g., contact, recategorization) have limited effects on improving intergroup relations. This situation seems specific to developed Western societies, where expression of ethnic prejudice among high-status groups is suppressed by strong societal norms of political correctness (Crandall et al. 2002). Most recent psychological studies performed on North American or West European student samples hardly detect any overt prejudice. The progress of integration and the civil rights movement influenced Americans' responses in racial attitudes surveys, while not changing structural power relations. As early as 1992, more than 95\% of American students declared acceptance of a black neighbor in a study of social distance (compared to $41 \%$ in 1949; Dovidio et al. 1996). At the same time, most Americans still chose to live in racially segregated rather than integrated cities (Goldsmith \& Blakely 2010). If people do not express their attitudes openly, then it should not be surprising that discriminatory behaviors cannot be well predicted by explicit measures of attitudes. We should expect "benevolent" and implicit prejudice to be the dominant expressions of intergroup hatred in such societies (McGrane \& White 2007). It is also obvious that in such societies, changes in expressed prejudice (caused by intergroup contact or tolerance education) do not automatically affect discriminatory intentions and behaviors.

In societies where ethnic conflicts are more intense and political correctness norms are weaker than in the West, blatant forms of prejudice are still operating - and systematically result in discrimination. The most recent European Value Survey (EVS 2011) shows that prejudice expression significantly differs across countries. In typical countries of Western Europe (such as Belgium, France, or Germany), less than $10 \%$ of participants declared that they would not accept people of different race as their neighbors, whereas in several countries of post-Communist Eastern Europe such prejudice was openly expressed by more than 20 percent of respondents. Our recent survey of prejudicial beliefs about Jews showed that in Poland such negative beliefs are good predictors of discriminatory intentions and behavioral nonhelping (Bilewicz \& Krzemiński 2010; Bilewicz et al., in press). More subtle measures (e.g., secondary anti-Semitism scale) were less predictive than traditional, blatant ones. In places of actual or recent blatant ethnic conflicts, such as Armenia, Turkey, or Northern Cyprus, up to $56 \%$ of citizens openly expressed unwillingness to accept neighbors of different race. In other European countries, anti-immigrant prejudice is still a strong predictor of discriminatory intentions-particularly among people of low income (Küpper et al. 2010). In regions where prejudice currently causes much more harm-in the global South and East, in impoverished areas - the link between prejudicial beliefs and discriminatory behavior remains strong and stable. These regions belong to most underresearched by social psychologists who often base their theories on American or West European students samples (i.e., "WEIRD" people: Western, educated, industrialized, rich, democratic; Henrich et al. 2010).

Dixon et al. suggest that old, blatant prejudice is currently being replaced with more nuanced ambivalent stereotypes or implicit infra-humanization. However, the same groups (i.e., Gypsies) who are subtly infra-humanized in Britain are still harshly and openly dehumanized in Romania, where they are subject to everyday discrimination (Marcu \& Chryssochoou 2005; Tileagă 2007).
And in most acts of genocide or ethnic cleansing, it was not subtle infra-humanization, but rather overt dehumanization that shaped propaganda and intergroup perceptions (Bandura 1999; Bilewicz \& Vollhardt, 2012). Ambivalent stereotyping is the result of a complex, two-dimensional structure of intergroup perception in Western societies. Recent research in Poland found systematic correlations between these two dimensions: Groups perceived as incompetent were also perceived as unfriendly (Winiewski 2010). It seems that a more general prejudiced attitude was responsible for all forms of out-group negativity.

Dixon et al. shed some light on the subtle mechanisms of discrimination that inhibit collective action in modern democratic societies. However, most ethnic violence occurs outside of this WEIRD world. In many underresearched societies of the global South and East, prejudiced remarks are still normatively accepted and hate speech is neither a felony nor a taboo. In such societies, social justice programs, as well as prejudice reduction programs, are effectively changing attitudes of both advantaged and disadvantaged group members. Gacaca tribunals in Rwanda - an effort leading to justice restoration after genocide of Tutsis - reduced prejudice among perpetrators and victims of the genocide (Kanyangara et al. 2007). Changing power asymmetries and changing attitudes went hand in hand. And this is where prejudice reduction campaigns and interventions could still be applicable - as they change the situation of both advantaged and disadvantaged social groups.

\section{Liking more or hating less? A modest defence of intergroup contact theory}

\author{
doi:10.1017/S0140525X1200115X
}

\section{Rupert Brown}

School of Psychology, Sussex University, Brighton BN1 9QH, United Kingdom. r.brown@sussex.ac.uk http://www.sussex.ac.uk/profiles/95042

Abstract: Here, I argue that Dixon et al. have overstated the prevalence of "benevolent" forms of prejudice; many stigmatised groups are currently the targets of overtly hostile evaluation and treatment by others (e.g., Muslims; immigrant groups). I also believe that the target article oversimplifies its presentation of prejudice researchers' primary theoretical and policy goals and that it overlooks important work in intergroup emotions.

Dixon et al. have written a provocative article, much of which I agree with. Nevertheless, I believe that they have neglected important data on the nature of contemporary prejudice and have oversimplified certain aspects of current theory and research on intergroup contact.

Dixon et al. base much of their argument on the claim that classical accounts of prejudice as a negative attitude do not do justice to the more ambivalent nature of prejudice in many societies. Dixon et al. are correct to point out that many modern manifestations of prejudice are, indeed, often more complex than mere antipathy; I acknowledged as much in the second edition of my book (Brown 2010 - not cited in the target article). However, if we should be aware that the wolf of prejudice (towards women and some minority groups) can sometimes come disguised in benevolent sheep's clothing, it is also important that we remember that the prejudice experienced by many groups is far from "benevolent." The two most obvious targets of overtly hostile prejudice in many Western societies are Muslims and immigrants.

In 2008 , the percentages of nationally representative samples reporting unfavourable opinions of Muslims ranged from 23\% (United Kingdom) to 52\% (Spain) (Pew Research Center 2008). Perhaps not unconnected with this Islamophobia, the number of racially or religiously aggravated offences recorded in England and Wales totalled over 33,000 for 2008/2009 (Chaplin et al. 2011). Immigrants are another group that is frequently the 
target of unfavourable attitudes. Semyonov et al. (2006) reported how anti-foreigner sentiment in 12 European countries showed substantial increases in the 1990s: in 1988, between $10 \%$ and $30 \%$ of national samples agreed with such items as, "the presence of foreigners is one of the causes of delinquency and violence"; by 2000 , those proportions had risen to between $40 \%$ and $70 \%$. Similarly, McLaren (2003) showed that attitudes about the expulsion of legally established immigrants in the 1997 Eurobarometer survey ranged from a low of 2.80 to a high of 3.73 , where 3.0 was the midpoint and 5.0 the unfavourable pole of the scale.

These data do not paint a picture of Muslims and immigrants as the targets of benevolent prejudice. Rather, members of these groups are often viewed and treated in an overtly negative fashion. For them, at least, conceiving of prejudice as antipathy seems to be entirely appropriate. And, it seems to me, a reasonable goal of progressive policy making would be to get members of the majority group, not necessarily to like those stigmatised groups more, as Dixon et al. suggest, but at least to hate them a little less. Properly designed contact interventions might be one tool (among several) that can assist in the achievement of that goal (Brown \& Hewstone 2005; Pettigrew \& Tropp 2011). Dixon et al. portray prejudice researchers as advocating contact as a major agent of social change. This is something of an oversimplification. Ever since Pettigrew and Tropp's (2006) meta-analysis of the contact-prejudice relationship, it has been clear that the correlation between contact and prejudice reduction is a modest one (typically between .2 and .3). It follows that most of the variance in prejudice must be accounted for by other factors. And some of us have been explicit about this (Brown 2010, p. 279; Pettigrew \& Tropp 2011, p. 216).

Dixon et al. also oversimplify when they characterise all contact theories as having the goal of dissolving group boundaries. Although such ideas are to be found in some perspectives (e.g., Brewer \& Miller 1984; Gaertner \& Dovidio 2000), they have not gone uncontested. Theoretically, such assimilationist models cannot easily deal with the problem of generalisation. And, pragmatically, intervention policies based on them are unlikely to win much acceptance from minority groups and so will have little chance of success. It is for that reason that some of us have long advocated a "dual identity" approach to contact interventions, in which a deliberate attempt is made not to dissolve group boundaries completely, either physically or psychologically (Brown \& Hewstone 2005).

Dixon et al. castigate contact researchers as being reductionist in their hope to change individuals' hearts and minds. However, the charge of individualism overlooks one key component of the contact hypothesis and fails to recognise the contribution of one of its extensions, the extended contact hypothesis (Wright et al. 1997). One of Allport's (1954) necessary conditions for contact was that there be "social and institutional support" for that contact. One reason why institutional support is important is that it creates a social climate in which egalitarian relationships between members of different groups are seen as the norm. Similarly, one of the mechanisms thought to underlie extended contact is that it helps to generate new in-group norms about the acceptability of such intergroup relationships (De Tezanos Pinto et al. 2010; Pettigrew et al. 2007). Such a normative explanation of behaviour change is far from the individualistic presentation that Dixon et al. give of contact research.

Finally, by their own admission, Dixon et al. pay little attention to intergroup emotions in their article. This was unfortunate because one of the significant contributions of this work has been to underline the variegated nature of people's feelings towards other groups and how these feelings are contingent on the specific nature of intergroup relationships (Smith 1993). An important lesson from research on group-based emotions is that we need to move away from a simple characterisation of intergroup orientations in terms of "like" or "dislike." Emotions such as fear, disgust, hostility, guilt, and shame can be evoked in particular intergroup contexts, and these will have very different implications for people's subsequent behaviour (or behavioural intentions) towards out-groups (Brown et al. 2008; Cottrell \&
Neuberg 2005; Rees et al., in press). Understanding the conditions that elicit - or inhibit - these different emotions is a significant challenge for social psychology, and is one that takes us far beyond the questions of "negative evaluations" and "liking one another" that are the main foci of Dixon et al.'s critique.

\section{Insights from studying prejudice in the context of American atheists}

\author{
doi:10.1017/S0140525X12001161
}

\section{Eric P. Charles, ${ }^{\mathrm{a}}$ Nicholas J. Rowland, ${ }^{\mathrm{b}}$ Brooke Long, ${ }^{\mathrm{c}}$ and Fritz Yarrison ${ }^{\mathrm{C}}$ \\ Departments of a Psychology and ${ }^{\mathrm{b} S o c i o l o g y, ~ T h e ~ P e n n s y l v a n i a ~ S t a t e ~}$ University, Altoona, PA 16602; ' Department of Sociology, Kent State University, Kent, $\mathrm{OH} 44242$. \\ epc2@psu.edu http://www.charlespsychology.com \\ njr12@psu.edu \\ http://www.sites.google.com/site/professorrowland/ \\ blong21@kent.edu fyarriso@kent.edu}

\begin{abstract}
Our research on non-religion supports the proposed shift toward more interactive models of prejudice. Being nonreligious is easily hideable and, increasingly, of low salience, leading to experiences not easily understood via traditional or contemporary frameworks for studying prejudice and prejudice reduction. This context affords new opportunity to observe reverse forms of interactive prejudice, which can interfere with prejudice reduction.
\end{abstract}

Despite their growing numbers (Kosmin \& Keysar 2009), the nonreligious face greater negative prejudice than almost any other group in America (Edgell et al. 2006); they also prejudge others, sometimes negatively. Although this makes non-religion an interesting context in which to explore prejudice and the possibilities for prejudice reduction, few studies document discrimination in this context. Drawing upon our interviews with religious and nonreligious members of American rural communities, we contend that further investigation will support Dixon et al.'s call to reevaluate current understandings of prejudice.

Non-religion is different from the context of traditional prejudice research. The four most crucial differences we see are as follows: First, no obvious outward markers demarcate atheists, especially because most are fully capable of engaging in the customs of religious society. Unlike the interactive contexts of sexism or racism, discriminating against nonbelievers first requires voluntary self-revelation of nonreligious identity. Second, contemporary nonreligious identity is rarely salient. In a 2008 survey, one in five American adults reported no religious identity (Kosmin \& Keysar 2009). This group, labeled "Nones," do not possess a deeply held rejection of God, rather they simply lack a belief in God; their nonreligiousness is not a positive-identity, but a negative or non-identity. Third, because contemporary prejudice against Nones is chiefly negative, the alternative frameworks offered by Dixon et al. do not apply - "Paternalism" requires a sense of dependence between groups; "ambivalent prejudice" requires a modicum of benevolence; "infra-humanization," when it occurs, is explicitly in the context of negative judgment; and, finally, the religious are rarely in a "helping relationship" with the nonreligious, certainly not one entailing "reaffirming the hierarchy." Our research did reveal one phenomenon that could easily be mistaken for ambivalent prejudice: Parents often described their children's lack of faith with expressions such as "it's just a phase" or "he'll grow out of it." This is unlike Ambivalent Sexism (AS), in which femininity is seen as both a positive and a negative. Parents can accept children as immature; however, there is no ambivalence about the atheism, it remains purely 
negative. Fourth, because Nones are defined by their outgroup-ness, "common identification" cannot get us to a "we" (darker side, or otherwise). In sum, discrimination against contemporary atheists and agnostics differs from more commonly studied contexts for discrimination because Nones face purely negative prejudice as a result of an easily hideable, nonsalient non-identity, which still manages to bar common identification between groups.

Contemporary non-religion lacks contextual elements crucial for enacting modern strategies for prejudice reduction. In hiding their nonreligious identity, Nones, in principle, may often be hiding to other hiders. This complicates the "social change" and "collective action" models of prejudice reduction, which assume a readily identifiable group of persecuted individuals to be approached and helped or mobilized for resistance. Even enacting the simple model of "bringing the two groups together" requires that someone know who the Nones are. But this is not known, and it is not likely to become known. Our interviews revealed, for example, parents who were suspicious about their child's faith but did not dare ask. Instead, they simply increased pressure on their child to participate in organized religion. Thus, particular theists or atheists could be surrounded by other atheists, whom they think highly of, without this fact having an opportunity to mediate negative bias or to create group solidarity.

Even if group membership could be identified, however, it is unclear if the models discussed by Dixon et al. would apply. The heterogeneity within nonreligious groups is not like the heterogeneity within religious groups. Admittedly, when prominent atheists engage the public, this faintly resembles the "collective action" model of prejudice reduction; however, people for whom "atheist" is a salient identity fail to represent the growing number of Nones who simply do not care. In sum, existing models of prejudice reduction are unlikely to work for Nones.

Yet, these are hardly the most interesting reasons to study prejudice against Nones. The most novel prejudice-related phenomena we observed can only really occur in the context of an easily hideable trait that is not highly salient. The two factors we have found most interesting are: (a) the justifications given for hiding or revealing nonreligious identity and (b) the efforts to mitigate prejudice for the good of the prejudiced person.

Hiding without hiding. As discussed in Rowland et al. (in press), many nonreligious individuals we interviewed claimed they would not deny their nonreligious identity. However, they were also masterful at avoiding situations that risked the question, and they required the question to be blatant and direct (e.g., "Are you religious?"). From their perspective, they were not concealing their identity, despite never having revealed it. Intriguingly, this strategy was adopted by several individuals who, when asked to speculate, did not expect to suffer greatly if their identity were to become more obviously public. This leads to a question relevant to the Dixon et al. discussion: If they do not care, and expect little to no personal problems, why not voluntarily self-disclose?

Prejudging the prejudiced. We found that closeted Nones hid their identity not out of a desire to protect themselves, but out of a desire to protect their loved ones. Respondents indicated, for example, that they would not tell their mothers about their identity as a means to protect her; sparing her the discomfort that knowing might bring. The greatest concern was voiced regarding grandparents; they were viewed as too intolerant and too close to death to be burdened with such potentially horrible news. Without negative connotation, these interviewees prejudged those around them as prejudiced individuals, who would benefit if protected from the truth about the interviewee's identity. This suggests that, although prejudice against Nones does not fit well into Dixon et al.'s discussion, the reverse-ambivalence and reverse-paternalism displayed by the Nones we interviewed fits quite nicely.

ACKNOWLEDGMENT

Wes Culp and Kaitlin Farnan collected and transcribed much of the data discussed.

\section{Prejudice is about politics: A collective action perspective}

\author{
doi:10.1017/S0140525X12001173
}

\section{John Drury}

University of Sussex, School of Psychology, Falmer, Brighton BN1 9QH, United Kingdom.

j.drury@sussex.ac.uk http://drury.socialpsychology.org/

Abstract: In line with Dixon et al.'s argument, I contend that prejudice should be understood in broadly political rather than in narrowly psychological terms. First, what counts as prejudice is a political judgement. Second, studies of collective action demonstrate that it is in "political" struggles, where subordinate groups together oppose dominant groups, that prejudice can be overcome.

Dixon et al. contend that unequal power relations between social groups are often characterized by attitudinal complexity, rather than simple hostility, and that collective action, rather than reduction in negative evaluations, is the solution to the problem of these unequal power relations. From a collective action perspective, there is agreement with the argument, implicit in their target article, that prejudice should be understood as a broadly political rather than as a narrowly psychological notion. The corollary of this point is that responses to prejudice and inequality should also be broadly political.

Dixon et al. argue that negative evaluation of group members is not the essence of "the problem." I agree. Far from being a problem at all, negative evaluations of groups may sometimes be appropriate. According to the orthodox conception of prejudice, and hence explicit in many of the definitions cited in Dixon et al., negative evaluations of members of other groups are wrong ("unjustified," "faulty," "irrational"). But what about the anti-Fascist's negative evaluation of all Fascists, the striking miner's dislike of all police officers, the Socialist's enmity to the capitalist class: Are these necessarily cases of prejudice? Whether negative evaluations of particular groups are judged to be wrong is not a matter simply of measuring perceptions against reality; rather, it is a matter of (political) perspective (Oakes et al. 1994; Stott et al. 2012).

Of course, the (broadly political) concern of prejudice research is specifically with disadvantaged groups. As Dixon et al. point out, changing relations of disadvantage is also a concern of collective action research. From this perspective, the world is socially structured by conflict between groups with different degrees of power (Tajfel \& Turner 1979). Historically, the ruling class has sought to construct, promote, and build upon division among subordinate groups, including by encouraging "racial" prejudice, in order to maintain its privileged position (Miles 1989). As Dixon et al. argue, collective action can improve racialized subordinate groups' material situation in relation to the powerful (cf. Piven \& Cloward 1977). Collective action can also have unintended consequences, including changes in relations within and between subordinate groups. These, in turn, can entail changes in identity: that is, who "we" are, who counts as "other," and hence how "we" feel about "them."

Oral histories of the United Kingdom miners' strike of 19841985 (Coulter et al. 1984; Green 1990; Salt \& Layzell 1985) are rich in examples of such changes. Over the course of the strike, which involved numerous picket-line confrontations, many strikers 
came to view the police no longer as a neutral protector of their rights but as a "political" force, sent by the Conservative government to break their strike and destroy their livelihoods. A reference point was the 1981 urban riots in London and other cities, which the official enquiry had blamed partly on police "racial" prejudice (Scarman 1981). For many among the predominantly white working-class strikers, the rejection of the police as a social category was linked to a positive re-evaluation of black people, and specifically those involved in the riots. Now they were "the same as us."

Our longitudinal study of a nonviolent direct action campaign investigated the process underlying this kind of psychological change (Drury \& Reicher 2000; 2005; Drury et al. 2003). The groups involved were "locals" and "activists" who both opposed a trunk road being built through the "village green" of Wanstead. At first, locals saw the activists, with their "scruffy" appearance, as "anathema" to respectable Wanstead. Later, however, many of these same locals came to embrace the activists (literally as well as figuratively) and, in some contexts, to redefine "them" as "us."

In their own explanation for locals' change of views, the activists offered a "contact" hypothesis. It was the long discussions they had together, they said, that allowed locals to get to know them, realize they were decent people, and understand their "political" (rather than parochial) critique of road-building. There were two problems with this explanation. First, contact did not seem to be necessary, as the locals also changed their evaluations of groups who they had not even met, including Irish republicans, the Nigerian Ogoni tribe, and other activists around the country. Second, the activists' critique only seemed to have become persuasive when relations between locals and the police had changed.

The change in relations with the police took place within a single event: the eviction by police of locals and activists from under a tree they were occupying on the green in Wanstead. Although the locals understood their action in defending the tree as legitimate, peaceful protest by various different individuals and groups, the police saw it as disorderly behaviour by a single, dangerous crowd. The police acted on this perception by using force against the crowd, without differentiating between activists (who expected some rough treatment) and locals (who did not). The social location of the locals in relation to the police was transformed. The contrast that now defined their identity was no longer that between "locals" and "activists," but between all those who were affected by "injustice" on the one hand and the police on the other. Thus, the locals' positive evaluations of the activists - like the miners' reevaluation of black people-were a function of a shared relationship of opposition to those who treated them all as a single oppositional group.

The evidence from industrial disputes and nonviolent direct actions suggests that "contact" may indeed enhance positive evaluations between groups - at least insofar as that contact takes place within a superordinate relationship of shared struggle against their subordination. However, the problem of inequality between groups is not essentially a problem of negative evaluations, but of power. Therefore, as Dixon et al. argue, the solution to the problem is mobilization for social change through collective empowerment (Drury \& Reicher 2009).

\section{Prejudice in context departs from attitudes toward groups}

doi:10.1017/S0140525X12001185

\author{
Alice H. Eagly a and Amanda B. Diekman ${ }^{\mathrm{b}}$ \\ ${ }^{a}$ Department of Psychology, Northwestern University, Evanston, IL 60201; \\ ${ }^{\mathrm{b}}$ Department of Psychology, Miami University, Oxford, OH 45056. \\ eagly@northwestern.edu http://www.wcas.northwestern.edu/psych/ \\ people/faculty/faculty_individual_pages/eagly.htm \\ diekmaa@muohio.edu \\ https://www.units.muohio.edu/psychology/user/43
}

Abstract: The analysis offered by Dixon et al. fails to acknowledge that the attitudes that drive prejudice are attitudes that are constructed in particular contexts. These attitudes (e.g., toward men as childcare workers) can diverge strongly from attitudes toward the group in general. Social change is thus best achieved through challenging the requirements of roles and by changing group stereotypes.

Dixon et al. have provided an insightful analysis of prejudice that wisely points to the insufficiency of equating prejudice with a negative attitude toward a target group. Despite our agreement with this key point, we depart from their emphasis on attitudes toward groups. Instead, we contend that the attitudes that drive prejudice are not general attitudes toward groups, but attitudes that are constructed in particular contexts. These attitudes - for example, toward men as childcare workers - can be quite different from attitudes toward the group in general.

Prejudice arises in contexts that present individuals with potential opportunities (Diekman et al. 2010). Job candidates, for example, are evaluated in the context of a particular job opening, and the most favorably evaluated candidate generally gets the job. Group membership is relevant to gaining such opportunities because one's sex, race or ethnicity, age, or social class often influences such judgments. However, the critical information is not how gatekeepers evaluate candidates' group memberships, but how they evaluate these memberships in relation to particular opportunities (e.g., Diekman \& Hirnisey 2007). For example, women are typically evaluated less favorably than men for jobs such as firefighter and corporate executive and men less favorably than women for jobs such as kindergarten teacher and clerical worker. It is not attitudes toward women and men in general that underlie such evaluations, but attitudes that emerge in context.

The reason that evaluations of group members in context often diverge from evaluations of them in general pertains to group stereotypes that underlie these attitudes. The overall attitude toward a group summarizes the evaluative content of the attributes ascribed to the group, often producing ambivalent attitudes (Eagly \& Chaiken 2007). With respect to producing prejudice, these stereotypes are critical because they convey information that is far more specific and relevant to the judgment-at-hand. For example, women are generally associated with positive communal qualities such as niceness and social sensitivity (e.g., Eagly et al. 1991). It is these culturally feminine qualities that can disqualify women from positions such as prosecuting attorney or corporate executive, which are generally thought to require culturally masculine qualities (Eagly \& Karau 2002). If no women seek such roles, this prejudice is latent, masked by generally positive attitudes toward women. Those who seek new roles bring prejudice to the surface; these women can be viewed as pushy, unqualified, and undeserving. People suspect that these new candidates do not possess the attributes that yield success in the role. Even if the group stereotype is generally accurate, these beliefs are often misapplied to an individual group member who seeks a nontraditional opportunity (Eagly \& Diekman 2005).

The second half of Dixon et al.'s article elaborates two models of social change that have captured the attention of psychologists. The prejudice reduction model focuses primarily on creating more positive attitudes toward disadvantaged groups, whereas the collective action model focuses on eliciting behaviors by which disadvantaged groups disrupt the societal status quo. Neither of these models provides an adequate analysis of social change because both fail to incorporate the principle that attitudes-in-context are the direct precursor of prejudice and discrimination.

The prejudice reduction model falls short because succeeding in making attitudes toward a group more positive misses the engine of prejudice. For example, making attitudes toward groups such as senior citizens or women more positive would not remove the discriminatory impediments they face as long as these attitudes are grounded in the very positive communal, interpersonally sensitive qualities that tend to be ascribed to these 
groups. They would continue to face prejudice in relation to opportunities requiring agentic, assertive attributes. In fact, a lessening of discrimination could be achieved by reducing the positivity of attitudes toward senior citizens and women by ascribing somewhat less positive agentic qualities to them such as assertiveness and competitiveness.

The collective action model falls short because of its failure to home in on the goals of collective action that would most readily improve the fortunes of disadvantaged groups. Effective social action enables access to roles that convey power and resources; indeed, these are the very roles that are off-limits to disadvantaged groups. This goal can be attained through challenging the requirements of roles and by changing the stereotypes associated with disadvantaged groups.

The requirements of many roles are surprisingly malleable in response to economic, political, and historical forces. For example, in the United States women rapidly entered "Rosie the Riveter" positions in formerly male-dominated fields such as welding and metalworking during World War II. Temporarily, these roles were understood as not necessarily requiring masculine levels of physical strength or of assertion and boldness. However, after the war, traditional beliefs resurfaced, and women were quite speedily removed from these positions. This rapid social change was likely not driven by changes in attitudes toward women or in the female stereotype. Instead, industrial jobs had been temporarily redefined as compatible with the psychological and physical attributes ascribed to women. In other circumstances, roles are gradually redefined in response to diffuse societal influences. For example, the cultural definition of leader roles has changed in the last decades away from masculinity toward androgyny that incorporates a larger measure of social skills (Koenig et al. 2011).

Changing the stereotypes of demographically defined social groups is no easy matter. Because role behavior constitutes the elementary observations that produce group stereotypes in the first place, stereotype change typically requires that group members actually undertake new roles. Effective social action therefore targets access to desirable social roles and to the educational and other socialization experiences that precede role access. Yet, vanguard group members who first enter new social roles do not produce much change in their group stereotype but can leave vestiges of positivity that pave the way for further role access for their group. As a critical mass of individuals succeed in entering nontraditional social roles, they eventually change the stereotype of their group, as well as the characteristics ascribed to the roles that they enter. Access to desirable roles thus underlies the social change that lessens prejudices.

\section{From extreme emotions to extreme actions: Explaining non-normative collective action and reconciliation}

\section{doi:10.1017/S0140525X12001197}

\section{Allard R. Feddes, Liesbeth Mann, and Bertjan Doosje \\ University of Amsterdam, Faculty of Social and Behavioural Sciences, Social Psychology Department, 1018 XA Amsterdam, The Netherlands. a.r.feddes@uva.nl http://home.medewerker.uva.nl/a.r.feddes/ I.mann@uva.nl http://home.medewerker.uva.nl/l.mann/ doosje@uva.nl http://home.medewerker.uva.nl/e.j.doosje/}

Abstract: A key argument of Dixon et al. in the target article is that prejudice reduction through intergroup contact and collective action work in opposite ways. We argue for a complementary approach focusing on extreme emotions to understand why people turn to nonnormative collective action and to understand when and under what conditions extreme emotions may influence positive effects of contact on reconciliation.

In reaction to a number of terrorist acts over the last decade, an impressive amount of studies have been conducted by social and behavioural scientists addressing the question: How do people become radicalised and prepared to use violence to achieve their goals? Following the classification as proposed by Martin (1986, in Wright et al. 1990), this ideology-based violence can be termed "non-normative collective action" as it does not conform to the norms of the existing social system. A key argument of Dixon et al. is that prejudice reduction - in the form of stimulating positive contact and a common identity between an advantaged group and a minority group - and collective action work in opposite ways, showing a "darker side” of both common identification and positive contact" (sect. 3.2, para. 7). We agree this may be the case for members of groups who are still on speaking terms with each other. However, we argue that for individuals who have been radicalised to such an extent that they are motivated to use violence as a means to reach social change, reducing prejudice and intergroup contact are hardly an option anymore. Mere antipathy is in this context the exception rather than the rule. We examine the role of intergroup emotions in explaining non-normative collective action.

Extreme emotions and non-normative collective action. Research has shown that specific emotions that are felt at a group level can lead to action tendencies and behaviour favouring the own group (Doosje et al. 1998; Mackie et al. 2008). Several authors have now pointed out the importance of extreme emotions like humiliation, hate, disgust, and contempt in (support for) violent behaviour (e.g., De Wolf \& Doosje 2010; Fischer \& Roseman 2007; Lindner 2001; Sternberg 2003; Tausch et al. 2011). Interestingly, anger has been proposed to be a key emotion in intractable conflict (e.g., Bar-Tal 2004), but recent findings by Tausch and colleagues (2011) indicate that anger may be more related to normative collective action (e.g., demonstrations) rather than non-normative collective actions (e.g., support for use of violence). Fischer and Roseman (2007) argue that anger can actually serve a useful social function. These authors claim that anger can have beneficial effects by, for example, enhancing self-esteem or restoring unfair situations. When anger turns into hate, however, reconciliation is less likely. Hate, unlike anger, is characterized by the "negation of intimacy," or distance seeking (Sternberg 2003). It is important to note that this tendency to avoid one another makes positive intergroup contact effects less likely to occur.

Other emotions that lead to avoidance but can lead to outgroup targeted violence are contempt and disgust. Contempt is considered an extremely negative emotion as it results in shortterm derogation, long-term social exclusion, a lack of reconciliation, and an absence of relational improvement (Fischer 2011; Fischer \& Roseman 2007). Interestingly, Tausch and colleagues (2011) report that not anger, but contempt predicted support for non-normative action.

Contempt but also disgust has been associated with extreme forms of violence (O'Gorman 2010). In line with this, research by Staub (1989) has shown that people are more prepared to engage in collective violence when they perceive the in-group as superior and the out-group as inferior or even as less human. An example is the Rwanda genocide in 1994. In this context, the Rwandese radio station RTLM called upon Hutus to exterminate the "Tutsi cockroaches." With members of the out-group dehumanised, it became easier to use violence against former neighbours and friends. Dehumanisation (Leyens et al. 2000) occurs when members of an outgroup are perceived to be less human compared with in-group members. In turn, this can result in excluding outgroup members from moral principles. Extreme emotions play a key role in this process, as dehumanisation often goes along with feelings of disgust and contempt (De Wolf \& Doosje 2010). 
Besides hate, contempt, and disgust, humiliation also seems to be an important emotion that can lead to violent behaviour towards others. War-crimes, genocide, and terrorism have all been mentioned to be a result of humiliation (Lindner 2001). Humiliation is defined as "the deep dysphoric feeling associated with being, or perceiving oneself as being unjustly degraded, ridiculed, or put down - in particular, one's identity has been demeaned or devalued" (Hartling \& Luchetta 1999, p. 264).

As argued by Smith (2008) and Lindner (2001), group members may take different actions when their group has been humiliated. Besides conforming and escaping further humiliation, one response is to take revenge. As Bin Laden put it after the 9/11 attacks by Al Qaeda: "What the United States tastes today is a very small thing compared to what we have tasted for tens of years. Our nation has been tasting this humiliation and contempt for more than 80 years." (BBC 2001).

Extreme emotions and reconciliation. Importantly, extreme emotions may not only lead to violent non-normative collective action. We argue that these emotions can, under the right circumstances, also lead to reconciliation. This is nicely illustrated by research findings by Rimé et al. (2011) on effects of "Truth and Reconciliation Gacaca trials." In these trials, the perpetrators of genocide were trialed but also given the opportunity to show remorse. The emotional reactivation among the witnessing audience (often relatives of victims) as well as the perpetrator had a positive effect on the relation between victim and perpetrator groups of the 1994 genocide in Rwanda. Social cohesion between the groups was enhanced, in-group self-categorization decreased, and there were more positive attitudes regarding the out-group.

To conclude with this example, we argue that research on extreme emotions does not only inform our understanding of why people turn to non-normative collective action on behalf of a group, but also helps us understand when and under what conditions extreme emotions may influence positive effects of contact on reconciliation.

\section{History, prejudice, and the study of social inequities}

\section{doi:10.1017/S0140525X12001203}

\section{Jules P. Harrell ${ }^{\mathrm{a}}$ and Edna Greene Medford ${ }^{\mathrm{b}}$ \\ aDepartment of Psychology, Howard University, Washington, DC 20059; \\ ${ }^{\mathrm{b}}$ Department of History, Howard University, Washington, DC 20059. \\ jharrell@howard.edu}

Abstract: Integrating a historical perspective into studies of prejudicial attitudes facilitates the interpretation of paradoxical findings of the kind cited in the target article. History also encourages research to move beyond the study of prejudice and to consider institutional and structural forces that maintain social inequities. Multilevel approaches can study these factors in both field and laboratory studies.

Introduction. The evidence Dixon et al. summarize reveals that clusters and components of prejudicial attitudes are not unitary. Prejudices are better represented as a mosaic, where positive attitudes toward members of a targeted group sometimes coexist with negative evaluations of policies and programs that would reduce social inequities that these groups suffer. The target article signals a change in thinking about the "nature of prejudice" that may turn out to be as significant as the identification of unconscious components of prejudicial attitudes (Greenwald \& Banaji 1995).

We propose that history helps us interpret complex findings related to prejudice and broadens the paradigms in experimental social psychology and social neuroscience. The expanded approach includes studies of systemic and structural aspects of racism, sexism, and other oppressive social processes.

Historical complexity of prejudicial attitudes. Dixon et al. discuss the work of Fox-Genovese and Genovese (2005), revealing both aggressive and paternalistic attitudes toward the enslaved on the part of Southern plantation owners. Indeed, history is replete with such examples. Du Bois's (1935) in Black Reconstruction described the complex attitudes of northern and southern whites toward enslaved people and toward a war that might result in the dismantling of the slavery system. He recounted the search for a slogan around which people in the north and west would rally. Ultimately, the refrain that reflected their attitudes pledged allegiance to the flag, while "....all its foes we abhor/ we ain't for the n... but we are for the war" (p. 56).

John Hope Franklin's (1965) essay "Two Worlds of Race" reminds us that Lincoln often expressed ambivalent attitudes toward enslaved individuals and their capacity to succeed in the United States. Franklin pointed out that even among abolitionists there was no universal sentiment for social inclusion or close proximity with people of African descent. We know that those few, such as John Brown, who thought otherwise, had their behavior described as madness. Thus, professional historians would barely raise an eyebrow at the conclusions Dixon et al. advanced indicating that individuals show inconsistencies between the emotional evaluation of persons targeted by prejudice and policy-related attitudes.

History and research into social inequities. Citing important studies of the origins of the urban underclass, Chowkwanyun (2011) asserted that the inclusion of a historical perspective expands and deepens empirical studies of social inequities. Historical research identifies central actors and pivotal decisions that emanate from all levels of society and converge to produce current conditions. For history, studies of prejudice and quantitative listings of race differences in behaviors and conditions are mere starting points. Ultimately, historians determine how social groups and institutions and civic organizations-large and small-converge to structure social outcomes along racial lines. The integration of the historical method into behavioral science research moves the focus from "individual-level characteristics or behaviors and how much they predict life chances in larger social structure ... to how transformations of the latter can alter the former" (Chowkwanyun 2011, p. 259).

Thus, the historical perspective helps with the interpretations of intriguing findings of the kind Dixon et al. cite, but its contributions only begin there. History compels behavioral research paradigms to go beyond studies of prejudice and consider the role other oppressive individual and institutional practices play in supporting social inequities. Racism has been described in terms of power dynamics, structural components, and institutional actors that may operate in the absence of negative intentions (Bonilla-Silva 2001; 2006; Jones 1972/1997; Paradies 2006). Gee and Ford (2011) encouraged the study of the effects on health of structural factors in society, including neighborhood segregation and immigration policies.

Indeed, prejudice is an ostensible, but perhaps less critical factor contributing to inequalities. The structural elements, though less apparent, are largely responsible for the persistence of racialized and gender-related disparities. Dixon et al. called attention to a body of research indicating that among oppressed groups, attitudes toward policies aimed at reducing social inequities become more negative when social proximity increases positive between-group feelings. It may be that as intergroup contact reduces antipathy between advantaged and disadvantaged group members, it results in marginalized group members attributing continued inequities to the actions and behaviors of their 
group. Indeed, within group contact does nothing inherently to heighten the awareness and understanding of institutional and structural sources of inequities. It is essential to measure attitudes toward many oppressive societal forces in order to determine why the reduction of intergroup negative attitudes might reduce one's willingness to mobilize actions to combat inequities.

The mounting attention multilevel models are paying to institutionally based sources of social inequities (Krieger 2011; Sadanius et al. 2004) should not sideline the laboratory paradigms that experimental social psychologists and social neuroscientists favor. Systemic forces can be studied in the laboratory. Krieger (1994; 2011) employed a fractal metaphor to illustrate operation of factors from multiple levels on bio-behavioral phenomena. The fractal approach asserts that each causal factor is represented at the various levels of analysis. Hence, prejudicial attitudes are represented within cognitive schema, neural networks, as well as within institutional actions. Similarly, structural racism will be represented at the biological and psychological levels of analysis.

Consistent with the fractal approach, Harrell et al. (2011) discussed the internal psychological representations, as well as psychophysiological mechanisms, involved in various forms of racism. They suggested that structural racism could be examined in the laboratory in terms of the negative self-schema racialized outcomes generate, or in terms of the rumination and perseverative thinking that these disparities cause in marginalized groups. The task for the experimental social psychologist and social neuroscientist is to determine how systemic oppressive social processes are represented psychologically and to operationalize these manifestations in laboratory paradigms.

Conclusion. An awareness of history facilitates understanding of sometimes perplexing findings of the kind Dixon et al. cite. Historians are keenly aware that social inequities are multidetermined phenomena and are comfortable studying these factors using quantitative and qualitative methods. Thus, history is invaluable as investigators grapple with the interaction among complex forces, ranging from the psychological to macrosocial that determine social outcomes.

\section{What's so crummy 'bout peace, love, and understanding?}

\author{
doi:10.1017/S0140525X12001227
}

\section{Nick Haslam \\ University of Melbourne, Psychological Sciences, University of Melbourne, Parkville VIC 3010, Australia. \\ nhaslam@unimelb.edu.au \\ http://www.psych.unimelb.edu.au/people/staff/HaslamN.html}

\begin{abstract}
The target article challenges standard approaches to prejudice reduction, warning that they may inure people to inequality and deflect them from seeking collective solutions to it. I argue that the collective action approach has its own risks and limitations and that standard contact and common identity approaches may complement rather than work against it.
\end{abstract}

Dixon et al. prosecute a strong case against the view that prejudice is mere antipathy and against the sufficiency of standard prejudice reduction strategies for overcoming inequality, such as promoting intergroup contact and a sense of common humanity. These strategies may indeed reduce antipathy, but they do so at a cost. In particular, they blind people to the continuing existence of inequality, reduce the motivation of the disadvantaged to mount collective challenges to it, and discourage members of advantaged groups from seeking political remedies. These sedative, ironic, and atomizing effects of prejudice reduction may end up bolstering rather than overcoming inequality. According to Dixon et al., we would do better to support a collective action approach, in which the disadvantaged mobilize politically and conflict is seen as a sign of productive change rather than as a failure of social harmony.

This is a bracing and important message, but it is overstated. There need be no negative relationship between prejudice reduction solutions involving interpersonal contact and common identity and the collective action approach, and the latter is itself no panacea. The adversarial approach to intergroup relations that Dixon et al. propose, in which collective conflict is the crucible for social change, runs the risk of promoting an essentialist understanding of group differences. Whereas contact and common identity are de-essentializing - the former by individuating group members, the latter by reducing the salience of the intergroup divide - any approach that deepens and entrenches that divide, even for strategic and progressive reasons, increases the likelihood that group members will construe their differences as fundamental, defining, and immutable (Haslam et al. 2000). Essentialist thinking of this sort is consistently associated with intergroup hostility, aversion, accentuation, and separatism (e.g., Bastian \& Haslam 2008; No et al. 2008), and it can even increase acceptance of intergroup inequality (Williams \& Eberhardt 2008), one of the supposed sedative consequences of the standard prejudice reduction approach.

The deepening and solidifying of intergroup divides that essentialist thinking encourages has obvious implications for forgiveness, reconciliation, and compromise. Dixon et al. are probably correct to observe that major social change is often set in motion by mobilization of the disadvantaged. However, this collective action will usually provoke a substantial backlash, especially if the "us and them" dynamic is exacerbated by essentialist thinking on both sides. Similarly, once some structural change has taken place, the ideal outcome would involve intergroup reconciliation, but lasting conflict is likely to follow if an essentialist view of the relevant groups has taken hold. On its own, the collective action approach has little to say about this: the disadvantaged rise up and a new day of social justice dawns. However, that day usually also brings lingering resentments, grievances, and hatreds. Those animosities are especially likely to fester when group identities are understood in exclusive, timeless, and defining -in a word, essentialist - ways.

Here perhaps is one place where the prejudice reduction approach may enable or complement the collective action approach rather than work against it. There is ample evidence that contact enhances forgiveness and reconciliation. For example, in the Northern Ireland context, Tam et al. (2007) showed that contact increased intergroup forgiveness via more positive attitudes toward the out-group and reductions in anger and subtle dehumanization. Cehajic et al. (2008) similarly found that contact and common ingroup identification promoted forgiveness, trust, and reduced desire for social distance among Bosnian Muslims. With regard to essentialist thinking as a barrier to peace, Halperin et al. (2011) demonstrated that beliefs in the malleability of groups enhanced willingness to compromise for peace among Israeli Jews and Palestinians. In short, prejudice reduction strategies that involve contact and perceptions of shared identity and bridgeable category boundaries may help to meet the goal of social change, and without them collective action may backfire or curdle.

The collective action approach may also have some boundary conditions that leave standard prejudice reduction strategies as the best options. Some subordinate groups are so diffuse or disorganized that collective mobilization is difficult. In the Australian context, for example, public opposition toward asylum seekers is very hard to address except by a process of changing the hearts and minds of the majority through contact and 
humanizing media (Haslam \& Holland 2012). There is little prospect of organizing asylum seekers as a group on account of their cultural and linguistic diversity, dire circumstances, and geographic dispersion. Dixon et al. acknowledge that their approach is best suited to lasting and well-established inequalities, and it may not translate unproblematically to all forms of disadvantage.

Dixon et al. are surely right to remind us that prejudice is more than dislike and that social inequalities cannot usually be resolved merely by individual-level interventions that enhance liking. However, collective mobilization has its own problems as well and can harden hearts and intergroup boundaries in ways that work against lasting positive change. Ideally, social psychologists will discover ways in which the target article's two contrasted approaches are not "incommensurable," but indispensable.

\section{All about us, but never about us: The three- pronged potency of prejudice}

\author{
doi:10.1017/S0140525X12001215
}

\section{S. Alexander Haslam ${ }^{a}$ and Katherine J. Reynolds ${ }^{b}$ \\ aschool of Psychology, University of Queensland, St Lucia, QLD 4072, Australia; ' School of Psychology, Australian National University, ACT, 0200, Australia. \\ a.haslam@uq.edu.au@katherine.reynolds@anu.edu.au}

\begin{abstract}
Three points that are implicit in Dixon et al.'s paradigmchallenging paper serve to make prejudice potent. First, prejudice reflects understandings of social identity - the relationship of "us" to "them" - that are shared within particular groups. Second, these understandings are actively promoted by leaders who represent and advance in-group identity. Third, prejudice is identified in out-groups, not in-groups.
\end{abstract}

Over time, social psychology has increasingly construed prejudice as an "attitude problem" in which individuals' negative views of out-groups are understood to constitute a major obstacle to social progress. Under this model, if attitudes improve, the problem goes away. Accordingly, since World War II, researchers' energies have focused on shaping policies and developing interventions that might bring about attitude change of this form.

To this comfortable state of affairs Dixon et al. admit an uncomfortable constellation of observations and questions. First, they note that the dominant prejudice reduction model (PRM) draws attention away from material realities of inequality and injustice. Second, they argue that progressive goals may be better served by bringing these realities into the open through a collective action model (CAM) that makes conflict salient as a focus for collective efforts (particularly by members of disadvantaged groups) to produce meaningful social change. This analysis uncovers an ironic prejudice embedded in the very definition of prejudice, which serves to prioritize psychological conciliation over political action. Indeed, more controversially, one can see striving for such conciliation as a reflection of the political priorities of privileged groups for whom inaction is advantageous (or at least unproblematic).

With a view to framing understanding of this debate and also channeling future research efforts, there are three points that can be superimposed on, and drawn out from, Dixon et al.'s analysis. In different ways, all are informed by work within the social identity tradition (after Tajfel \& Turner 1979).

1. Prejudice is underpinned by shared social identity. Social identity theorizing draws attention to the fact that although psychologists routinely focus on prejudice as a problem of individual attitudes, socially potent forms of prejudice reflect collective understandings that are grounded in a particular model of social identity - a sense of "us" as different from and superior to "them" (Haslam et al. 1998; Oakes et al. 1994). It is thus the fact that group members come to share particular beliefs about both in-group and out-group that gives those beliefs their force (Tajfel 1981).

In highlighting the fact that intergroup relations are underpinned by an explicit sense of "us" and "them," this is something that proponents of the CAM generally recognize. However, it is more easily overlooked within the PRM because this promotes, and draws strength from, collective beliefs that tend to downplay overt (or at least challenging) us-them distinctions. In this way, the greater part of the prejudice literature is founded upon an implicit sense that, in reality, "we're all individuals" and an ironic denial of the fact that such beliefs are themselves a reflection of collective identities.

In this regard, alongside problems identified by Dixon et al., a particular danger of prevailing approaches to prejudice (i.e., those that promote the PRM) is that they direct attention away from the socially structured nature of prejudice. By neglecting the motivated understandings of in-group and out-group that underpin coordinated social behaviour (even those that are seemingly "benign"), this model allows many researchers and commentators to persist in a belief that problems of prejudice reflect "misunderstandings" that can be remedied either through purely cognitive interventions or through social rearrangements that are blind to power and vested interests. They cannot.

2. Prejudice is promoted through identity-based leadership. A second problem with prevailing approaches to prejudice is that their psychological focus tends to position all parties as passive vessels rather than as active agents. In particular, the PRM tends to see both perpetrators and victims of prejudice as slaves to circumstance (e.g., the need to save time, to reduce uncertainty, or to belong) who can only be rescued from their sorry condition through the intervention of well-meaning third parties (e.g., researchers and the policy makers they instruct).

Prejudice, though, is never an accident of cognition, never an unintended by-product of neural architecture, never an unmediated expression of biological or evolutionary "primitives." Instead-whether hostile or benign-it is an expression of valued social identities that are internalized, embraced, and enthusiastically promoted by group members. Importantly too, leaders (i.e., those who represent and therefore influence the group) play a key role in actively crafting the meanings of social identity and the interpretations of intergroup relations that give rise to various forms of prejudice (Haslam et al. 2011).

Dixon et al.'s analysis suggests that this is as true for scientific leaders as it is for those in the political realm.

3. Prejudice is identified in out-groups, not in-groups. This leads to a third point - that leaders win followers to their cause because, in terms of the social identities they represent and promote, leaders are understood to be right. Phenomenologically, there is no such thing as "our prejudice." The map of perceived prejudice is one that charts the contours of out-group identity, and it is the fact that it is invisible in a mirror that explains the influence of different prejudices for different groups at different points in time, including the powerful grip of benign forms of prejudice today.

Here again, an attraction of Dixon et al.'s analysis is that it promotes recognition of group members as collaborators in the making of their own world and encourages researchers to reflect on their own role as agents of influence who promote and embed particular instantiations of identity. Like the CAM, the PRM is itself an identity-management project whose success is structured by the identity-based relationship between its advocates and those they would influence.

In these same terms, progress in the study of prejudice needs to be seen as a political, not just a psychological, venture in which 
advocates of particular models of identity draw attention to perceived limitations in the collective views of others and seek to supplant these with their own. It was such progress-and the problematization of race psychology-that led to prejudice being identified as a research topic in the first place (Reynolds et al. 2012). Likewise, the success of Dixon et al.'s own leadership will hinge on whether it motivates researchers to interrogate their own "attitude problem" or else cling to their prejudices (and the identities that underpin them) ever more strongly.

\section{Of babies and bathwater, and rabbits and rabbit holes: A plea for conflict prevention, not conflict promotion}

\author{
doi:10.1017/S0140525X12001239
}

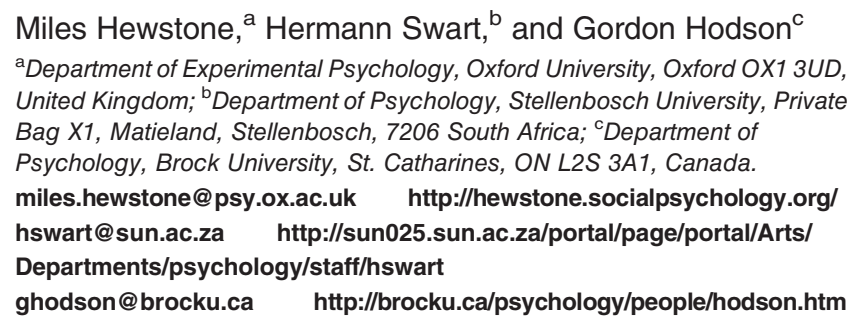

Abstract: Dixon et al. overlook the fact that contact predicts not only favorable out-group attitudes/evaluations, but also cognitions, affect, and behavior. The weight of evidence supporting the benefits of intergroup contact cautions against throwing the (contact) baby out with the bathwater. The goal to "ignite struggles" in pursuit of social equality, we argue, incautiously risks hurling us down the proverbial rabbit hole.

There is much to admire in Dixon et al.'s elegantly written piece. Given space limitations, we focus our reply on how research on intergroup contact is characterized within the target article.

By focusing on direct (face-to-face) intergroup contact and the reduction of prejudice, the target article does not adequately capture the complexities in contemporary contact theory. In some ways, the authors attack a "straw man": there are multiple forms of contact (notably direct and indirect/extended contact; see Harwood et al. 2013) that affect a wide range of outcomes that are cognitive, affective, and/or behavioral in nature (Hewstone 2009; for a review, see Hodson et al. 2013). Suggesting that the contact literature is preoccupied with prejudice reduction alone ignores the body of evidence demonstrating that contact goes beyond simply eliminating negative states and perceptions, but also fosters empathy, increases cooperation, and encourages future contact (Hodson et al. 2013). Impressively, contact even works among contact-resistant, prejudiced persons (e.g., those high in authoritarianism or social dominance, see Hodson 2011).

The target authors trivialize research focusing on attitude outcomes as simply "getting us to like one another more." Although attitude change is not the only, or even the ultimate, outcome variable, achieving increased liking between members of different groups will be seen as a critical achievement for those working in settings where members of different social, ethnic, and religious groups do (have to) coexist (e.g., diverse schools). In other settings (e.g., post-conflict societies such as Northern Ireland), other outcome variables may be considered more important, such as promoting outgroup trust and forgiveness or reducing dehumanization. Fortunately, contact achieves these objectives (Hewstone et al. 2006; Tam et al. 2007; 2008; 2009). Arguably, contact's impact on the proximal predictors of attitudes (e.g., reducing anxiety and promoting empathy; for reviews, see Brown \& Hewstone 2005; Hodson et al. 2013) is as important as promoting "mere" liking. We must not do social science research a disservice, nor confuse policy makers, by underplaying the prejudice-relevant achievements of contact. Before the baby is thrown out with the bathwater, we ought to revisit the failures of alternative interventions (see Paluck \& Green 2009), compared with the robust metaanalytic support for intergroup contact (see Pettigrew \& Tropp 2006). Moreover, without increased contact, we risk perpetuating segregation and separation. This is no solution, whether under actual apartheid in South Africa pre-1994 or the "benign apartheid" of highly segregated neighborhoods and schools in many countries.

We are sympathetic to the challenge the authors pose between prejudice-reduction and social change solutions. Yet the pressing needs in the social context should guide the research agenda. As such, we consider neither prejudice reduction nor collective action as the de facto outcomes to be pursued. In some situations, and for some scholars, social change may trump other goals (as it seems for the target authors). Elsewhere, the social change agenda may seem less relevant. In contemporary Northern Ireland, for example, there has been a massive reduction in discrimination against Catholics in housing and education and the emergence of a burgeoning Catholic middle class. Here, contact theory's focus on a range of outcomes - e.g., promoting perspective-taking or increasing the complexity of outgroup images - is arguably more relevant than emphasizing collective action. Likewise, in our current work in multiethnic schools in the north of England (the scene of riots in 2001), we see the primary goal being one of promoting positive coexistence through contact, rather than of encouraging further disturbances. As academics, we consider it unwise to encourage collective action that will exert unknown and potentially negative impact on others (typically not ourselves). In the wake of the Arab Spring of 2011 it may be tempting to "ignite struggles" to bring about social change. Yet we find ourselves thinking of Alice's rash journey to Wonderland, compelling us to urge strong caution before going down this particular rabbit hole without seriously considering the potentially negative consequences of encouraging intergroup conflict in the name of social change.

Dixon et al. are right to point to the two models of social change and the possible tensions between them. However prejudice reduction and collective action need not be conceptualized as zero-sum goals. If, as the authors contend, contact is negatively associated with precursors of social change, then it is incumbent upon the field to harness the power of contact to induce change in the dominant group without blunting the subordinate group's striving for equity. There will be less bloodshed when the majority is convinced to change their out-group evaluations and when there is widespread normative support for change. Contact can therefore facilitate social change by bringing majority members to understand the world from the perspective of the disadvantaged minority (Jeffries \& Ransford 1969; Mallett et al. 2008). It is important, therefore, not to underplay the great successes of intergroup contact. Even knowing about or observing intergroup contact is associated with reduced prejudice (Turner et al. 2007; Wright et al. 1997), and recent longitudinal and multilevel analyses show that contact typically drives effects at the neighborhood level (not simply at the individual level; Pettigrew et al. 2007). In contrast to alternative interventions, contact effects generalize, from individual out-group members to the out-group as a whole (Brown \& Hewstone 2005), and from views of a primary outgroup to secondary outgroups (Tausch et al. 2010). Such research on contact's "secondary transfer effects" allay the target authors' concerns that, for members of a minority group, contact with the majority group negatively impacts attitudes toward other minorities.

Although contact is only part of the solution, not the solution, its role remains essential. As social psychologists, we see great value in exploring the potential of multiple forms of intergroup contact to impact multiple outcomes, via multiple mediating processes, at micro- meso-, and societal-levels (Pettigrew 1996; Wagner \& Hewstone 2012). This view does not negate or deny the importance of collective action, but rather sets the record straight 
about what contact can achieve and situates contact-based attitude change and social change as complementary (not inherently conflicting) objectives.

\section{The politics of moving beyond prejudice}

\author{
doi:10.1017/S0140525X12001240
}

\section{Caroline Howarth, ${ }^{\text {a } W o l f g a n g ~ W a g n e r, ~}{ }^{\text {b,c }}$ Shose Kessi, ${ }^{d}$ and Ragini Sen ${ }^{\mathrm{e}}$}

aInstitute of Social Psychology, London School of Economics and Political Science, London, WC2A 2AE, United Kingdom; ' Institute of Education and Psychology, Johannes Kepler University, 4040 Linz, Austria; ${ }^{\circ}$ Dept de Psicología Social, University of the Basque Country, San Sebastián, Spain; ${ }^{d}$ Department of Psychology, University of Cape Town, Cape Town 7701, South Africa; ${ }^{\mathrm{e}}$ Centre for Policy Research, New Delhi, India, 110021.

c.s.howarth@Ise.ac.uk http://www2.Ise.ac.uk/socialPsychology/
faculty/caroline_howarth/Home.aspx
w.wagner@jku.at http://www.swp.jku.at/team/wagner
shose.kessi@uct.ac.za raginisen2011@gmail.com

Abstract: Dixon et al. have highlighted the importance of a political conceptualisation of intergroup relations that challenges individualising models of social change. As important as this paper is for the development of critical debates in psychology, we can detect at least three issues that warrant further discussion: (a) the cultural and historical conditions of structural inequality and its perception, (b) the marginalisation of post-colonial works on collective mobilisation, and (c) acknowledging the complex perspectives and politics of those targeted by prejudice.

Before and beyond the existence of psychology as a science, revolutionaries of all times-Spartacus, Robespierre, Lenin, Mao Zedong, Lumumba, Malcolm X, Mandela, and leaders of anticolonial movements - knew that one needs a dedicated group of people to attempt and sometimes succeed in overthrowing an institutionalised social structure of oppression and discrimination. They also knew that dominant classes would not cede power voluntarily. Their struggle was directed against a well-organised stratum of society whose power, structural dominance, and exclusive privileges were legitimised by divine or secular law. In such social structures, it does not make sense to attribute prejudice to the "oppressors." It is not prejudice to treat the "historically disadvantaged" in hostile, denigrating, or even paternalistic terms because the differences in access to rights and resources are structurally given and their subordinated status appears "natural." Hence, the slave holder who is indulgent to his obedient slaves (Dixon et al., sect. 3.2, for example) is taking care of his means of production and not paternalistically prejudiced towards a potential equal.

Prejudice becomes an issue as soon as societies are more or less successful in reducing structural obstacles to social mobility to varying degrees, usually by implementing some form of democracy, particularly the Universal Declaration of Human Rights (UDHR) of 1948. Differences in access to rights and resources then appear as the "natural" consequence of individual achievement and evidence of capitalist market forces. Under these conditions, it is conceptually correct to talk about the "historically disadvantaged" as recipients of prejudice; and it is these conditions that the psychology of prejudice addresses in its humanist intention to create harmony among people where we "like each other."

Dixon et al. merge these conditions in somewhat arbitrary ways: the structurally divided societies of the U.S.-American slave-owning society or the apartheid system in South Africa on the one hand and seemingly benevolent, positive relations in supposedly egalitarian societies on the other. In doing so, these authors confuse the unstable character of hierarchies in democracies with structurally and legally divided societies in other historical periods. In our opinion, juxtaposing the collective action model and the prejudice reduction model as models of social change constitutes a confusion in conceptual levels of analysis. The first deals with collective action to abolish structural conditions of which historical revolutions are a more extreme example. The latter is a humanist attempt at smoothing daily social encounters with (constructed) otherness, which does not aim for social change per se. Conflating these as dealing with the relationship between advantaged and disadvantaged groups belittles and simplifies the complex political identities and multifaceted political ambitions of the structurally disadvantaged (cf. Bourdieu 2000).

Nevertheless, we applaud the attempt by Dixon et al. to highlight the individualisation of prejudice within psychology. Indeed, there is a long history of the individualisation and psychologisation of prejudice that has excluded more political psychological accounts that may be better equipped to tackle social inequalities and promote social change (Elcheroth et al. 2011). Hence, it is troubling to see this marginalisation occurring in this very paper with the omission of relevant theories on collective mobilisation and group solidarity based on the works of Biko, Fanon, and other post-colonial writers (beyond one fleeting reference to Fanon 1965). Although the authors critique the simplistic notion that positive emotions lead to a reduction in prejudice, they make the reverse and equally simplistic assumption that negative emotions lead to collective mobilisation. By contrast, post-colonial psychology promotes the development of positive emotions towards self and others to inspire a desire for collective action and social change (Biko 1978). As a result, individuals from disadvantaged communities begin to see themselves as knowledgeable and capable agents of change (Howarth 2006). In this way, we can see collective mobilisation as a process of conflict resolution to achieve social justice and not merely a mechanism to "instigate intergroup conflict” (Dixon et al., sect. 3.1, para. 11).

In our recent research (on development in Tanzania and South Africa, Kessi 2011; community art projects for mixed-heritage families in the UK; Howarth et al. forthcoming; representations of the veil in India and Indonesia, Wagner et al., forthcoming), we have documented how individuals and groups challenge stigmatising representations (of development, of race, and of Islam) and forge positive emotions towards self and others in these communities. As a result, we see how our research participants have developed a consciousness of themselves as agents of change, which was reinforced through the networks of social solidarity forged through the collective activities and the positive recognition that they received from community members. These examples demonstrate that prejudice reduction and collective mobilisation can go hand in hand and do not necessarily draw on competing psychological processes as Dixon et al. argue.

Furthermore, when these authors discuss the findings of prejudice reduction programmes and show that these can sometimes lower support for antidiscriminatory measures, they attribute a false consciousness in the sense of "They should know better that they are being discriminated against!" This is a problematic move that diminishes the perspective and politics of those categorised as "disadvantaged" and overlooks the ideological and intersectional construction of advantaged and disadvantaged groups. Their analysis implies that there are always clearly divided and competing groups: men and women; blacks and whites; Jews and Arabs. This reifies social categories, obscures the intersectionality of all social groups, and loses a perspectival approach that recognises that these are located, socially constructed and ideologically maintained (Gillespie et al., forthcoming).

Dixon et al. have developed an important political conceptualisation of intergroup relations that challenges individualising models of prejudice and social change. However, we suggest that there are a number of problems with this analysis: first: the 
comparison between the models of prejudice reduction and collective action apply to different historical and political settings; second: the marginalisation of post-colonial texts on collective mobilisation; third: the attribution of false consciousness to disadvantaged groups. By highlighting these points, we also reveal, as do Dixon et al., the difficulties in moving away from dominant perspectives on prejudice reduction.

\section{What's so insidious about "Peace, Love, and Understanding"? A system justification perspective}

\section{doi:10.1017/S0140525X12001252}

\section{John T. Jost, Chadly Stern, and David A. Kalkstein Department of Psychology, New York University, New York, NY 10003. john.jost@nyu.edu http://www.psych.nyu.edu/psychology.html cds330@nyu.edu dak414@nyu.edu}

Abstract: We agree that promoting intergroup harmony "carries insidious, often unacknowledged, 'system-justifying' consequences” (sect. 4.1.3, para. 2) and identify several ways in which "benevolent" and "complementary" stereotypes, superordinate identification, intergroup contact, and prejudice reduction techniques can undermine social change motivation by reinforcing system-justifying beliefs. This may "keep the peace," but it also prevents individuals and groups from tackling serious social problems, including inequality and oppression.

Near the end of a provocative discussion of typical prejudice reduction efforts and their potentially deleterious consequences for society, Dixon et al. mention that promoting intergroup harmony "carries insidious, often unacknowledged, 'system-justifying' consequences" (sect. 4.1.3, para. 2). We flesh out this important but underdeveloped point, demonstrating that system justification theory can help to explain how and why "benevolent" and "complementary" stereotypes, superordinate identification, positive intergroup contact, and standard prejudice reduction techniques all serve to undermine social change motivation and maintain support for unequal social systems.

From a system justification perspective, "cognition is deployed in the service of the social system" (Jost 2001, p. 95), which is a way of saying that individuals and groups construct belief systems that disproportionately bolster existing societal arrangements. As Allport (1954) pointed out long ago, stereotypes are a major vehicle for the rationalization of inequality among social groups (Jost \& Hamilton 2005). Glick and Fiske (2001) observed that even seemingly benevolent stereotypes of women as warm, nurturing, and deserving of admiration and protection reinforce gender disparities. Jost and Kay (2005) demonstrated that simply reminding female college students of benevolent or complementary stereotypes (e.g., "Women are more considerate than men," and "Men are more ambitious than women") caused them to profess greater satisfaction with the status quo by endorsing "system-justifying" statements such as, "Most policies relating to gender and the sexual division of labor serve the greater good," and "In general, the American political system operates as it should."

Becker and Wright (2011) found that exposure to hostile sexism caused women to express stronger desire for collective action, whereas exposure to benevolent sexism made them less supportive of feminist causes. Furthermore, these effects were mediated by gender-specific system justification. Calogero and Jost (2011) showed that exposure to benevolent and complementary stereotypes led women (but not men) to view themselves as sexual objects, engage in more self-surveillance, and experience more body shame. In summary, seemingly "benevolent" gender stereotypes can strengthen women's ideological and behavioral conformity to a social system that disadvantages them profoundly.

Such effects are hardly confined to the context of gender. When individuals are exposed to "poor but happy" or "poor but honest" stereotype exemplars, they report more satisfaction with the societal status quo, as measured by the general (or diffuse) system justification scale (Kay \& Jost 2003). Confronting participants with criticisms of the national system causes them to respond defensively on its behalf, drawing on benevolent and complementary stereotypes to bolster the sagging legitimacy of the social system. Exposure to system criticism leads Americans to describe the obese as lazier but more sociable (Kay et al. 2005) and Israelis to describe Mizrachi Jews as less intelligent but more friendly than Ashkenazi Jews (Jost et al. 2005). Consistent with Dixon et al.'s analysis, it is precisely because complementary stereotypes such as these are laden with positivity (and an "illusion of equality") that they are effective in undermining support for social change.

It follows that a focus on negative evaluation as the major problem of intergroup relations neglects the insidious role of complementary stereotyping and other Panglossian forms of rationalization in sustaining inequality (e.g., see Kay et al. 2007). Positive intergroup contact as a prejudice reduction strategy can attenuate unambiguously negative evaluations of low-status groups (Pettigrew \& Tropp 2006), but it can also thwart social change by leaving system-justifying beliefs (such as essentialism with respect to race and sex and meritocracy with respect to social and economic status) fully intact.

Personal relationships between those who are advantaged and those who are disadvantaged may foster a sense of equality and social progress that is more illusory than real (Jackman 1994). Even trivial interpersonal ties to the advantaged can facilitate system justification among the disadvantaged (Cheung et al. 2011). Positive intergroup contact is associated with more favorable implicit evaluations of outgroups by members of disadvantaged (e.g., blacks, Muslims) but not advantaged groups (whites, Christians; Henry \& Hardin 2006). Given that implicit outgroup favoritism among the disadvantaged is associated with conservative, system-justifying responses (Ashburn-Nardo et al. 2003; Jost et al. 2004), the net effect of intergroup contact may be to suppress rather than promote meaningful social change. The same can be said of many efforts to foster common (or superordinate) forms of in-group identification that gloss over differences between advantaged and disadvantaged (sub)groups (Dovidio et al. 2009). Such efforts encourage the disadvantaged to believe (often falsely) that they will be treated fairly (Saguy et al. 2009) and that the social order is legitimate (Saguy \& Chernyak-Hai 2012).

For substantive social change to occur, members of disadvantaged groups must build solidarity within their ranks and take decisive action against the status quo (e.g., Wright et al. 1990). Such action may necessitate intergroup tension to forcefully resist the social system and ideologies that justify it (Becker \& Wright 2011; Jost et al. 2012). Attacking system-justifying beliefs and demanding equitable resource distributions will be far more difficult and psychologically unsettling than trying to assimilate, establish positive intergroup relations, or otherwise accommodate the demands of the status quo. System justification theorists point out that it will almost always be easier to encourage individuals and groups to make the best of a bad situation than to actually fix it.

For these reasons, we would go further than Dixon et al. to hypothesize that prejudice reduction strategies that frame problems of inequality as operating exclusively at the level of individuals and groups are heralded because they are psychologically comforting, as are other system-justifying illusions (Jost \& Hunyady 2002). To the extent that prejudice can be marginalized as simply a problem of "hate," conflict, or misunderstanding, citizens can deny the extent to which inequalities of wealth, power, and privilege remain firmly 
entrenched in our social, economic, and political systems (from colonialism and slavery to capitalism and corporate control of democratic institutions). The kind of "motivated ignorance" that follows from system-justifying ways of thinking may help to "keep the peace," but it can also prevent us from tackling serious social problems, including structurally embedded forms of inequality and oppression.

\section{What works to address prejudice? Look to developmental science research for the answer}

\author{
doi:10.1017/S0140525X12001410
}

\section{Melanie Killen, ${ }^{a}$ Kelly Lynn Mulvey, ${ }^{a}$ Aline Hitti, ${ }^{a}$ and Adam Rutland ${ }^{b}$ \\ ${ }^{a}$ Department of Human Development and Quantitative Methodology, University of Maryland, College Park, MD 20742; ${ }^{\mathrm{b}}$ Department of Psychology, Goldsmiths, University of London, New Cross, London SE14 6NW, United Kingdom. \\ MKillen@umd.edu KImulvey@umd.edu \\ AHitti@umd.edu a.rutland@gold.ac.uk}

\begin{abstract}
Developmental perspectives on prejudice provide a fundamental and important key to the puzzle for determining how to address prejudice. Research with historically disadvantaged and advantaged groups in childhood and adolescence reveals the complexity of social cognitive and moral judgments about prejudice, discrimination, bias, and exclusion. Children are aware of status and hierarchies, and often reject the status quo. Intervention, to be effective, must happen early in development, before prejudice and stereotypes are deeply entrenched.
\end{abstract}

The target article by Dixon et al. is provocative and will create new dialogue about how to create effective interventions for addressing prejudice. As developmental scientists, though, we were disappointed by the absence of any attention to research on the developmental origins of prejudice, especially given that extensive research indicates that for intervention to be effective it must start early in life, before negative attitudes and stereotypes are deeply entrenched by adulthood (Levy \& Killen 2008; Quintana \& McKown 2007). Even more telling is that, according to the argument laid out by Dixon et al., developmental research is ahead of the pack. Dixon et al.'s call for research to reflect both historically advantaged and disadvantaged perspectives has been reflected in developmental research for at least a decade (see Killen et al. 2002; Verkuyten 2003).

Dixon et al. assert that researchers studying prejudice reduction focus too much on how it is that we can get individuals to think more positively about others. They view this approach as a problem because it ignores issues of hierarchies and status that do not change even when people "like each other" (as with gender relations in which females may experience inequality but not necessarily "dislike" from men in high-status positions). Yet, child development research on prejudice reveals a complex pattern in which young children view inequalities as wrong even when adults condone it and, even further, they have an awareness of the conventions, hierarchies, and societal expectations about group membership that perpetuate the status quo (Turiel 2002).

Using a theoretical framework in which children's moral, social-conventional, and psychological attitudes are examined, developmental researchers have shown that children's interpretations of intergroup peer encounters reflect a mixture of fairness and equality judgments (when it is wrong to exclude based on race), social-conventional judgments (when it is okay to exclude because of traditions and societal expectations), and judgments about autonomy (when it is okay because of personal choice). Although it has also been shown that group identity is a core part of these judgments such that identification with groups results in ingroup bias (Dunham et al. 2011), even these judgments are highly contextual (Nesdale \& Lawson 2011). Children reject in-group members who express inequality regarding allocation of resources, but with age, adolescents differentiate their view of what the group will do from their own preference about what would be the right course of action (Killen et al. 2012). Intervention is not just about promoting positive attitudes about each other, but also about determining when it is that children interpret interracial encounters with a biased lens and how to address the underlying social cognitive constraints related to the attributions of intentions based on race (or group membership).

Children as young as 6 years of age, from both minority and majority status ethnic and racial backgrounds, discuss what makes exclusion based on race wrong (e.g., unfair treatment). Children's social reasoning reflects the social action called for by Dixon et al., through the rejection of acts of exclusion based on group membership; importantly, this comes from both historically advantaged, as well as disadvantaged groups contesting the thesis that collective action occurs only with disadvantaged groups. With age, children do, in fact, challenge the status quo: "When someone excludes another person for that type of reason ["race"] then maybe they were brought up with people who thought that blacks were different, and they didn't like them because of that and sometimes you have to teach them that racism is wrong." In contrast, the status quo and social expectations are often invoked to justify exclusion: "Blacks and whites didn't hang out with each other before so why should they now? It's just the way it is" (Crystal et al. 2008). Developmental science research, has empirically demonstrated significant links between intergroup contact (cross-race friendships) and the use of moral judgments to reject social exclusion based on race (Crystal et al. 2008), as well as the reduction of prejudice and bias (Feddes et al. 2009).

What happens, then, with age, that creates the adult world in which prejudicial attitudes are perpetuated at the individual and at the institutional level? As children move into adolescence, exclusion is often justified based on group functioning and group identity (Abrams \& Rutland 2008). Prejudice is not a unilateral quantitative measure on a scale; it is a complex profile of different types of judgments applied to a wide range of intergroup social encounters (Killen \& Rutland 2011).

How should we address prejudice? We assert that the answer lies in "all of the above." Programs designed to reduce prejudice are essential and help to diminish the developmental emergence of negative attitudes about outgroups. Supporting children's judgments to challenge the status quo when it contradicts moral judgments about equality, fairness, and justice serves as a form of collective action from the ground up developmentally (see Tinker v. Des Moines School District, 1969, where the U.S. Supreme Court upheld three public school children's decisions to wear black armbands to protest the U. S. government's policy in Vietnam). In childhood and through to adulthood, moral judgments about right and wrong are differentiated from conventional judgments about social groups, hierarchies, and conventions (Smetana 2006; Turiel 1998). When and how these judgments are used to reject or support social exclusion is essential to investigate.

As adults we have to convey to children what makes it wrong to promote in-group identity, traditions, customs, and stereotypic expectations at the expense of moral judgments about fairness, equality, and justice. Children do not have to be taught morality, though; they begin to understand its underlying conceptual structure very early in childhood. Intervention, to be effective, though, has to occur early in development before stereotypic expectations are deeply entrenched and hard to change, and must involve all children from both majority and minority status groups. The efforts at reducing prejudice and creating collective action in childhood are both fundamental goals for promoting justice and equality. 


\section{Heterosexism, homonegativity, and the sociopolitical dangers of orthodox models of prejudice reduction}

\section{doi:10.1017/S0140525X12001264}

\section{Darren Langdridge}

Department of Psychology, Faculty of Social Sciences, The Open University, Milton Keynes MK7 6AA, United Kingdom.

darren.langdridge@open.ac.uk http://www.open.ac.uk/ socialsciences/staff/people-profile.php?name=Darren_Langdridge

Abstract: Criticism of orthodox models of prejudice reduction is particularly relevant for lesbians, gay men, and bisexuals, particularly when considering stage models of coming-out. If social change is to be effected regarding endemic homonegativity and heterosexism, then it is argued that a radical rethink is needed to the understandable but misinformed desire to get us to like each other more.

Dixon et al. highlight the unintended consequences of an orthodox prejudice reduction model of intergroup relations founded on fostering a sense of harmony between groups in conflict. The issues they raise are particularly salient for understanding the impact of prejudice on lesbian, gay, and bisexual (LGB) people, three groups considerably affected by oppressive attitudes and behaviours. Whilst there has been substantial progress in reducing prejudice against such marginalized groups, in the West at least, there is a continuing and ongoing struggle to reduce both overt and subtle forms of discrimination (see, for example, Badgett et al. 1992; Tilcsik 2011).

Coming-out has been positioned within the psychological and sociological literature as a key move in reducing discrimination against people who are LGB (Lewis 2011). The argument invariably revolves around an orthodox model of prejudice reduction based on increasing contact between people from LGB minorities and those from the heterosexual majority. Pettigrew and Tropp's (2006) meta-analysis of contact theory revealed that contact with LGB people typically has stronger effects than contact with other marginalized groups. Whilst the impact is smaller for political conservatives and evangelical Protestants, it appears that even here there is evidence of positive impact through contact alone (Lewis 2011). It is believed that anti-LGB prejudice is particularly susceptible to intergroup contact because of the possibility of LGB people "passing" as heterosexual and heterosexuals learning that a person is LG or B after a relationship has already been established.

However, the complex and pernicious nature of prejudice, alongside the dangers of naïve intervention strategies, become apparent when we consider psychological models of "comingout" in the context of the arguments forwarded by Dixon et al. Dominant models of sexual identity development (Cass 1979; Coleman 1981/1982; Woodman \& Lena 1980), widely in use amongst psychologists, counselors, and psychotherapists today, invariably incorporate a belief that successful coming-out involves a move towards quiet acceptance of the wider social world. For instance, the Cass (1979) model, which remains one of the most dominant, involves six stages of development from identity confusion through to identity synthesis. The model is based on interpersonal congruency theory (Secord \& Backman 1961), which proposes that individual stability and change are dependent on the degree of congruence or incongruence between an individual and his or her environment. Movement through stages therefore occurs as a result of an attempt to resolve an inconsistency between the perception of self and others. The penultimate stage ("Identity Pride") not only involves pride at one's sexual identity, but also anger at an apparently homophobic society, whilst the final stage ("Identity Synthesis") involves recognition that this "them and us" strategy is mistaken, with the LG or B person accepting that there is considerable similarity between him or herself and heterosexuals. Whilst there has been some empirical support for this model (Cass 1984; Halpin \& Allen 2004), there has also been criticism concerning the failure to differentiate male/female and homo/bisexual experience and problems with the fit of this model to the lives of many LGB people (see, for example, Horowitz \& Newcomb 2001). Regardless, this model remains powerful in shaping expectations about the developmental progression of LGB people, being anchored into academic discourse and everyday representations of the coming-out process. The sixth "Identity Synthesis" stage, in particular, resonates with concerns over the need for LGB people to act in ways appropriate with being a "good homosexual" citizen (Smith 1994).

When thinking through the sociopolitical implications of extant coming-out models in the light of Dixon et al.'s arguments, what emerges is the implicitly conservative and individualistic character of such psychological models of sexual identity development. That is, coming-out as a political act is transformed into a social move designed - through positive contact - to effect change in attitudes amongst the heterosexual majority towards LGB people. The question that needs to be raised concerns the appropriate endpoint of "successful" coming-out and whether this should not necessarily be quiet contentment with oneself and one's social world, but appropriate and justifiable anger, at the continuing and endemic heterosexism and homonegativity faced by LGB people in the contemporary world (Langdridge 2008). That is, has the desire to encourage people to like each other more fuelled a passive model of development that may actually reduce political action on the part of LGB people? If collective action is vital for effecting social change, then we might arguably want to abandon such stage models, or at the very least the final "identity synthesis" stages, and instead encourage greater pride, militancy, and even anger, as necessary conditions for the ingroup solidarity and passion needed to engage in coordinated and concerted collective political action.

If psychological and sociological work on intergroup relations is to play a role in further effecting sociopolitical change, then recognition of the subtle ways in which orthodox models of prejudice reduction may now entrench rather than challenge existing lines of oppression is vital, as Dixon et al. state: "In so far as prejudice reduction undermines the already tenuous possibility that subordinate group members will develop the kind of insurgent consciousness that fuels resistance to inequality, it may ultimately reproduce rather than disrupt the status quo" (sect. 4.2., para. 7). Without the appropriate anger necessary to fuel sociopolitical change, it may well be the case that ideas from orthodox prejudice reduction models, alongside quietly "accepting" LGB communities, paradoxically act against the desire for further social justice that motivates most working within this field.

\section{Statistical learning and prejudice}

\section{doi:10.1017/S0140525X12001422}

\section{Guy Madison ${ }^{\mathrm{a}}$ and Fredrik Ullén ${ }^{\mathrm{b}}$}

${ }^{a}$ Department of Psychology, Umeå University, SE-901 87 Umeå, Sweden; ${ }^{\mathrm{b}}$ Department of Neuroscience, Karolinska Institutet, SE-171 77 Stockholm, Sweden.

guy.madison@psy.umu.se fredrik.ullen@ki.se

Abstract: Human behavior is guided by evolutionarily shaped brain mechanisms that make statistical predictions based on limited information. Such mechanisms are important for facilitating interpersonal relationships, avoiding dangers, and seizing opportunities in social interaction. We thus suggest that it is essential for analyses of prejudice and prejudice reduction to take the predictive accuracy and adaptivity of the studied prejudices into account. 
Dixon et al. provide an interesting overview of how relations between social groups may be influenced by beliefs and attitudes held by members of one group towards the members of another group. They refer to negative attitudes of this kind as "prejudices." A major argument is that certain positive intergroup attitudes should also be considered as prejudices, because they may impede political progress toward what the authors call "social justice in the fuller sense" (Abstract, para. 2).

From our perspective of the neuropsychology of skill learning and performance, we found this argument incomplete, because no distinction was made between attitudes based on accurate versus inaccurate statistical models. In fact, only three of the eight definitions of prejudice in Table 1 (see Dixon et al.) consider whether an attitude is "faulty" or "unjustified." Distinguishing between more and less accurate statistical models appears essential for understanding prejudices in this broader sense, that is, as predictive models about how other people and the world in general tend to behave, because they are likely to differ in their underlying mechanisms and behavioral consequences.

Evolution has endowed the human brain with many systems to acquire and update models of the external world. Some of this learning is explicit and cognitive, relying on personal experiences, as well as on second- and third-hand information acquired from various channels. Much of it also occurs implicitly from mere exposure, without intention to learn and with limited or no conscious awareness of what is being learned. Implicit learning has been widely studied for a range of phenomena, from simple perceptual and motor sequences to language and social cognition (Frith \& Frith 2012; Perruchet \& Pacton 2006; Shanks 2005). Finally, learning itself is influenced by our evolutionary heritage. Numerous studies have shown that we are biologically prepared - prejudiced by evolution, as it were - to learn certain associations and that we are contraprepared to learn other associations. These biases are functional from the perspective of natural selection (Seligman 1970). As a simplistic example, humans are predisposed to learn a fear of snakes and spiders, but not of flowers (Óhman 2009).

It appears evident that these mechanisms are also sources of prejudices in the narrower sense discussed in the target article and, therefore, that both the cognitive and emotional aspects of intergroup attitudes in many instances reflect knowledge about the actual behavioral tendencies of groups. Furthermore, such knowledge is likely to be highly useful. For example, there are established statistical differences between men and women in a number of variables; how they express emotions (e.g., Kring \& Gordon 1998), spend their time (e.g., Shanahan \& Flaherty 2001), how often they cry (e.g., Lombardo et al. 2001), and which types of work they prefer (e.g., Lippa 2010). The genetic, cultural, and environmental sources of these differences need not concern us here. The point is that the differences as such are highly informative about what people feel and do in various situations and can be used to modify one's actions to avoid conflict and social tension (cf. Gigerenzer 2010).

A common objection to this line of reasoning is that individuals deviate considerably from the typical behavior of the many and multifarious groups to which they belong. This may make prediction inaccurate in each particular case and can hence lead to an unfair and inappropriate treatment of that person. Three comments in relation to this point are in order. The first point is essentially a reality check. In many social situations, both information about the other individual and the time to make a decision are severely limited. The brain is thus forced to make decisions based on necessarily imperfect predictions of the likely outcomes of the available behavioral alternatives. Secondly, the dangers of faulty overgeneralizations may not be as large as is sometimes suggested. Empirical studies on stereotypes suggest that people do not believe that all members of a group, but rather a larger proportion of that group compared to other groups, share the stereotypical properties (McCauley \& Stitt 1978). We can easily embrace the statistical statement that men are taller than women without expecting every man to be taller than any woman. Thirdly, although actions based on statistical predictions may result in unfair treatment of individuals, the effects of this can go both ways. Individuals that deviate in one direction from the group mean on a socially relevant variable may get more negatively treated than they would if they had been evaluated solely from their merits as individuals. However, by the same token, individuals that deviate in the opposite direction will receive a more positive treatment than they deserve.

Needless to say, many prejudices are based on blatantly wrong beliefs about other groups. We wholeheartedly support the notion that it would be beneficial for humankind to reduce intergroup prejudices that are negative, incorrect, and nonadaptive. Nevertheless, we believe that prejudices involving positive biases towards in-group members are of special interest both theoretically and practically. A recent comprehensive argument for that ethnocentric bias may increase inclusive fitness through kin selection has, for example, been provided by Salter (2007). Group cohesion without kinship gradients may also be adaptive under many circumstances (Hamilton 1971). Although there is scientific controversy around these ideas, they appear highly relevant to any theory of prejudice.

In conclusion, we think that the study of prejudice may benefit from considering statistical learning and evolutionary perspectives. To use the terminology of Zawadzki (1948): a "monistic" treatment of prejudices that solely regards their contents as "emotional hallucinations," uncorrelated with the realities of group behavior, appears unlikely to be fruitful. Accurate models of the social, neuropsychological, and evolutionary mechanisms underlying prejudice are necessary for evaluating the feasibility and likely outcomes of various interventions designed to reduce prejudice. All of this will be essential information when considering political issues, but science and politics are better kept separate.

\section{The dangers of prejudice reduction interventions: Empirical evidence from encounters between Jews and Arabs in Israel}

\author{
doi:10.1017/S0140525X12001276
}

\section{Ifat Maoz}

Department of Communication, Hebrew University of Jerusalem, Mount Scopus, Jerusalem 91905, Israel.

msifat@mscc.huji.ac.il

Abstract: This commentary focuses on Dixon et al.'s discussion on the dangers of employing prejudice-reduction interventions that seek to promote intergroup harmony in historically unequal societies. Specifically, it illustrates these dangers by discussing my work in Israel (now mentioned in Dixon et al.'s note 6) on the processes and practices through which reconciliation-aimed encounters between Jews and Arabs mitigate sociopolitical change.

The context of the relationship between Jews and Arabs in Israel makes for an interesting and resonant example of the dynamics discussed by Dixon et al. in which attempts at achieving intergroup "harmony" through prejudice reduction interventions may intentionally or unintentionally mitigate sociopolitical change. My empirical research on contact interventions between Israeli Jews and Arabs enables me to extend on Dixon et al.'s discussion in the context of a realistic asymmetric intergroup conflict. In particular, it allows me to further address the important questions posed by Dixon et al. (see sect. 4.2., para. 4) regarding the nature of the underlying mechanisms and the psychological processes through which contact interventions that attempt to promote harmony may in fact safeguard and 
perpetuate the existing status quo of asymmetric power relations.

As a social psychologist interested in intergroup relations, I have been researching, for the past 25 years, structured intergroup encounters aimed at reducing hostility and increasing understanding and cooperation between Israeli-Jews and Israeli Arabs. My research relies on systematically analyzed empirical data derived from a series of research programs I have conducted between 1988 and 2012, tracing the evolution of models of planned contact interventions between these two groups. The research tools used include: in-depth interviews, discussions, and conversations that have been conducted over the years with organizers, directors, facilitators, and participants of Jewish-Arab encounter programs; questionnaires and surveys, including measures of attitudes and attitude change; and observations of encounter activities and encounter program staff meetings, as well as analysis of documents related to encounter programs.

Structured encounters between Israeli Jews and Arabs are encounters that take place between two groups with asymmetric power-relations, engaged in competition over scarce resources; the Jewish majority (some 80 percent of the Israeli population) is in control of most material and political resources and determines the national character of the country (Abu-Nimer 1999). The relationship between the Jewish and Arab citizens of Israel is also significantly affected by the larger protracted, asymmetrical conflict between the State of Israel and the Palestinians living in the West Bank and Gaza Strip territories. Hence, like other contact interventions conducted in settings of intergroup conflict, encounters between Israeli Jews and Arabs represent a paradoxical project that aims to produce equality and cooperation between groups embedded in a reality of conflict and asymmetry (Maoz 2000a; 2000b; 2011).

Inspired by a recent school of thought that examines processes and effects of contact in deeply divided societies (Dixon et al. $2005 ; 2007)$, the major questions that lead my research concern the extent to which these interventions - which aim at improving intergroup relations-perpetuate the existing reality of asymmetric power relations between the Jewish majority and the Arab minority in Israel, or present transformative potential towards more symmetrical Jewish-Arab relations.

A primary model used in Jewish-Arab contact interventions is the coexistence model, which seeks to promote mutual understanding and tolerance between Jews and Arabs, reduce stereotypes, foster positive intergroup attitudes, and advance other goals in the spirit of the contact hypothesis (Allport 1954; Pettigrew 1988). This model was imported to Israel from the United States in the 1980s; it constitutes the first and the most dominant model, guiding the majority of these contact interventions (Maoz 2006).

The coexistence model emphasizes interpersonal similarities ("we are all human beings") and cultural and language commonalties, as well as supporting notions of togetherness and cooperation. Critics cynically refer to it as "the Hummus and Falafel model" because of its promotion of folkloristic, seemingly superficial aspects that join Jews and Arabs. As this model focuses on interpersonal interaction and on personal identities (Tajfel \& Turner 1986), it does not tend to confront issues such as the conflict between Israeli Jews and Arabs, dilemmas of national identity, and claims concerning discrimination towards the Arab citizens of Israel (Maoz 2011). Consequently, the coexistence model tends to support the status quo of the existing structural relations between Jews and Palestinian-Arabs in Israel rather than seeking social or political change (Abu-Nimer 1999; Halabi \& Sonnenschein 2004) At worst, this model can be viewed as intentionally perpetuating existing asymmetrical power relations by focusing on changing individual-level prejudice while ignoring the need to address collective and institutionalized bases of discrimination (Bekerman 2007; Dixon et al. 2005; Maoz 2011).

Indeed, research shows that contact interventions guided by the coexistence model tend to preserve and perpetuate Jewish dominance and control while encouraging Arab submissiveness and passivity, thus strengthening existing stereotypes of Jews as overdominant and controlling and of Arabs as lazy and passive (Maoz 2000a; 2000b; 2004). Furthermore, organizational structural analyses indicate that the vast majority of organizations that employ the coexistence model display high Jewish dominance in their hierarchy and distribution of resources and very low to no representation of Arabs in the different levels of management and decision making (Maoz 2004).

Analysis of the discourse characterizing such coexistence model encounters makes visible the tactics and practices of the Jewish directors, showing how these restrict discussion of inequalities and of the conflict between the sides. Such discussion was defined by the Jewish directors as destructive, subversive, and as bound to spoil the good atmosphere of the encounter, and thus as contradicting the goal of fostering coexistence. The Arab participants, for their part, expressed a lack of identification with the goal of advancing coexistence and fostering rapprochement: these goals were perceived as forced upon them, as unrepresentative of the true reality of Jewish-Arab relations in Israel, and as restricting their ability to express their national identity and present the minority's point of view - the less legitimized Palestinian version of the history and current realities of the conflict (Maoz 2000a; 2011).

Thus, the empirical data derived from studies of the coexistence model between Jews and Arabs in Israel can help describe and empirically ground the paradoxical effects of this kind of "harmonious" encounter. By explicitly illustrating the consequences of delegitimizing the discussion of inequalities within these contact interventions, these studies help to support and extend Dixon et al.'s broader argument about the paradoxical interrelations between harmony and sociopolitical change.

\section{Faustian bargains for minorities within group-based hierarchies}

doi:10.1017/S0140525X12001434

\section{David Navarrete and Melissa M. McDonald \\ Department of Psychology; Ecology, Evolutionary Biology and Behavior \\ Program; Michigan State University, East Lansing, MI 48824. \\ c.d.navarrete@gmail.com / cdn@msu.edu \\ mcdon348@msu.edu}

Abstract: A dual-audience signaling problem framework provides a deeper understanding of the perpetuation of group-based inequality. We describe a model of underachievement among minority youth that posits a necessary trade-off between academic success and peer social support that creates a dilemma not typically encountered by nonminorities. Preliminary evidence consistent with the approach is discussed. Such strategic agent perspectives complement the psychological approach put forth by Dixon et al., but with minimal ancillary assumptions.

In their target article, Dixon et al. argue that the conceptualization of intergroup prejudice should not require the presence of intergroup animus. We seek to complement this discussion by drawing attention to the authors' emphasis on how animus can often be irrelevant to the perpetuation of group-based inequality and to develop an example from recent theory and research in economics. Although the authors emphasize the psychological and affective mechanisms that serve to reinforce inequality, we provide an example of how such approaches can be complemented by a rational-agent approach that assumes very little about the internal states of actors.

Given that minorities typically coexist quite closely with dominant majorities, minority individuals may seek to better their position via assimilation into the dominant group. By doing so, though, they risk weakening their ties to their ethnic group and its collective bargaining power or long-term viability. From the 
perspective of a dual-audience signaling framework (Austen-Smith \& Fryer 2005), a person's educational attainment is an "honest signal" of characteristics that are attractive to the institutions of modern societies, such as conscientiousness, intelligence, and conformity to societal norms (Spence 1973). However, individuals are also compelled to send signals of sociocultural competence to their ethnic group. Whereas signals of educational competence are exchanged for financial support, signals of sociocultural competence are exchanged for social support and friendship.

From this view, because dominant groups have had longer histories of codevelopment with societal institutions than minority groups, there is likely to be greater congruence in the information content (e.g., language dialect) of the signals needed to appease both institutional and ethnic groups. However, because ethnic groups are likely to have shorter histories of codevelopment with societal institutions due to discriminatory policies or recent immigration, such minorities experience less congruency between these two types of signals. Even if one has deep attachments to his or her group, increased time and effort spent on education necessarily diminishes the time and effort available to spend with peers and maintain cultural competence, thereby limiting the benefits gained from group membership. This problem is particularly acute when one considers the opposite must be true as well: that time and energetic resources devoted to social competence within one's social groups takes away from one's limited resources for increasing educational competence. For some, the social consequences of group exclusion might be offset by increases in economic benefits, but for others, economic utility pales in comparison to the cost of losing social support. This Faustian trade-off necessarily places limits on economic mobility for minority group members, but not for majority group members.

This model makes only two core assumptions: (1) individuals seek to increase their own economic standing, and (2) individuals prefer social interaction with, and the social support of, members of similar social categories (Becker 1957). Fryer (2010) describes several important predictions that are generated when applying this model of behavior to black and Latino versus white American students in the United States. Because there is no trade-off between academic achievement and peer-group acceptance for white students, and they are overrepresented in high-achieving environments, achievement should be positively related to peer group acceptance for whites. However, the link between achievement and friendship is expected to be tenuous for minority students, and may even trend negative, as their racial groups are underrepresented in high-achieving environments. Additionally, and consistent with the challenges associated with intergroup contact described by Dixon et al., the erosion of same-race friendships for minorities should be exacerbated in contexts that foster greater intergroup contact, such as in racially integrated schools.

In an analysis of data from the National Longitudinal Study of Adolescent Health involving over 90,000 research subjects, Fryer (2010) tested these predictions on white, black, and Latino American high school students. Fryer found that the strong, positive correlation between grade point average and popularity typically found among white American students in public schools is less strong for black American students. Furthermore, among the highest achieving black students $(\mathrm{GPA}>3.5)$, the relationship between academic achievement and popularity trended negative. The link between GPA and friendship was even more tenuous for Latino American students, with popularity trending negative at even average levels of achievement, with the highest performing Latino students having the fewest friends.

Of particular relevance to the target article, Fryer (2010) found that the trade-off between signaling educational competence versus social support among minorities was strongest and, in some cases, only detectable in schools with a high degree of ethnic integration. Intriguingly, high-achieving minorities were found to have more other-race friends than did lower achievers. However, the increase in cross-race friendships did not make up for the loss in same-race peers, implying same-race preferences among white high-achieving students or among high-achieving students of all groups. We note that there is little reason to assume that minorities are "punished" by same-race peers for demonstrating success and competence in domains important to the majority group (sensu Fordham \& Ogbu 1986). But, rather, network dynamics between majority and minority groups are sufficient to produce incentive structures that perpetuate inequality merely by assuming that we want economic resources, as well as group-based social support from others like ourselves.

Our description of the challenges faced by minority youth complement the approach described by Dixon et al. in that we provide an example of how intergroup animus can be irrelevant and intergroup contact can have its downside. At root, this model is not specific to race relations in the United States, but should be applicable anywhere where similar conditions apply (e.g., Buruku in Japan, Aboriginals in Australia/New Zealand). If there is a point of incongruence between the strategic approach we describe and other advocates for equality, it is of emphasis on the idea that there can sometimes be clear victims of the network dynamics of strategic action, but it can be quite difficult to see who the winners are, let alone the blameworthy villains. We are curious as to how Dixon et al. might incorporate this perspective into their analysis for future directions in theory and research in this area.

\section{The dominance of the individual in intergroup relations research: Understanding social change requires psychological theories of collective and structural phenomena}

\author{
doi:10.1017/S0140525X12001288
}

\section{Elizabeth Levy Paluck \\ Department of Psychology, Princeton University, Princeton, NJ 08540. epaluck@princeton.edu http://betsylevypaluck.com}

Abstract: Dixon et al. suggest that the psychological literature on intergroup relations should shift from theorizing "prejudice reduction" to "social change." A focus on social change exposes the importance of psychological theories involving collective phenomena like social norms and institutions. Individuals' attitudes and emotions may follow, rather than cause, changes in social norms and institutional arrangements.

Dixon et al. provide important direction to the psychological literature on improving intergroup relations by shifting the research goal from "prejudice reduction" to "social change." The authors review the history of prejudice conceived as an individual's negative attitude or emotion and argue that a model of collective action is preferable to one of individual prejudice reduction for achieving intergroup equity and justice. However, their proposed model of collective action is also founded on ideas about the primary role of individual attitudes and emotions, "including anger and a sense of relative deprivation" (sect. 3.1, para. 11). In this way, Dixon et al. overlook an equally strong historical idea within psychology, which is that social change and the achievement of intergroup equity and justice will not result from a bottom-up change in attitudes. In the words of Thomas Pettigrew (1991), theorizing social change as a project in changing individual attitudes is a "reductionist view that [denies] social and structural factors" (p. 10).

What are the social and structural factors that are useful for a psychological model of social change? Prior to Allport's (1954) seminal work on intergroup relations and prejudice, psychologists theorized that intergroup social norms are critical determinants of intergroup behavior. A social norm refers to group members' perceptions of the group consensus regarding the typical or appropriate treatment of another group. An early and continuing tradition of research in psychology conceptualizes prejudice $a$ s a perceived social norm, rather than as an individual's personal attitude or emotion (e.g., Crandall \& Stangor 2005). An individual's attitude 
may interact with a social norm; for example, when personal attitudes are aligned with the perceived norm, the norm gives individuals social permission to act. When the attitudes are not aligned, the perceived norm encourages repression of attitudinal expression. Including social norms in a model of social change is critical because behavioral conformity to the perceived group consensus is a normal, universal process (Crandall \& Stangor 2005).

Indeed, research has consistently suggested that perceptions of social norms regarding the appropriate treatment of an outgroup are more powerful predictors of intergroup behavior than individual attitudes toward that group (e.g., Blanchard et al. 1994; Paluck 2009a). Furthermore, norms are important psychological constructs for investigators interested in the mobilization of collective behavior (e.g., Latané 1980) because they define the standards of behavior for a group, not just for an individual (Paluck \& Shepherd, under review). This research suggests that to change intergroup relations, the critical target is not what an individual personally thinks or feels about another group, but rather what he or she perceives other members of his or her group think or feel. Examples of social norms interventions, or where these new social norms can originate, include media messages depicting a social consensus of nondiscrimination or referent group leaders announcing support for stigmatized group members.

Psychologists have also theorized the role of structural factors for improving intergroup relations. Some psychologists have even argued that the top-down process of change starting with institutional change has been the most successful method for promoting intergroup justice and equity (Pettigrew 1991). This model of change starts with formal regulations and other types of institutional arrangements that channel behavioral action (Lewin 1951) created by nations, organizations, or communities, which affect collective patterns of behavior and perceived social norms, and finally individual level variables like attitudes and emotions. Top-down theories were cited in response to arguments that an authoritarian personality was responsible for racism and discrimination. Theorists argued that "direct structural change to which individuals (even authoritarian personalities) must accommodate is both more practical and effective ... individual personality and attitude changes remain important for the successful completion of the change cycle. But they are usually not initially causal" (Pettigrew 1991, pp. 10-11).

A recent empirical review of the organizational diversity literature, cited by Dixon et al., provides support for this argument. The review (Kalev et al. 2006) suggests that an organization's institutional diversity initiatives, such as appointing managers responsible for maintaining diversity, are responsible for advancing minorities and women into higher and better paying positions, not individually directed attitude change efforts like diversity training. In contrast to attitudinal change, diversity in managerial positions is the kind of material and behavioral outcome to which Dixon et al are referring as the goal for psychological intergroup relations research.

Theories of individual attitudes and emotions can be fruitfully combined with theories of social norms and structural factors in intergroup relations research. For example, our research program has focused on measuring the success of interventions that target the collective norms of a group, and this research has shown that changes in perceived norms regarding harassment and bullying change behaviors in schools over the course of one year (Paluck \& Shepherd, under review). Future research should investigate whether attitudes, which do not change in the first year, eventually follows these normative and behavioral changes.

Additionally, psychologists have identified a number of individual level attitudes and emotions that might speed the process of social change once institutions or social norms have started to shift. For example, a belief that institutional changes are inevitable and permanent weakens people's resistance to and increases support for the changes (Laurin et al. 2012). Additionally, disconfirming fears or anxieties about outgroup members is predicted to improve intergroup interaction in times of social transition
(Pettigrew 1991). Making positive examples of outgroup members accessible through storytelling or through the mass media, as a form of extended intergroup contact, are two examples of such interventions (Cameron \& Rutland 2006; Kenrick \& Paluck, in progress).

Without negating the importance of individual level variables like attitudes and emotions, research suggests that psychologists reweight the importance of social and structural factors in theories of social change. I applaud the authors for their timely review and provocative reformulation of critical questions about improving intergroup relations. It seems time for psychologists to revisit the historical debate of whether we as a discipline should reweight bottom-up versus top-down models of social change, and of what role psychology can play in either effort.

\section{Inequality is a relationship}

\section{doi:10.1017/S0140525X1200129X}

Deborah A. Prentice and J. Nicole Shelton

Department of Psychology, Princeton University, Princeton, NJ 08540. predebb@princeton.edu

http://psych.princeton.edu/psychology/research/prentice/index.php nshelton@ princeton.edu

http://psych.princeton.edu/psychology/research/shelton/index.php

Abstract: A view of inequality as a relationship between the advantaged and the disadvantaged has gained considerable currency in psychological research. However, the implications of this view for theories and interventions designed to reduce inequality remain largely unexplored. Drawing on the literature on close relationships, we identify several key features that a relational theory of social change should include.

Marriage counselors are famous for admonishing couples that responsibility for everything that happens in their marriage is shared 50-50 between them. Although many an unhappy spouse has challenged the justice of this even-handed formulation, it captures an important truth about relationships: They are never reducible to individual experience. Every action taken within a relationship is also a reaction, every response a stimulus to a response in return.

Inequality is a relationship, one that links haves with have-nots. The participants in this type of relationship are members of paired social categories: men and women, whites and blacks, Christians and Muslims, gays and straights (Tilly 1998). Their relationships share much in common with the interpersonal relationships with which psychologists are more familiar: For example, the relationships take different forms, depending on the participants. They exist in time and change in response to both internal and external events. They are situated in a broader context, and this context also changes over time. Given these many similarities, one might expect relational models to play a major role in the study of categorical inequalities.

Dixon et al. offer several strong arguments for why they should. The authors highlight the complex, ambivalent attitudes that members of unequal categories have toward each other and analyze those attitudes in terms of the power and dependency relations between them. Dixon et al. consider the unintended, and largely overlooked, effects that a prejudice-reduction intervention aimed at the advantaged member of the relationship has on the disadvantaged member, and explicitly advocate a focus on how interventions aimed to improve one intergroup relationship affect the broader network of relationships between groups within a society. All of these contributions are consistent with a relational approach.

However, when it comes to the question of how to produce social change, Dixon et al. abandon their relational emphasis and instead seek to determine who is right and who is wrong. 
They propose two models: the prejudice reduction model, in which the advantaged category provides the impetus for social change, and the collective action model, in which the disadvantaged category provides the impetus for social change. They argue, on the basis of three case studies, that the weight of the historical evidence favors the superiority of the collective action model over the prejudice reduction model. Then, to reconcile the two models, they argue for the identification of moderating variables that determine the conditions under which each is effective. Lost, in this analysis, is their earlier insight that inequality is fundamentally a relationship between the advantaged and the disadvantaged. Both must act, in synchrony, to change the relationship between them.

What might a relational theory of social change look like? The development of such a theory is beyond the scope of this brief commentary, but we can sketch some of the features it would need to include (Murray \& Holmes 2011).

1. A psychological and behavioral analysis of the unequal relationship. To change the relationship between unequal groups in society, one needs to have an ongoing understanding of how individuals on both sides of the advantage divide experience the relationship. Just as researchers of close relationships explore the motives partners bring to their relationship and how they behave in interactions, respond to each other's needs, and build trust and intimacy, so inequality researchers should explore these aspects of unequal relationships. For example, recent research has shed considerable light on how blacks and whites in the United States relate to each other, the goals and concerns they bring to their interactions, the kinds of behaviors they find reassuring or stressful in an interaction partner, and the obstacles they face to the development of close bonds (e.g., Shelton \& Richeson 2006).

2. A structural analysis of the unequal relationship. Achieving social change also requires an understanding of the structure of inequality. Just as close-relationship researchers probe partners' backgrounds, roles, and resources to determine the structural features of their relationship, so inequality researchers must examine how resources are unequally distributed across a category pair and the processes sustaining that asymmetry. For example, consider the structural features of racial and gender inequalities. Racial inequalities tend to coincide with contextual boundaries: Blacks occupy less advantaged contexts (e.g., neighborhoods, schools, occupations) than do whites. Gender inequalities, by contrast, crosscut these boundaries; women and men occupy the same contexts, but are unequal within them. These structural features have implications for the psychology of change. An intervention to reduce racial inequality must overcome the inclination of both blacks and whites to self-segregate, whereas an intervention to reduce gender inequality must overcome the widespread belief that it is natural and even desirable (Tilly 1998).

3. A temporal dimension. Relationships, including relationships of inequality, develop and change over time. This temporal dynamic is of interest in its own right and is also important for understanding how relationship partners evaluate their current and future circumstances. These evaluations are often based more heavily on the trajectory of outcomes (i.e., whether they are improving or declining), than on their absolute value. For example, the same pay gap may be evaluated negatively if it used to be smaller, positively if it used to be bigger, or negatively if it used be bigger but ought to be shrinking more quickly (Crosby 1976; Eibach \& Keegan 2006).

4. Incorporation of the broader societal context. Relationships do not exist in a vacuum; they are profoundly influenced by the broader societal context they inhabit. Just as a close relationship depends on its familial, social, and cultural environment, so too does the relationship between unequal categories depend on its broader societal and political context. Indeed, lasting change in these relationships is much more likely to come from an exogenous source (e.g., political leadership, legal actions, organizational policies) than from an endogenous source (e.g., changing thoughts, feelings, and behaviors of the relating parties). Hence, any theory of social change needs to be able to account for how unequal relationships react to change, as well as how they generate it.

\section{Beyond prejudice to prejudices}

\section{doi:10.1017/S0140525X12001306}

\author{
Mark Schaller ${ }^{\mathrm{a}}$ and Steven L. Neuberg ${ }^{\mathrm{b}}$ \\ ${ }^{a}$ Department of Psychology, University of British Columbia, Vancouver, BC \\ V6T 1Z4, Canada; ${ }^{\mathrm{b}}$ Department of Psychology, Arizona State University, \\ Tempe, AZ 85287-1104. \\ schaller@psych.ubc.ca \\ steven.neuberg@asu.edu \\ http://neuron4.psych.ubc.ca/ schallerlab \\ http://psychology.clas.asu.edu/neuberg
}

Abstract: Different groups, because they are perceived to pose different threats, elicit different prejudices. Collective action by disadvantaged groups can amplify the perception of specific threats, with predictable and potentially counterproductive consequences. It is important to carefully consider the threat-based psychology of prejudice(s) before implementing any strategy intended to promote positive social change.

Dixon et al. observe that it is problematic to equate prejudice with antipathy - that doing so limits scientific understanding of prejudice and discrimination and retards efforts to undo inequitable treatment of disadvantaged groups. We agree. They also suggest that discrimination and group inequality may be more effectively reduced by interventions that focus not on prejudice reduction, but on collective action instead. We are less convinced of that.

Prejudice comes in many different forms. Although prejudice is often defined simply as a negative attitude directed toward a group, this definition fails to convey the fact that different groups elicit different kinds of prejudicial attitudes. One study within the United States revealed that prejudices against Mexican Americans and gay men were equally negative, but negative in very different ways. Prejudice against Mexican Americans was characterized substantially by fear, whereas prejudice against gay men was characterized primarily by disgust (Cottrell \& Neuberg 2005). These differences matter. They are associated with different stereotypes, different inferences, and different forms of discrimination that have implications for the fortunes of different disadvantaged groups (e. g., Cottrell et al. 2010).

Different groups elicit different prejudices because they are perceived to pose different threats. For example, whereas Mexican Americans are perceived to threaten physical safety, gay men are perceived to threaten disease transmission (Cottrell \& Neuberg 2005). Findings such as these follow from an evolutionary perspective on prejudices (Schaller \& Neuberg 2012), in which prejudices are conceptualized as highly automatized stimulus-response linkages that, in ancestral environments, facilitated specific behavioral responses to people who appeared to pose specific forms of threat to reproductive fitness. In contemporary circumstances, these prejudices are elicited by the perception of superficial cues that heuristically (and sometimes incorrectly) imply threat. Disgust-based prejudices are elicited by features connoting a person's potential to transmit infectious diseases (or to violate behavioral norms that serve as buffers against disease transmission). For example, because morphological anomalies have been symptomatic of many diseases throughout history, disgust-based prejudices may be elicited not only by people who actually are infectious, but also by people whose facial or bodily appearance is anomalous in any way (Park et al. 2007). In contrast, fear-based prejudices are elicited by features connoting a person's potential to commit intentional harm. 
Because of high rates of intergroup violence in ancestral ecologies, these features may include any trait (e.g., different language, different clothing, different values) suggesting membership in a coalitional outgroup - even if the actual intentions of these outgroup members are benign.

Threat-based prejudices are amplified when people perceive themselves to be vulnerable to the specific form of threat and are inhibited when people feel less vulnerable. Disgust-based prejudices against many disadvantaged groups are reduced when people feel less vulnerable to disease transmission, such as when they have been recently inoculated against seasonal influenza (Huang et al. 2011). Analogously, fear-based prejudices are reduced when people feel less vulnerable to intergroup hostility. Within the context of actual ethnopolitical conflict, Sri Lankans who were induced to perceive their ethnic in-group to be relatively numerous compared to the out-group (a perception that connotes "safety in numbers") consequently perceived the out-group to be less hostile and were also more favorable toward peaceful conflict resolution (Schaller \& Abeysinghe 2006).

These and other findings suggest that interventions focusing on prejudice reduction can be successful. But to be successful, they cannot be informed merely by idealism and hope or by crude conceptualizations that equate prejudice with undifferentiated antipathy. They must be informed by realistic consideration of the distinct nature of specific prejudices and by an awareness of the distinct psychological antecedents that produce these prejudices. Failure to do so may produce intervention strategies that are ineffective or even counterproductive.

The same is true for collective action strategies. Collective action may indeed foster group identification among disadvantaged individuals and facilitate their efforts to challenge the status quo; but these immediate outcomes do not translate neatly to positive social change. When people perceive the actions of others as representing the collective objectives of coalitional outgroups, they tend to appraise such actions as threatening. This distrustful "us versus them" mindset gives rise to fearful prejudices and demonizing stereotypes, which in turn promote coordinated resistance to those objectives and to hostile rather than conciliatory responses (Insko \& Schopler 1998; McDonald et al. 2012; Schaller \& Abeysinghe 2006). Can this inflamed battle of wills hasten an end to group inequalities? Perhaps sometimes it can. Many times it will not, however, and may lead to even more desperate and blood-stained inequalities instead.

We suspect that collective action strategies will be most successful if they are perceived not as united actions of a coalitional outgroup, but as coordinated actions of individuals instead. And if disadvantaged individuals are to be perceived as a group, their fortunes are likely to improve more swiftly if they publicly (if not privately) adopt attitudes that minimize the perception of "us versus them" coalitional threat and, thus, reduce the likelihood for hostile resistance. The U.S. civil rights movement was successful not simply because it was a form of collective action. It was successful in part because prominent civil rights leaders such as Martin Luther King Jr. cleverly employed strategies that made the movement less overtly threatening (protesters were actively nonviolent; the protest rhetoric echoed with white majority Christian narratives and values; etc.). Had the movement been defined solely by the more confrontational tactics of Malcolm $X$ or the Black Panthers, the response is likely to have been more fearful and more violently repressive-and the movement's landmark accomplishments are likely to have gone unrealized for yet another generation or more.

It is important to consider the threat-based psychology of prejudice before implementing any strategy intended to change the societal status quo (whether that strategy focuses directly on prejudice reduction, collective action, or something else entirely).
To do so, it is necessary to move beyond any simplistic definition of prejudice (singular) and to attend carefully to the many different causes, and consequences, of prejudices (plural).

\section{Prejudice and personality: A role for positive-approach processes?}

\author{
doi:10.1017/S0140525X12001318
}

Charles Seger and Philip J. Corr

School of Psychology and Centre for Behavioural and Experimental Social Sciences (CBESS), University of East Anglia, Norwich NR4 7TJ, United Kingdom.

c.seger@uea.ac.uk p.corr@uea.ac.uk

http://www.uea.ac.uk

Abstract: Individuals differ in their support for social change. We argue that examinations of inequality and change would benefit from consideration of underlying personality processes. New data suggest that Right-Wing Authoritarianism and Social Dominance Orientation, indicators of support for inequality, may be motivated by biologically driven personality processes, particularly those related to positiveapproach motivation.

In their thought-provoking article, Dixon et al. outline the ways in which traditional methods of prejudice reduction, based on attempts to reduce negative evaluations of an out-group, may fail to produce the desired change to the structures, practices, and ideologies that maintain prejudice and discriminationindeed, the authors note that such attempts sometimes entrench prejudice. They should be commended for their attempt to reconcile the prejudice-reduction literature with the larger goal of sociopolitical change. We were especially struck by their call for a more nuanced approach that included the role of positive emotions and motivation.

We argue that a full account of inequality and social change requires not only examination of institutional and social action, but also consideration of the personality processes and individual differences that influence people's willingness to support statuslegitimizing ideologies. In the same way that personality variables can inform and contribute to our understanding of economic behaviour (Ferguson et al. 2011), integrating personality processes with support for structural inequalities and social change movements may lead to a deeper understanding of the person-level bases of these phenomena. We contend that consideration of the role of personality processes is essential; therefore, it follows that we should apply knowledge of these processes (including basic ones relating to emotion and motivation) to the wider prejudice literature.

Social Dominance Orientation (SDO; Pratto et al. 1994) reflects individual differences in the endorsement of statuslegitimizing ideologies, interpersonal dominance, and a preference for hierarchical stratification between groups. Right-Wing Authoritarianism (RWA; Altemeyer 1988; 1998) reflects dispositions toward authoritarian submission (to authorities perceived as "legitimate"), a conventional worldview, and aggressiveness or punitiveness toward those who are perceived to challenge this authority or worldview. Both RWA and SDO are associated with increased prejudice toward out-groups, principally ethnic minorities, immigrants, and women (Ekehammar et al. 2004; Whitley 1999). Although RWA and SWO are moderately correlated and can predict generalised measures of prejudice, their origins and consequences differ. In particular, RWA is more likely to predict prejudice in response to a social or moral threat; SDO is more likely to predict prejudice when an outgroup is viewed as competitive (Cohrs \& Asbrock 2009), such as when a minority group strives to end discriminatory practices. 
Is it appropriate to connect these individual difference constructs to collective action and societal-level inequality? In support of this connection, Son Hing et al. (2007) demonstrated that individuals high in SDO or RWA make decisions that are more unethical than others. Both variables predict willingness to oppose minority groups' collective action and decrease the likelihood of engaging in action against authority (Duncan 1999). Members of low-status groups who are high in SDO are likely to support inequality and favour high-status groups, to the extent to which they perceive the system to be legitimate (Jost \& Burgess 2000).

These measures of prejudice must be motivated; but where should we look for this motivation? Certainly, there are beliefs, attitudes, and norms that are part of the fabric of a society, and to which, on average, members of society conform, but history is witness to the fact that people do not equally conform to norms supporting inequality: society evolves by people opposing them (e.g., racial discrimination in the United States and South Africa). The question is: Why do some people conform more than others?

The notion that individual differences between people, based on basic emotion and motivation processes, play no role in susceptibility to prejudice may be seen as somewhat fanciful (although it is far from being the whole story, and the extent of their influence is still open to debate). But, what are the bases of these causal processes? There are links to the fivefactor model (FFM), with RWA and SDO linked, for example, to (lack of) openness to experience (Sibley \& Duckitt 2008). However, the FFM does not provide links to the biologically based, causally efficient brain systems that may underpin basic emotion and motivation. One approach that addresses these systems is the Reinforcement Sensitivity Theory (RST) of personality (Corr 2008; 2009), which provides a framework for understanding important aspects of the FFM (particularly extraversion and neuroticism) but, potentially, also the more complex personality variables that are associated with prejudice and support for structural inequality. Dixon et al. call for greater attention to considering positive aspects of prejudice and not exclusively negativity as the emotional and cognitive signatures of prejudice. We endorse their view that past research has downplayed the importance of positive emotions.

Recent data collected by Corr et al. (unpublished) in England $(N=110)$ replicated the association between SDO and RWA, whilst providing evidence that both measures are related to fundamental processes underlying emotion and motivation, as outlined by RST: SDO was positively associated with Defensive Fight $(r=.24, p=.014)$ and Reward Interest $(r=.19, p=.048)$; and RWA was positively associated with Defensive Fight $(r=.30, p=.001)$, Reward Interest $(r=.31, p=.001)$, GoalDrive Persistence $(r=.35, p=.001)$, Reward Reactivity $(r=.34$, $p=.001)$ and Impulsivity $(r=.22, p=.05)$, in addition to Fear $(r=.19, p=.05)$.

Such data suggest that the endorsement of status-legitimizing ideologies and the willingness to accept and uphold societal inequality has an origin in the basic, biological determinates of personality, particularly those related to positive-approach motivation. These associations support the call by Dixon et al. for a more nuanced perspective on prejudice, replacing the notion of the bigoted person who needs (re)education and more contact with one that focuses more specifically on underlying emotion and motivation, including positive-approach drivers. This conclusion supports Dixon et al.'s contention that attempts at prejudice reduction by education and contact are not a panacea. It seems that both social dominators and authoritarian submissives will not relinquish their support for the status quo of inequality if their underlying emotions and motivations are not addressed. Although this nuanced picture complicates matters, it may lead ultimately to a fuller understanding of the causes of prejudice and how it might be ameliorated.

\section{Understanding the psychological processes involved in the demobilizing effects of positive cross-group contact}

\author{
doi:10.1017/S0140525X12001446
}

Nicole Tausch ${ }^{\mathrm{a}}$ and Julia C. Becker ${ }^{\mathrm{b}}$

aschool of Psychology, University of St Andrews, St Mary's Quad, South Street, St Andrews, KY16 9JP, Scotland; ' Department of Psychology, Philipps-University Marburg, Social Psychology, Gutenbergstraße 18, 35032 Marburg, Germany.

nt20@st-andrews.ac.uk http://www.st-andrews.ac.uk/profile/nt20 beckerj2@staff.uni-marburg.de http://www.uni-marburg.de/fb04/ team-wagner/Team-en/staff/juliabecker_en?language_sync=1

Abstract: A theoretical framework is required that explains why and how cross-group contact reduces collective action and how the demobilizing effects can be counteracted. We propose that at least two mechanisms are involved: an affective process whereby the positive affect created offsets negative emotions and action tendencies, and a more strategic process whereby individual advancement comes to seem like a possibility.

One of the most troubling issues raised by Dixon et al. is that prejudice-reducing interventions such as cross-group contact seem to have a demobilizing effect on members of disadvantaged groups, increasing their acceptance of a biased system and weakening their resolve to act for change. Although the role of cross-group contact in social change is likely to be complex (see Pettigrew 2010), understanding the psychological processes involved should be a priority for future work. Hence, a theoretical framework that explains why and how contact reduces collective action is required. This may provide insights into when contact is more or less likely to result in reduced commitment to social change among the disadvantaged.

How does cross-group contact demobilize subordinate groups? One pathway, described by Dixon et al., is through fostering mutual affective bonds (see also Jackman 1994), which can undermine collective action directly, by offsetting adversarial feelings and action tendencies (Tausch et al. 2012), as well as indirectly by making the inequality seem just and not the result of discrimination by the advantaged group (Dixon et al. 2010a; Saguy et al. 2009) But increased positive affect toward the outgroup is unlikely to be the only process involved; more strategic considerations, concerning the benefits of the current system, are also likely to be at play. Research on the effects of exposure to Benevolent Sexism, for example, has shown that it is not so much the positive affect associated with Benevolent Sexism that reduces willingness among women to engage in actions for gender equality, but the perceived advantages of the existing gender system generally as well as personally (Becker \& Wright 2011; see also Glick \& Fiske 1996).

This second, important issue is not explicitly discussed by Dixon et al. It is, however, presented by Jackman (1994) as another strategy employed by dominant groups to maintain the status quo. Specifically, Jackman suggests that the propagation of "individualism" as a social value can promote individualistic (at the expense of collective) strategies among members of subordinate groups, leaving the existing power structure intact. According to social identity theory (Tajfel \& Turner 1979), individualistic strategies are most likely to be favored when group boundaries are viewed as permeable and individual upward mobility seems like a possibility. The social mobility "mind-set" is characterized by attempts to disassociate oneself from one's group, adherence to the outgroup norms (Wright et al. 1990), and attempts to display the qualities required for upward mobility (Reicher \& Haslam 2006). Importantly, it reduces collective action. For example, Wright et al. (1990) demonstrated that when disadvantaged group members believe that even only a select few can move up, their willingness to protest against inequality is dramatically reduced. Moreover, these successful "tokens" sometimes shift their allegiance to the advantaged group and help to maintain the discriminatory system. This is illustrated poignantly by research on the so-called "Queen Bees" who are less supportive of the 
advancement of other women (Ellemers et al. 2004), particularly when they experience social identity threat (Derks et al. 2011).

Does positive, equal-status contact foster the belief (or illusion) that the social system is permeable (Reicher 2007), promoting an individual mobility orientation? Initial evidence suggests that it does. For example, Saguy et al. (2009) showed that commonality-based contact can create (false) expectations for equal treatment among members of disadvantaged groups. Similarly, among African Americans and Latinos, positive contact with Anglo-Whites was associated with reduced identification with one's group (in line with the dissociation associated with an individual mobility orientation) and increased beliefs that members of one's group could move up (Wright \& Lubensky 2009). Both reduced identification and permeability beliefs partly explained the negative relation between contact and collective action tendencies. Similarly, Tausch et al. (2012) provided evidence that Latinos' friendship with AngloWhites is negatively related to collective action intentions, but positively related to individual mobility intentions. The latter link was mediated by beliefs that one has the ability to get ahead personally. Future research needs to substantiate the causal effect of contact on individual mobility orientations, and more needs to be done to understand how it comes about. Does positive, equal-status contact create a belief that one is not different from the advantaged group and therefore likely to have the same opportunities, or that one is "special" and likely to receive the social support required to move up?

An examination of the mechanisms involved in this demobilization presents the question of how these processes can be counteracted. A central issue seems to be the communication of legitimacy, either indirectly through the creation of positive ties that make the detection of discrimination difficult, or directly by creating the impression that individual advancement is open to everyone. Recent research has highlighted the fundamental role of communication about perceptions of the legitimacy of intergroup inequality during contact. Becker et al. (2012) demonstrated that positive cross-group contact undermines collective action among the disadvantaged only when the advantaged group partners describe their group's advantaged position as legitimate or when they leave their feelings about their group's advantage ambiguous. In contrast, when the partners explicitly described the group inequality as illegitimate, contact did not undermine participation in collective action. Hence, contact with "just" outgroup friends (cf. Nagda \& Gurin 2006) who communicate their disapproval of the group hierarchy does not have demobilizing effects.

To conclude, the question of why or how contact reduces collective action points to at least two mechanisms; (1) a process whereby the positive affect created offsets the negative emotions and action tendencies required for collective action and makes the inequality seem fair and not the result of discrimination, and (2) a process whereby group boundaries come to be seen as permeable and personal benefits in the form of individual advancement seem like a possibility. Initial work has also addressed the "when" question and suggests that the demobilizing effects of contact can be counteracted through the direct communication of the illegitimacy of the system by members of the advantaged group.

\section{Prejudicial behavior: More closely linked to homophilic peer preferences than to trait bigotry}

doi:10.1017/S0140525X12001458

Jacob M. Vigil and Kamilla Venner

Department of Psychology, University of New Mexico, Albuquerque, NM 87131-1161.
Abstract: We disagree with Dixon et al. by maintaining that prejudice is primarily rooted in aversive reactions toward out-group members. However, these reactions are not indicative of negative attributes, such as trait bigotry, but rather normative homophily for peers with similar perceived attributes. Cognitive biases such as stereotype threat perpetuate perceptions of inequipotential and subsequent discrimination, irrespective of individuals' personality characteristics.

We disagree with Dixon et al. by maintaining that prejudice is primarily rooted in avoidant reactions toward out-group members. However, the conventional assumption (reiterated in the target article) that prejudice stems from certain negative (pejoratively described) personality characteristics, such as trait bigotry of majority-group members, is also misleading. This assumption commits the fundamental attribution error in and of itself, attributing others' behaviors to personal, rather than situational, factors. It is also erroneous to assume that prejudice reflects biologically irrelevant or maladaptive attitudinal decisions, which implies some degree of cognitive, emotional, and/or sociopolitical deficiencies. Clearly, the tendency to selectively interact with conspecifics (e.g., mate discrimination) is a normative and evolutionarily adaptive component of social development. On the basis of these points, we agree with Dixon et al. that many current models of the causes of prejudice are ineffective and probably counterproductive for guiding strategies for reducing societal discrimination. Describing prejudice instead in terms of normative cognitive processes may reduce defensiveness and increase receptivity to interventions that seek to reduce the harmful effects of prejudice.

A more objective and potentially parsimonious conceptualization of the causes of prejudice can be framed within the concept of homophily, which is the ubiquitous tendency for individuals to show attraction toward, and to desire to affiliate with, other people who share similar personal characteristics. Homophilic peer preferences play a predominant role in shaping the information that individuals receive, the attitudes they form, and the interactions they experience within families, peer networks, and isomorphic societal positions (McPherson et al. 2001). People exhibit the strongest homophilic peer preferences for attributes that indicate personal agency, or one's capacity to reciprocate with others, such as physical appearance (a biosocial proxy for healthiness), intelligence, and financial resources. Peers who are perceived as possessing significantly higher or significantly lower levels of these traits as compared to the individual are less preferred than are peers with similar, if not slightly higher, trait levels as the individual (Vigil 2007). This pattern makes sense from the standpoint that humans possess the implicit motivation to interact with social affiliates who have the most equipotential and hence incentive to reciprocate with the individual.

A conceptual representation of this hypothesis as it pertains to economic-based discrimination is shown in Figure 1. People are most attracted to peers who are perceived to possess slightly higher economic resources than oneself, and people are averse to interacting with peers who either possess much lower (e.g., destitute affiliates) or much higher (e.g., prosperous affiliates) economic resources (see Vigil 2007). Homophilic preferences for peers with slightly higher financial potential enables the individual to procure a net gain across his or her reciprocal interchanges with others, within the parameters that provide the highest probability of receiving said reciprocation.

This model explains the tendency for superordinates to discriminate against subordinates, as well as the reverse pattern, for subordinates to discount affinity for people with higher social status. For example, experimental research shows that people are incentivized to pay a cost to reduce the rewards provisioned to both high-wage (token) earners, as well as low-wage contributors (Johnson et al. 2009). Other research shows that when participants receive either significantly higher or 


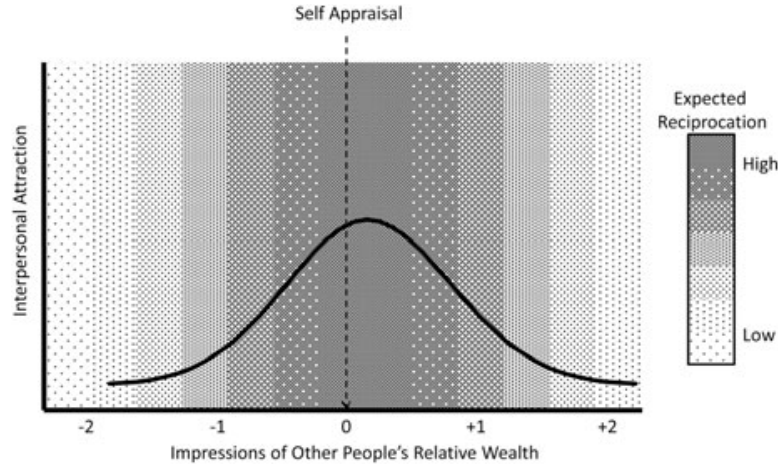

Figure 1 (Vigil \& Venner). Interpersonal affinity as a function of homophilic economic potential and implicit expectation of reciprocation.

significantly lower rewards relative to others, they are less likely to invest in public goods provisions (Anderson et al. 2008). These findings are typically interpreted as the tendency for people to punish free riders; however, an alternative hypothesis is that people are averse toward peers who possess disparate capacity resources. Phenotypic homophily for capacity-endowment attributes in others may also help explain the reciprocal expression of racial discrimination (e.g., anti-white biases among blacks; Lecci \& Johnson 2008) and gender discrimination (e.g., anti-male biases in family courts). That is, some intergroup biases are probably the result of historically low exposure to, or to low prevalence of, the stereotype that outgroup members in fact possess varying competency levels (e.g., low rates of exposure to specific ethnic groups and genders in certain societal and/or domestic roles).

Another concept that influences intra- and interindividual perceptions of personal competencies is stereotype threat. Stereotype threat stems from a classic study showing that test instructions influence performance on cognitive tasks (Steele \& Aronson 1995). When students were told that a task was not diagnostic of intelligence, black and white students performed similarly; however, when students were told they were taking an intelligence test, the black students performed worse than did the white students. The assumption is that instructional cues about intelligence triggered the prevalent erroneous stereotype that black people are not as smart as white people and negatively impacted performance. Repeated experiences of stereotype threat and poorer performance may influence the process of internalized racism whereby a person begins to believe that he or she is not as competent as someone of the dominant group, ultimately resulting in a self-fulfilling prophecy.

Dixon et al. highlight the "ironic" and troubling outcomes of many prejudice reduction interventions as maintaining social inequality. One way to reduce prejudice and social inequality may be to focus on decreasing stereotype threat. Individual-based interventions may include encouraging self-affirmations, emphasizing the strengths of the individual, communicating confidence in individuals' ability to achieve high standards, and providing external attributions for social anxiety (Burgess et al. 2010; Cohen et al. 2006; Martens et al. 2006). From the perspective of providers (e. g., teachers, evaluators, clinicians), interventions may include managing cues that could trigger stereotype threat (e.g., altering the test instructions, deemphasizing race or ethnicity, and placing demographics at the end of a test), focusing on the strengths of the individual, and providing external attributions for anxiety expressed by diverse individuals (e.g., Burgess et al. 2010; Johns et al. 2005). This would help decrease what Dixon et al. refer to as the "indirect violence of structural inequality" (sect. 4.1.3, para. 3). Maintaining the status quo of unequal access to institutional resources, power differentials continue to exist in our society. Unfortunately, disrupting these disparities are likely to present a continuous challenge given that the cognitive biases (e.g., homophily, stereotype threat) that contribute to discrimination are likely canalized at early stages in social development.

\section{Are attitudes the problem, and do psychologists have the answer? Relational cognition underlies intergroup relations}

doi:10.1017/S0140525X1200146X

\author{
Sven Waldzus, ${ }^{\text {a }}$ Thomas W. Schubert, ${ }^{\mathrm{a}}$ and \\ Maria-Paola Paladino ${ }^{b}$ \\ aInstituto Universitário de Lisboa (ISCTE-IUL), Lisboa, Portugal, Av. Forças \\ Armadas, Ed. ISCTE-IUL, 1649-026 Lisboa, Portugal; ' ${ }^{\mathrm{b}}$ Department of \\ Cognitive Sciences and Education, University of Trento, University of Trento, \\ Corso Bettini 31, 38068 Rovereto (TN), Italy. \\ sven.waldzus@iscte.pt http://www.cis.com.pt/profiledetail.php?pid=37 \\ schubert@igroup.org http://www.igroup.org/schubert/ \\ mariapaola.paladino@unitn.it \\ http://www5.unitn.it/People/it/Web/Persona/PER0000767
}

\begin{abstract}
The focus on negative attitudes toward other groups has led to a dichotomy between the prejudice reduction and the collective action approach. To solve the resulting problems identified by Dixon et al., we suggest analyzing the psychological processes underlying the construction of relationships (and their alternatives) between own and other groups.
\end{abstract}

The target article forcefully reminds researchers of the context that research on prejudice faces. Dixon et al. expose a tendency in the field of intergroup research toward an appeasement approach to social conflict. Although we applaud their exposition, we find the comparison of the prejudice reduction and the collective action models lopsided. Considered in isolation, the latter also suffers from a lack of attention to the context in which social psychological research is conducted. Moreover, a framework for the relational view recommended by the authors is still missing. Let us focus on each point in turn.

Dixon et al.'s contribution targets the relation between social psychological research and the sociopolitical reality in which such research is embedded. They cogently diagnose a lack of awareness of such embeddedness for the prejudice reduction model. But the collective action model also relies on implicit assumptions, including the assumption that demands for social changes raised by disadvantaged groups are always legitimate. Dixon et al. adopt these decontextualized assumptions without considering the typically diverging perspectives of involved groups and third parties. But adopting these premises unintentionally legitimizes all kinds of mobilization for collective action and conflict escalation, including, for example, hate-preachers' support of religious fundamentalism.

However, the question of how to attain a more just society by resisting or supporting social change is not a psychological question to begin with. Hence, it cannot be answered by suggesting decontextualized psychological principles - neither general prejudice reduction nor general increase of mobilizing emotions.

Social change toward equality always acts within a context of shared, often controversial cultural understanding about what inequalities are legitimate in a certain domain. Decisions on the direction of social change should be the choice of the members of the studied groups as political agents, which possibly includes the researchers themselves. The task for researchers as researchers is what comes after that decision: the investigation of underlying processes. This is the second aspect we want to comment on: We believe that Dixon et al. do not go far enough in their proposal of paradigmatic change 
in intergroup research. Dixon et al. propose "recovering the relational character of intergroup attitudes" as one future direction (sect. 4.1.1), but translate this only into studying effects on both advantaged and disadvantaged groups. They do not attend to the psychological processes underlying the relational nature of intergroup attitudes and behavior as such.

So far, the focus of psychological research on intergroup relations has been attitudes toward, and representations of, the perceivers' own or other groups, and Dixon et al. adhere to that focus. To gain a common perspective for both social change models, it is necessary to analyze the psychological processes involved in the construction of social relations. In particular, we should study representations of, and attitudes toward, relations between own and other groups, including probable or desired alternatives to existing relations. To do so, we propose to use Relational Models Theory (RMT; Fiske 1992; 2004).

RMT is a general theory of social relations positing that all social relations are coordinated by utilizing four basic relational structures supported by specific motives and emotions: (1) communal sharing, coordination of social interaction according to shared identity; (2) authority ranking, coordination according to linearly differentiated ranking of status and prerogatives; (3) equality matching, where the organizing principle is balanced one-to-one correspondence among participants; and (4) market pricing, governed by ratios (for example, of contributions and benefits).

The principles behind communal sharing and authority ranking elucidate problems of the prejudice reduction model identified by Dixon et al. The goals of prejudice reduction are increased liking, together with identification as a common ingroup; this constitutes coordination in terms of communal sharing. Advantaged groups might, however, coordinate according to authority ranking, which predicts paternal benevolence toward low-status relational partners and hostility toward those striving to overturn the rank order. A focus solely on prejudice reduction is problematic because it does not differentiate between liking based on communal sharing - on being the same-and paternalistic fondness for loyal subordinates. Furthermore, when disadvantaged groups comply with "superior" groups' benevolent offers to coordinate according to authority ranking, further efforts to advocate more fundamental change are compromised.

Applying RMT to intergroup relations provides a framework for the understanding of the cognition, emotion, motivation, and moral judgment underlying intergroup behavior. In order for RMT to model dynamic change appropriately, it can profit from integration with Social Identity Theory (Tajfel \& Turner 1979; Waldzus \& Fiske, in preparation), which can be considered an early integration of prejudice reduction and social change perspectives.

Conceptualizing desired or probable alternatives of intergroup relations through RMT does not require fixing in advance whether or how social relations should be changed. The parties involved in the intergroup relation must make the decisions, possibly including the researcher with her/his own political and ideological convictions and aspirations. For example, a disadvantaged group can have the goal to retain authority ranking in the relation to the advantaged group, but to gain more paternal treatment. It could also aim to retain the legitimacy of status differentiation while moving to a higher position, or, more radically, to reverse the status relations between the groups (i.e., revolution). Finally, it could have the goal to switch from authority ranking to an equality matching relation, in which resources and burdens are allocated according to principles of even balance and one-to-one correspondence among distinct groups with equal entitlements. Collective action movements could also include aspects of communal sharing (i.e., constituting a common essence) that are conducive to reconciliation. Similar considerations apply to intentions of advantaged groups and even third parties.

Dixon et al.'s comparison of prejudice reduction and collective action should be followed by integration at a new level.
Investigating relational cognition will enable us to describe and predict psychological processes at work in the interaction between disadvantaged and advantaged groups. Such research can provide involved individuals and groups with conceptual tools to understand their own and others' actions and motivations - and to change their relationships by prejudice reduction, collective action, or otherwise.

\section{Echoing the call to move "beyond prejudice" in search of intergroup equality}

\author{
doi:10.1017/S0140525X1200132X
}

\author{
Stephen C. Wright and Lisa M. Bitacola \\ Simon Fraser University, Burnaby, BC V5A1S6, Canada. \\ scwright@sfu.ca http://www.sfu.ca/psyc/faculty/wrights/ \\ Ibitacol@sfu.ca
}

\begin{abstract}
We also critique the myopic focus on prejudice reduction, but we do not support the call for a reconceptualization of prejudice. Redefining key psychological constructs is unproductive. Also, we point to interpersonal dynamics in cross-group interaction as a key mechanism in the prejudice reduction/collective action paradox and point to solutions involving intrapersonal/interpersonal processes, as well as broader structural intergroup relations.
\end{abstract}

Dixon et al. provide an excellent integration of research relevant to widening concerns about psychology's unquestioned conviction about the value of prejudice reduction. In the first half of the article, the authors summarize evidence that advantaged group hostility and negative evaluations of the disadvantaged group (i.e., prejudice) may not be the genesis or the only agent of protracted intergroup inequality. We strongly agree (see, Wright \& Baray 2012) but wondered about the authors' proposed solution. Repeatedly, they call for a broad redefinition of prejudice to include other processes, claiming that research has converged "to challenge the traditional concept of prejudice as negative evaluation" (sect. 2.6., para. 1) and instead favour a definition like the one provided by Rose (1956), which would include a full "set of attitudes which causes, supports or justifies discrimination" (sect. 4, para. 1). We are not convinced that broadening the concept of prejudice is wise at all. For example, even their extremely inclusive new definition would not include intergroup helping (one of their culprits in maintaining inequality), which is not "an attitude," but rather a behaviour. Further, prejudice would now apparently include attitudes about anything as long as the downstream outcome of that attitude is that some group is unfairly disadvantaged. So, my love of coffee (an attitude) could be prejudice if it leads me to buy coffee grown by a company that actively subjugates the rights of workers. Moreover, defining a psychological process by its inevitable outcome is problematic. We cannot know if something is prejudice until we see all of its subsequent consequences to determine if one outcome involves discrimination. Finally, how we conceptualize and define psychological constructs is not a trivial issue. If we cannot agree on the meanings and parameters of important concepts, we cannot engage in scholarly arguments about causes and consequences. So, a better solution to the literature's myopic focus on prejudice is to leave the definition of prejudice alone-prejudice is an evaluation of a group and its members and encourage others to follow the suggestion in the article's title to go "beyond prejudice" and consider other processes that also cause and maintain inequality.

Dixon et al. review several perspectives (including ours; e.g., Wright \& Lubensky 2009) on how and why cross-group contact, while improving intergroup attitudes (reducing prejudice), can also undermine the psychological underpinnings of collective 
Response/Dixon et al.: Beyond prejudice

action. They also argue that among advantaged groups there may be a weak relationship between positive intergroup attitudes and support for meaningful structural change. Our recent theorizing concludes that in fact the harmonious interpersonal interactions described by contact researchers as critical to reducing prejudice can also be responsible not only for undermining collective action intention, but also for reaffirming, reinforcing, and legitimizing inequality (Wright \& Baray 2012). Our position is based on Ridgeway's (2001) Status Construction Theory, which holds that members of both high- and low-status groups learn and strengthen their shared group status beliefs by participating in or observing numerous specific interpersonal cross-group interactions. When inequality is a basic element of an intergroup relationship, crossgroup interactions will be influenced by the shared stereotypes that exist to explain these inequalities. Hence, high- and lowstatus group members will simultaneously engage in subtle behaviours that demonstrate and legitimize these status differences. These subtle cues, enacted over and over again in cross-group interactions, reinforce and legitimize the status differences that produce them. In fact, it may be precisely when harmonious interpersonal behavior is encouraged that members of both groups are most likely to tune their behaviour (e.g., Sinclair et al. 2005) to match group stereotypes in an effort to smooth the interpersonal interaction. Furthermore, explicitly structuring situations so groups are thought to have "equal status" during the interaction (a key condition of optimal contact) may only exacerbate this problem, because when the inevitable subtle cues demonstrating the superiority of one group emerge, the obvious attribution is to the character of the groups (not the situation). Hence, efforts to "get along" lead both advantaged and disadvantaged group members to rely on shared expectations of how to act. The resulting positive cross-group interactions, while leading to liking, can be precisely the place where group status differences are enacted and reified (Wright \& Baray 2012).

The final section focuses on solutions and reconciling the prejudice reduction and collective action approaches. In our own discussions, we focus on two levels of solution. First, individual and interpersonal level solutions (Wright \& Lubensky 2009) involve ways that cross-group interaction partners may manage the competing psychological requirements of contact and collective action. One example of a solution at this level (among others) involves the process of subtyping, whereby the disadvantaged group member distances his or her friend from the rest of the advantaged outgroup, describing that friend as "an exception to the rule." Hence, positive feelings about the friend need not undermine perceptions of the rest of the outgroup as agents of discrimination. In addition, this offers an alternative identity to the advantaged group member; one of ally or coconspirator in the fight for justice. Especially if the advantaged group partner accepts this subtype, the friendship is unlikely to be misconstrued as evidence of intergroup harmony. Second, like Dixon et al., we believe that "for group-based equality to be cultivated and maintained we need to move beyond a model dominated by a focus on prejudice reduction, and recognize that efforts to change unjust and unequal social structures will require both harmony and managed conflict, a recognition of group differences as well as similarities, open discussion of existing inequalities that exposes both discrimination and privilege and enough animus and acrimony to stimulate assertive action" (Wright \& Baray 2012, p. 245). One possibility is a temporal approach with periods of segregation, identity building, conflict, and social change followed by periods of integration, community building, harmony, and cooperation. The timing and duration of each phase would depend on the history and on the social and political realities of that particular intergroup context.

In short, we share many of the views expressed in this article and join the authors in encouraging a broader dialogue exploring the limits and benefits of both harmony and conflict in intergroup relations.

\section{Authors' Response}

\section{Beyond prejudice: Relational inequality, collective action, and social change revisited}

\author{
doi:10.1017/S0140525X12001550
}

\author{
John Dixon, ${ }^{a}$ Mark Levine, ${ }^{\mathrm{b}}$ Steve Reicher, ${ }^{\mathrm{c}}$ and \\ Kevin Durrheim ${ }^{\mathrm{d}}$ \\ ${ }^{a}$ Department of Psychology, Open University, Milton Keynes MK7 6AA, United \\ Kingdom; ${ }^{\mathrm{b}}$ Department of Psychology, Exeter University, Exeter, Devon EX4

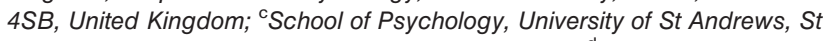 \\ Andrews, Fife KY16 9AJ, Scotland, United Kingdom; 'School of Psychology, \\ University of KwaZulu-Natal, 3209, South Africa. \\ john.dixon@open.ac.uk \\ http://www.open.ac.uk/socialsciences/staff/people-profile.php? \\ name=John_Dixon \\ m.levine@exeter.ac.uk \\ http://psychology.exeter.ac.uk/staff/index.php?web_id=Mark_Levine \\ sdr@st-andrews.ac.uk \\ http://www.st-andrews.ac.uk/ www_sp/people/lect/sdr.shtml \\ durrheim@ukzn.ac.za \\ http://psychology.ukzn.ac.za/staff.aspx
}

Abstract: This response clarifies, qualifies, and develops our critique of the limits of intergroup liking as a means of challenging intergroup inequality. It does not dispute that dominant groups may espouse negative attitudes towards subordinate groups. Nor does it dispute that prejudice reduction can be an effective way of tackling resulting forms of intergroup hostility. What it does dispute is the assumption that getting dominant group members and subordinate group members to like each other more is the best way of improving intergroup relations that are characterized by relatively stable, institutionally embedded, relations of inequality. In other words, the main target of our critique is the model of change that underlies prejudice reduction interventions and the mainstream concept of "prejudice" on which they are based.

\section{R1. Introduction}

"Horror succeeds horror and we cannot put a stop to it," Nehru wrote to Lord Mountbatten on June 22, 1947 (cited in Godbole 2006, p. 3). Nehru was writing of the first clashes between Hindus and Muslims during the partition of the Indian subcontinent, but his words serve as well to describe the seemingly endless catalogue of atrocities that stretch up to the present day. As we write, there are 328 armed conflicts taking place in 59 countries around the world (http://www.warsintheworld.com/? page=static1258254223) and many more instances where intergroup hostility falls short of armed confrontation but continues to blight day-to-day relations. What is so depressing is not simply the quantity, but also the quality of these conflicts. In his 1994 Amnesty lecture, the eminent historian Eric Hobsbawm observed that "barbarism has been on the increase for most of the 20th century, and there is no sign that this increase is at an end (1998, p. 335). Tragically, in the early years of the present century, one can all too easily find fresh instances of violent conflict between groups, new examples of the capacity of human beings to mistreat those whom they deem different, threatening, inferior, or less than human. For this reason, we can understand fully why some 
commentators have expressed reservations about our critique of the concept of prejudice as negative evaluation. Do we really want more conflict? After all the horror, "what's so crummy 'bout peace, love, and understanding" (N. Haslam)?

Well, of course, there is nothing crummy and a lot that is good and right and worth defending - as long as, that is, peace really does go along with love and with understanding. Our concern is that peace and love can sometimes coexist with - or even promote - a lack of understanding that cruel inequalities persist in the world. It is not enough that people smile and hug when they meet if they then ignore the fact that some go back to luxury and others back to hovels.

In making this point, we do not want our argument to be misread either as an "incautious" (Hewstone, Swart, \& Hodson [Hewstone et al.]) call for the indiscriminate escalation of conflict or as an unconditional rejection of the value of prejudice reduction. Rather, we want to highlight some psychological, social, and political processes that may be obscured by the concept of prejudice as negative evaluation. First, we should not presume that the absence of negative intergroup feelings and conflict necessarily indicates the absence of discrimination and inequality. Second, we should not presume that their presence is necessarily an impediment to the reduction of discrimination and inequality. Third, by implication, we should not presume that nurturing warm feelings and harmonious relations necessarily creates a better society. Better for whom, in what ways, and at what costs? These are questions that have been marginalised in much of the prejudice literature, which has treated the reduction of negative evaluations as an unquestioned end in itself, quietly eclipsing more fundamental debates about how to implement sociopolitical change most effectively. These are questions that we have brought loudly to the fore in our target article.

The rest of this response is organised as follows. To begin with, in section R2, we consider commentaries that have challenged our central thesis. Here we sometimes concede ground, sometimes clarify our position, and sometimes stand our ground. Next, in section R3, we consider commentaries that have sought to exemplify, extend, refine, or qualify our central thesis, identifying important avenues for future research. Finally, in section R4, developing themes that run through several commentaries, we emphasize the importance of: (1) moving beyond a singular concept of prejudice as unalloyed negativity in order to explore the multiplicity of feelings, thoughts, and behaviours that may sustain discrimination; (2) investigating the complex "top-down" and "bottom-up" links between relationships of inequality and group members' shared understandings of, and attitudes towards, self and other; and (3) reevaluating the role of intergroup contact in challenging social inequality.

\section{R2. Prejudice, prejudice reduction, and the limits of collective action models of social change}

In our target article, we basically made four points:

1. Long term relationships of inequality between groups (e.g., relations of class, race, and gender in many societies) are accompanied not only by negative intergroup attitudes, but also by ambivalent or even positive attitudes.
2. The latter sometimes help to sustain broader forms of inequality and discrimination. That is, however strange the idea may initially appear, warm feelings and positive thoughts about others are sometimes part of the social and political cement that solidifies an unequal status quo.

3. As such, interventions aimed at getting us to like one another are not necessarily an effective mechanism to promote social change. They can have the paradoxical consequence of inhibiting the social psychological impetus for change, particularly for members of historically disadvantaged groups.

4. In consequence, we believe it is time to reevaluate the efficacy of the prejudice reduction model in relation to other models of social change. In this regard, we have discussed an alternative model based around collective action to achieve equality. We have also invited critical reflection on the relationship between these two models of social change, which might be conceived, for example, as incommensurable, reconcilable, or complementary (see also Wright \& Lubensky 2009).

Several commentators have challenged these central strands of our argument. To begin with, they have worried that our critique of the orthodox conception of prejudice goes too far, underestimating the extent to which disadvantaged groups continue to be targeted for antipathy, hostility and violence. Although conceding that prejudice may take diverse forms, both Abrams, Vasiljevic, \& Wardrop (Abrams et al.) and Brown argue that its "old-fashioned" expressions remain an urgent problem in many societies. Animosity towards immigrants and Muslims in Britain and other parts of Western Europe provides a stark illustration. Outside of Western democracies, in societies where comparatively little research on prejudice has been conducted, the situation is probably worse. Bilewicz's reflections on relations in Armenia, Romania, Poland, Turkey, and Northern Cyprus, for example, suggest that blatant forms of prejudice are alive and well and that they predict discriminatory actions more strongly than the "subtle" indices that have dominated recent psychological research in the West. In this vein, Brown warns that: "if we should be aware that the wolf of prejudice (towards women and some minority groups) can sometimes come disguised in benevolent sheep's clothing, it is also important to remember that the prejudice experienced by many groups is far from 'benevolent”' (para. 2).

Developing a related argument, several commentators have vigorously defended the utility of traditional prejudice reduction interventions, particularly interventions based on Allport's (1954) contact hypothesis (Abrams et al.; Brown; N. Haslam; Hewstone et al.). After all, if old-fashioned antipathy remains an urgent problem in many societies, then surely we need interventions that can encourage us to like one another more or at least "hate one another less" (Brown)? Intergroup contact especially when it occurs under favourable circumstances - has consistently been found to accomplish this goal. It works even on the attitudes of the highly prejudiced (Hodson 2011). Moreover, as Hewstone et al. observe, contact has closely related benefits: it promotes intergroup forgiveness, empathy, and perspective-taking and reduces intergroup anxiety and distrust. Unlike collective action interventions, moreover, it facilitates peaceful coexistence, reducing the likelihood of disturbances, unrest, or bloodshed. 
In any event, as several commentators warn, the collective action model has problems of its own and is no panacea for discrimination and inequality. Some disadvantaged groups are simply too fragmented, numerically small, or lacking in political clout to mount a meaningful challenge to the status quo, leaving prejudice reduction as a more feasible option for improving intergroup relations (N. Haslam). Relatedly, in many cases of collective mobilization, protagonists ultimately fail to achieve meaningful change, and they may even create conditions that are appreciably worse (Abrams et al.). Struggles to transform the status quo may meet with violent resistance from members of advantaged groups; and this may set in motion a downward, destructive cycle of intergroup conflict that is ultimately costly to both sides (N. Haslam; Hewstone et al.; Schaller \& Neuberg). Because it sharpens and magnifies group differences, collective action may also help to "essentialize" social categories and relations (N. Haslam). It may thus encourage processes of mutual dehumanization and hinder long-term prospects of reconciliation. In light of these problems, it might seem that the perils of collective action outweigh its prospects. Hence, out of pragmatism if nothing else, some may concur with Abrams et al. that the objective of getting the powerful to like the less powerful "can surely only be helpful" (para. 2).

In responding to these criticisms, we wish to make three initial points that were perhaps not articulated clearly enough in our target article.

1. The focus of our argument was (and remains) on intergroup relations marked by relatively stable, institutionally embedded, relations of inequality. Certainly there can be prejudices in the absence of inequalities, between redheads and brunettes, between Manchester United and Manchester City fans, between people from Yorkshire and those from Lancashire, and so on. However, like most researchers who have studied prejudice, our interest derives from the concept's relevance to the entrenched inequalities that scar our societies such as racism, sexism, and anti-Semitism.

2. In societies where equality has been achieved and institutionalised disadvantages are negligible or nonexistent, we wholeheartedly embrace the goal of achieving intergroup harmony as a valuable end in itself. We also acknowledge that in such contexts collective action to transform unequal and discriminatory relations is, by definition, unnecessary.

3. Our concern is therefore with the idea that prejudice reduction is the way forward where there are existing inequalities and practices of discrimination between groups. More specifically, we identify and contest the widespread assumption that enhanced liking will be a "bottom up" driver that leads to transformations at a cultural, institutional, and legal level (contra Alicke).

Bearing in mind these points, we offer the following additional responses to our critics. Our first response addresses the prevalence of "hostile" versus "benevolent" forms of prejudice. Those who point out that hostile prejudice remains alive and well throughout the world are quite right. However, they are quite wrong to believe that we think otherwise. Indeed, building on the work of Leach (2005), we would conjecture that the supposedly universal shift from "old" to "new" forms of prejudice has been overstated in recent psychological literature, an idea reinforced by Bilewicz's thoughtful commentary.

In discussing research on "benevolent" prejudices, we were not making a point about prevalence at all. Rather, we were underscoring a conceptual argument. That is, if researchers think that the answer to social inequality is to promote harmony, then they should look closely at those instances where intergroup harmony seems to reign and majorities talk positively about minorities. They will find that things are not necessarily much better for the minority. It might even be that their prospects are worse.

To put this point more precisely, prejudice research has, throughout its long history, focused almost exclusively on the problem of measuring, explaining, and changing negative evaluations. Until recently, this focus has largely obscured the role of ostensibly positive and ambivalent attitudes in sustaining relational inequality between groups. It has masked the fact that "unalloyed antipathy" (Glick \& Fiske 2001) is neither practical nor ideologically functional in such relationships and in fact impedes their smooth operation. "Paternalistic" power relations entail (and require) more complex constellations of social attitudes and beliefs - often blending positive attributions about those who follow ascribed roles and display valued attributes with hostility towards those who step out of line. These attitudes and beliefs in turn shape the unfolding actions and reactions of both dominant and subordinate groups and help to reproduce their unequal relationship in ways that cannot be readily captured by a simple model of prejudice as negative evaluation. As our target article elaborated, they find expression in seemingly benevolent forms of (conditional) inclusion, relations of helping, idealization of (certain) attributes of disadvantaged groups, and heartfelt support for general principles of social equality amongst the advantaged (offset by continuing resistance to its implementation).

In drawing together recent evidence on these kinder, gentler forms of prejudice, we have sought to highlight some limitations of mainstream work in the field, flagging the need for alternative theoretical, methodological, and applied perspectives. It is in the arena of social change that these limitations are most troubling to us and, as we shall see, to several other commentators on our target article. We do not deny that the prejudice reduction has a beneficial impact on negative intergroup emotions and beliefs. Nor do we deny that, in many intergroup contexts, getting people to like one another more is a vitally important objective. However, we do deny that prejudice reduction is an effective mechanism for improving intergroup relations (i.e., reducing discrimination and promoting equality) in contexts where intergroup relations are marked by long-standing patterns of institutional discrimination and where intergroup relations are relatively stable and "harmonious." Moreover, even in contexts where intergroup relations are far from stable and harmonious but remain unequal, we argue that prejudice reduction is sometimes more clearly in the interest of advantaged than disadvantaged groups. As outlined in our target article and developed by the commentaries discussed in the next section, we have reason to suspect that interventions to reduce prejudice may, paradoxically, entrench existing status and power relations in unequal societies. 
This takes us to the second set of concerns raised in the responses. Our central argument is that, in this kind of context, collective action becomes an essential motor of social change (see also Drury; S. Haslam \& Reynolds; Maoz; Tausch \& Becker; Wright \& Bitacola). It is important to note, however, that this is a conditional and not an absolute statement in support of collective action. On the one hand, it does not suggest that collective action is essential in all contexts. We have already pointed to this, but it is sufficiently important to bear repetition. Collective action is not essential where intergroup hostility occurs in the absence of a history of intergroup inequality. Equally, it is no longer essential where intergroup hostility remains after a history of intergroup inequality has been overcome. As Wright \& Bitacola suggest, we may need to introduce a temporal dimension to our analysis. It may well be that prejudice reduction is particularly relevant precisely when bitter and prolonged collective struggles have defeated a system of inequality. In South Africa, the anti-apartheid struggle gave way to a Truth and Reconciliation process. Intergroup theorists have much to learn from this kind of process, and we agree with Wright \& Bitacola that the value of interventions may be a matter of timing.

On the other hand, to argue that collective action is essential to overcoming inequality is not to argue that any form of collective action will do or that collective action will always be successful. That would be far too stringent a test for any intervention to pass. Commentators are therefore right to note that the ability of protest to undermine institutional inequalities is contingent on a range of factors, including the material and communicative resources available to protesting groups and their capacity to form effective coalitions and third-party alliances. We also acknowledge that collective action may have unintended negative consequences (e.g., Abrams et al.; Brown; N. Haslam; Schaller \& Neuberg), including an upsurge in the violence faced by the disadvantaged - and that therefore it is indeed irresponsible to advocate revolt when the conditions are not ripe. Yet the lesson here for us is not to abandon collective action, but rather to develop our analyses of when and how people can be mobilised to act together, how they can build alliances and win third parties to their side, how (in other words) we can better understand the conditions under which collective action succeeds. To this end, we draw on a wealth of evidence that shows the value of collective action in transforming unequal relations between groups, only a fraction of which was discussed in our target article. Indeed, the extensive psychological literature on social identity and collective action - a literature to which some of our most trenchant critics have contributed - is premised on the assumption that, where group members are in a subordinated social position, social change occurs precisely to the extent that they act together as group members and directly challenge the dominant group (Tajfel \& Turner 1979).

This brings us to a related point, which concerns the relationship between collective action and social categorization. We disagree with $\mathbf{N}$. Haslam's point that collective action tends to "essentialize" human categories, encouraging us to treat particular social divisions in society as pre-given, natural, or inevitable. To the contrary, by disrupting the institutional structures that entrench and reify categories (e.g., structures of segregation), it often has precisely the opposite effect! It reveals the contingent, historical specific, and fluid nature of our social identities and relationships. It also enables the realignment of established ways of constructing such identities and relationships. To use more everyday terms, constructions of "us" and "them" are often profoundly altered as collective action unfolds, a point emphasized by Drury.

In sum, our argument is not about the attempt to change hostile attitudes in itself. Rather, it is about the means by which fundamental changes to inequality come about. To repeat, the issue is about models of social change. Everything else is secondary. We are not arguing that contemporary prejudice is primarily benevolent rather than hostile. We are not arguing per se against contact between social groups or denying that prejudice reduction interventions can have beneficial consequences under some conditions. What we are suggesting is that the way to reduce inequality is not to get people to like each other but to get them to mobilise collectively against the structures of inequality. This, if nothing else, is the point to retain. On this our position stands or falls. But that is not the end of the matter. Once this point is acknowledged, we can then go back and ask how intergroup hostility or benevolence contribute to (or stifle) collective mobilization. We can reexamine prejudice reduction interventions (e.g., intergroup contact) from the perspective of how they affect our readiness to acknowledge and challenge social inequality and to participate in collective action (and not simply how they affect our liking of other groups). Indeed, that is precisely what we do over the course of the following sections.

\section{R3: "Let them eat harmony?" The limits of "prejudice" and "prejudice reduction" revisited}

Our critique of the Prejudice Reduction Model of social change was based in part on the claim that prejudice reduction can have ironic effects on the political attitudes of the historically disadvantaged. In promoting warmer feelings and thoughts about the historically advantaged, we argued, such interventions may also decrease the disadvantaged's support for policies designed to combat inequality, acknowledgement of institutional discrimination, and willingness to engage in collective action to transform social inequalities. As one of the original reviewers of our target article pointed out, however, empirical evidence to support this claim remains comparatively sparse. Moreover, the contextual boundary conditions for these "ironic" effects are poorly understood, and theoretical explanations of how and why they occur remain underspecified. Several commentaries on our target article have begun to address these gaps.

Eagly \& Diekman at once support and qualify our core argument. They agree that it is insufficient to equate prejudice with negative attitudes precisely because discrimination is sometimes grounded in seemingly positive attributions about other groups (e.g., women are more socially sensitive than men). They agree, too, that standard prejudice reduction interventions may be ineffective in challenging institutionalised patterns of discrimination; indeed, in some settings, it may sometimes be more effective to foster less positive attributions about groups such as women and senior citizens (e.g., attributions of ambition, 
aggression). However, Eagly \& Diekman also argue that many researchers, including ourselves, commonly fail to recognise that it is context specific rather than abstract evaluations that are most critical in sustaining discrimination. For example, whereas women's social sensitivity may be a quality that contributes to their generally positive evaluation by men, it may carry costs in contexts where normative role requirements specifically valorise other qualities (e.g., corporate executive), leading to discrimination and exclusion.

Related to this, Eagly \& Diekman hold that the key to political change lies in widening the access of disadvantaged groups to desirable and powerful social roles (or, presumably, in redefining role requirements so that they are no longer incongruent with the attributed qualities of disadvantaged group members). Over time, this process alters group stereotypes (e.g., the belief that women are too nice to take the hard-nosed decisions required of a corporate executive) and gradually erodes the likelihood of future discrimination. Eagly \& Diekman suggest that neither prejudice reduction nor collective action is likely to achieve this goal. The former tends to promote a general positive evaluation whilst leaving intact the context specific attitudes that underpin discrimination. The latter does not directly target access to the social roles associated with political power and economic advantage.

In our view, Eagly \& Diekman's analysis raises several important points. We accept that discrimination is often grounded in context-specific evaluations - both positive and negative - rather than in generic intergroup attitudes. We also accept that this point was somewhat neglected in our target article. However, we disagree with Eagly \& Diekman's dismissal of the value of collective action in transforming access to social roles associated with power and social advantage. In discussing how such transformation occurs, they rightly point to the role of broader historical and economic shifts in society (e.g., how World War II opened up opportunities for women to enter employment roles that were traditionally reserved for men). Yet we would argue that disadvantaged communities are not simply the passive beneficiaries (or victims) of such shifts nor, crucially, can they afford to patiently await reforms generated by those in powerful roles already. We fear this will be a very long wait indeed. Rather, under the right social conditions, the disadvantaged can and must also become active agents in the transformation of role discrimination; and collective action is often the primary mechanism through which this agency finds expression. To be sure, as Eagly \& Diekman imply, individual instances of social mobility into valued social roles may form a vanguard that eases the path for others. Equally, though, in the absence of collective action to alter the institutional structures of opportunity, such instances will all too often result in tokenism. Members of disadvantaged groups will be cast as "exceptions to the rule," and normative practices of discrimination will remain intact.

Langdridge applies our core thesis to a quite different sociopolitical process - one not anticipated by our target article - namely the process of "coming out" within the lesbian, gay, and bisexual communities. Orthodox models of "coming out," he contends, tend to propose a developmental pathway that takes as its ideal endpoint a "quiet acceptance of the wider social world" (para. 3). Whereas responses to living in a homophobic society may initially involve negative feelings such as identity confusion and anger, there is an underlying assumption that individuals should accommodate to, and become assimilated within, the wider heterosexual majority, becoming "good homosexual citizen[s]" (para. 3). In this framework, the significance of "coming out" as a political, as well as personal, event is marginalised. Members of lesbian, gay, and bisexual communities are encouraged to accept inequalities as "well-adjusted" individuals rather than challenge them as a mobilized collective.

Jost, Stern, \& Kalkstein (Jost et al.) similarly extend our argument by drawing on the insights of Systems Justification Theory. This theory was originally devised to explain how, when, and why individuals and communities adopt beliefs that legitimate inequitable political systems. Jost et al. suggest that it also challenges the mainstream psychology of prejudice. First, in line with our position, they hold that acceptance of systemic inequalities is encouraged not only by negative but also by positive and complementary stereotypes about the disadvantaged. For example, endorsement of stereotypes of the working class as "poor but happy" is related to acceptance of inequalities of class. Second, Jost et al. hold that prejudice reduction interventions may actually facilitate rather than undermine this ideological process, encouraging the disadvantaged to view the status quo as legitimate or to misattribute the causes of economic or political disadvantage to in-group failings (e.g., lack of ambition or intelligence). If the commentaries discussed in the previous section suggest that our critique of the mainstream psychology of prejudice reduction went too far, Jost et al. suggest that it did not go far enough! They contend that prejudice reduction not only has a "sedative" effect on collective action to combat social injustice, but also a "palliative" effect, assuaging a deep-seated motivation to believe that we exist in a just world where people generally get what they deserve.

We welcome Jost et al.'s commentary as an important extension of our argument, with two qualifications. First, we think it is important to be careful not to imply that the disadvantaged have a natural or inevitable inclination to support the status quo. Second and related, we agree with Howarth, Wagner, Kessi, \& Sen's (Howarth et al.'s) warning about the dangers of imputing a uniform "false consciousness" to the disadvantaged, implying that they simply "misperceive" their own situation as fairer than it "really is"-a criticism that could, with some justice, be levelled at our target article as well as at Jost et al.'s commentary. To clarify, for us the key point is that not that the disadvantaged are somehow a singular group of ill-informed or misguided "dupes" or that they have a natural tendency to accept passively the legitimacy of (unequal) social systems. Rather, we argue that the project of establishing warmer relations with the advantaged may, under certain sociopolitical circumstances, decrease the likelihood that members of particular communities will actively acknowledge and challenge inequality.

Jost et al. touch upon another more specific aspect of our argument. They cite emerging evidence that harmonious contact between the advantaged and the disadvantaged acts as a mechanism through which the system-justifying effects of prejudice reduction occur (e.g., see Cheung et al. 2011; and for related examples, see Saguy \& 
Chernyak-Hai 2012; Sengupta et al., in press). This theme is developed in other commentaries.

Maoz reflects upon a compelling tradition of research on programmes of "planned encounters" between Arab and Jewish Israelis that have sought to apply Allport's (1954) contact hypothesis within a context of long-standing (and some believe intractable) intergroup conflict. She argues that the outcomes of such programmes may be less favourable than the optimistic tone of recent work on intergroup contact might suggest. Yes, they have improved intergroup attitudes, particularly amongst Israeli Jewish participants. In seeking to implement a pleasant atmosphere of social harmony that promotes peaceful "coexistence," however, they have also sidelined or suppressed Arab concerns over continuing social injustices in Israeli society. At worst, Maoz argues, such programmes "can be viewed as intentionally perpetuating existing asymmetrical power relations by focusing on changing individual-level prejudice while ignoring the need to address collective and institutionalized bases of discrimination" (para. 6).

Both Tausch \& Becker and Wright \& Bitacola also extend our analysis of the limits of intergroup contact as mechanism for reducing prejudice and promoting social change. Tausch \& Becker highlight the need for a more complete theoretical model that can explain how and why contact has "demobilizing effects" on members of disadvantaged groups. In our target article, we suggested that such effects are partly explained by the role of contact in: (1) reducing perceptions of personal discrimination that then generalise to an intergroup level and (2) increasing positive emotional responses towards the advantaged. Building on the work of Jackman (1994) and Wright and Lubensky (2009), Tausch \& Becker posit a third theoretical mechanism, namely, the role of positive contact in perpetuating the belief that social systems are permeable and that it is therefore possible for individual members of disadvantaged groups to climb the ladder of social and economic advancement. They cite some preliminary evidence that confirms this idea, showing how a so-called "individual mobility" orientation partly mediates the relationship between intergroup contact and collective demobilization. Clearly, this line of analysis dovetails with the systems justification perspective proposed by Jost et al.

Wright \& Bitacola posit a fourth mechanism through which positive interactions between members of advantaged and disadvantaged groups may legitimate social inequalities and diminish motivations to participate in collective action. Building on Ridgeway's (2001) Status Construction Theory, they argue that such interactions may serve as an arena for the display (and situated reproduction) of wider status relations, expressed via an array of subtle cues that convey the superiority of one group over another. For example, linguistic and nonverbal markers of gender identity may subtly reinforce gender hierarchies during cross-sex conversations, a process evidenced by the extensive literature on gender and language use (e.g., Uchida 1992). Wright \& Bitacola’s commentary, then, demonstrates the need to investigate the nature of unfolding interactions between the members of advantaged and disadvantaged groups in order to understand how intergroup status and power differences are reproduced. We see this as a promising avenue for future research.

Another promising avenue might attempt to establish the conditions under which intergroup contact-and similar interventions to reduce prejudice - do not decrease the likelihood that disadvantaged group members will recognise, reject, and resist social inequalities or mobilize collectively to challenge the status quo. Tausch \& Becker argue that nature and content of intergroup communication is crucial in this regard. In interactions where advantaged group members treat social inequality as illegitimate, for example, contact may not undermine participation in collective action. Similarly, Wright \& Bitacola argue that positive feelings towards particular members of an advantaged group will undermine the collective action orientation of the disadvantaged only if such members are perceived as representative of that group. If they are perceived as a distinct subgroup or as "exceptions to the rule," then positive interactions are unlikely to exercise "ironic" effects on political attitudes.

In sum, in this section we have explored commentaries that have developed or refined the core arguments of our target article, identifying valuable directions for future research. These commentaries have further demonstrated the inadequacies of a model of social change based on getting the advantaged to like the disadvantaged more. At the same time, they have explored the boundary conditions under which intergroup contact may be commensurable with a collective action model of social change, a point that we develop in the next section. Although this line of research remains at an early stage of development, we note that commentators have cited several recent studies that did not feature in our target article (e.g., Becker \& Wright 2011; Becker et al., under review; Cheung et al. 2011). In the next section, reflecting in more detail on how this emerging paradigm of research might develop, we discuss themes that recurred across a number of commentaries.

\section{R4. Emerging themes in the psychology of prejudice, discrimination, and social change}

\section{R4.1. From prejudice to prejudices}

Reflecting on our target article, several commentators have emphasized the importance of acknowledging the multiplicity of prejudice, an idea that challenges its equation with simple antipathy (Abrams et al.; Brown; Charles, Rowland, Long, \& Yarrison [Charles et al.]; Schaller \& Neuberg; Seger \& Corr). Our affective responses to others, they argue, are marked by complexity and variation, and "prejudice" towards different out-groups typically features different signature emotions and associated stereotypes. As Harrell \& Medford elegantly put it, "prejudices are better represented as a mosaic" (intro.) than as a unitary response. In America, for example, prejudice towards gay people is dominated by disgust reactions, whereas prejudice towards African Americans is dominated by fear reactions (Schaller \& Neuberg). In Britain, prejudice towards the disabled is dominated by the emotion of pity, whereas prejudice towards Muslims is dominated by reactions of anger (Abrams et al.). Crucially, these variations may be associated with different patterns of discrimination that carry may different implications for social change. Disgust primarily engenders practices of purification and withdrawal: anger, pity, and fear engender other discriminatory practices. Complicating matters further, "extreme emotions" (Feddes, Mann, \& Doosje 
[Feddes et al.]) may carry different implications for understanding and changing discrimination than moderate emotions.

Accounting for the complexity of prejudice, Mackie et al. (2008) have developed an influential model based around understanding the interrelations between social categorization, social identification, and appraisals of intergroup threat. This model would seem to fit with the theoretical commitments of Brown and Abrams et al. Schaller \& Neuberg sketch an alternative model based around the role of distal evolutionary processes in shaping current intergroup attitudes (see also Madison \& Ullén). Specifically, they argue that automatic, genetically inherited, "stimulus-response" reactions are evoked by out-groups that pose specific kinds of threats to the reproductive fitness of in-group members. The controversial question of whether or not such threats are accurate - in an evolutionary sense - is raised explicitly by Madison \& Ullén and is implicit in Schaller \& Neuberg's commentary.

We see this proposed shift towards a more variegated conception of prejudice as broadly consistent with the argument offered in our target article. However, we wish to add a few further reflections on how it might be best accomplished. First, researchers should recognise that positive and ambivalent, as well as negative, reactions can sustain practices and institutions of discrimination. As the examples used by our commentators illustrate, even work that has advocated a shift from "prejudice to prejudices" has continued to prioritize negative reactions to others (notably fear, anger, and disgust). Second, and equally important, the complexity of reactions of the disadvantaged towards the advantaged requires far greater attention from researchers. Emotional variation and nuance is not a oneway street. Third, though not discounting the role of distal evolutionary dynamics, we would focus attention on the role of intergroup attitudes in maintaining more proximal relations of social inequality. As we have emphasized throughout this debate, such attitudes are often delicately attuned to the business of legitimating, maintaining, or challenging the status quo. Of course, Wright \& Bitacola are quite correct to observe that this conceptual expansion may ultimately stretch the notion of prejudice to the point where it ceases to maintain its specificity. We also acknowledge S. Haslam \& Reynold's point that what counts as prejudice for ordinary people is often relative to their social identities and perspectives. One group's righteous anger is another's unwarranted contempt, and it is revealing that prejudice is more readily attributed to the outgroup than to the in-group.

\section{R4.2. A relational perspective on intergroup attitudes}

In our target article, we suggested that the literature on prejudice has focused mostly on how members of dominant groups respond to members of subordinate groups. That is, the problem of downwards antipathy has dominated the field. As such, the attitudes of subordinate group members have often fallen outside of the main spotlight of empirical and theoretical inquiry. Yet relationships of discrimination and inequality are just that-they are relationships. Recognition of this fact is critical to understanding how they operate and what can be done to combat them.
Several commentators have developed our plea for a relational perspective on intergroup prejudice and discrimination. Prentice \& Shelton and Waldzus, Schubert, \& Paladino (Waldzus et al.) tackle this theme most directly (though we note that other commentators have also broached it in intriguing ways; e.g., Charles et al.; Navarrete \& McDonald). Prentice \& Shelton draw an analogy between intergroup processes and family dynamics. Just as we cannot understand the attitudes of individual family members outside of the complex totality of family relations, they argue, so we cannot understand the attitudes of group members outside of the complex totality of intergroup relations. They thus commend our target article for highlighting how paternalistic prejudices express a holistic relationship in which both advantaged and disadvantaged groups participate. They also commend it for highlighting how attempts to reduce dominant group bigotry may also alter the attitudes of the disadvantaged, as well as the overall pattern of intergroup relations.

At the same time, Prentice \& Shelton criticise our article for not following through on this relational perspective. By advocating collective action by the disadvantaged as the primary engine of political transformation, they suggest, we forget that true social change always involves joint participation. In order to develop a truly relational model of change, they propose that researchers need to: (1) uncover the motivations and beliefs of all parties involved in an inequitable relationship; (2) explore the structural features (e.g., access to particular resources and social roles) that help to create or reproduce specific forms of inequality between them; (3) appreciate that relationships evolve over time and that different perceptions of this process may shape reactions to social change; and (4) recognise the importance of wider societal shifts in structuring change. With regards to the latter, Paluck rightly emphasises the importance of "top-down" normative and institutional shifts in transforming intergroup attitudes and relationships and warns of the dangers of individualizing the determinants of change.

Waldzus et al. similarly advocate a perspective that addresses how members of both disadvantaged and advantaged groups understand their evolving relationships. Specifically, they offer a taxonomy of relational structures that underpin intergroup relations, namely, communal sharing, authority ranking, equality matching, and market pricing. The nature of these relational structures and how they connect to social change are sketched in their thought-provoking commentary. For us, its overall spirit is what is worth emphasizing here:

Investigating relational cognition will enable us to describe and predict psychological processes at work in the interaction between disadvantaged and advantaged groups. Such research can provide involved individuals and groups with conceptual tools to understand their own and others' actions and motivations - and to change their relationships by prejudice reduction, collective action, or otherwise (para. 11).

We agree with many of Prentice \& Shelton's and Waldzus et al.'s main points. Although their analogy between intergroup relations and family dynamics is rather strained, we accept the validity of the Prentice \& Shelton's overall argument. Inequality is indeed a relationship. We cannot hope to challenge it without recognizing this fact. Likewise, we accept that Waldzus et al.'s 
"Relational Models Theory" has the potential to enrich our understanding of political change and look forward to reading their forthcoming manuscript on this topic (Waldzus \& Fiske, in preparation). Finally, we accept that our target article did not discuss the relational implications of different models of social change clearly enough, particularly with regards to the collective action perspective (see also Abrams et al.; Brown; N. Haslam; Schaller \& Neuberg). We revisit this theme, amongst others, in the final section of our article, where we reconsider the relationship between prejudice reduction and collective action models of change.

\section{R4.3. Collective action, intergroup contact, and social change revisited}

The process of reading, discussing, and responding to this rich set of commentaries has helped us to develop our own perspective. It has moved us beyond our original argument-basically an attempt to explore the limits of mainstream work on prejudice and to make space for a collective action approach to challenging inequalitytowards a positive agenda for advancing future research. We are now in a position to advocate a new line of work; that is, to consider how the promotion of intergroup contact might impact positively upon the likelihood and the effectiveness of collective action (e.g., see also Tausch \& Becker; Wright \& Bitacola). We suggest that this topic can be broken down into three specific areas for enquiry.

First, who is in contact with whom? Traditional contact research presupposes a focus on dominant group members' contact with subordinate group members. In a collective action approach, this process may remain important. However, there are other equally (if not more) important possibilities. To begin with, contact between different minorities may be essential to create solidarity based on the recognition of a shared oppression (see also Drury; Wright \& Bitacola). Work on collective movements, for example, has shown that the realisation of common treatment at the hands of the police creates unity between different groups of protestors and may even encourage solidarity with other, uninvolved groups who are seen to suffer similar mistreatment (e.g., Drury \& Reicher 2009). Another possibility is contact between different subgroups within the majority. This form of contact, for example, may undermine the belief that those who are critical of institutional discrimination are traitorous or irrational. A final possibility is contact between minorities and third parties (see also Waldzus et al.). This form of contact may enable, for example, the formation of strategic alliances through which movements of the powerless can overcome their more powerful opponents.

Second, why does contact matter? The shift from a prejudice reduction to a collective action model has obvious implications in terms of the outcomes we investigate. Rather than measuring changes in (negative) thoughts and feelings, the focus shifts to support for collective action (and associated variables such as perceptions of injustice, stratification beliefs, and support for policies of redress). However, such action may take different forms, depending on whether one is considering subordinate groups, dominant groups, or third parties. For subordinate groups, the principal concern is with action to challenge directly intergroup inequality (and, to take on board Eagly \& Diekman's point, action that targets specific role exclusions). For dominant groups, sympathy with or even participation in such actions is also important. Yet equally important is action to counter in-group resistance to social change or to mobilise in-group values and norms in ways that de-legitimate inequality and fragment the political unity of the in-group (e.g., the use of the U.S. Constitution to challenge southern segregation in the United States). Here - as in the case of third-party alliances - an understanding of history is essential to appreciating the different ways in which people can mobilise against oppression, a point that resonates with Harrell \& Medford's commentary.

Finally, how and when does contact work? This, in many ways, is the most critical issue and one to which several commentaries have devoted attention (e.g., Hewstone et al.; Tausch \& Becker; Wright \& Bitacola). How does contact impact on collective action and hence what forms of contact are most likely to promote (or "sedate") it? The key point here is that the types of contact that increase collective action tendencies are likely to be very different from those that increase liking. Hence, our argument is not against contact but for different types of contact. In particular, some of Allport's (1954) classic optimal conditions for contact are decidedly suboptimal when it comes to promoting collective action. Indeed, this is precisely what Ifat Maoz and others have demonstrated so powerfully in their work on the Palestinian case (e.g., Maoz 2011). In a nutshell, there are times when being confrontational, highlighting the inequality between groups, and addressing uncomfortable issues of the illegitimacy of certain dominant group practices can serve to mobilise both subordinate and dominant group members for change. One of our tasks - and we see this as a collective enterprise in which others will want to be involved - is to specify the conditions under which intergroup contact will promote collective action most effectively. Of course, we concede that such conditions may vary as a function of the nature of contact (minority-majority, minority-minority, majority-majority, or minority-third-party), as well as the broader sociopolitical context in which social change is unfolding.

What should be clear, then, is that far from rejecting the study of intergroup contact, we want to open up new avenues of research. One such avenue might seek to integrate work on contact with a collective action approach to social change that goes beyond the reduction of prejudice. Another might seek to reevaluate the efficacy of collective action and prejudice reduction strategies at different phases of development of intergroup relations (from when inequality is assailed to when it has been overcome). We also hope that other productive lines of research are stimulated by this dialogue, which has raised so many important directions for the psychology of prejudice, some of which we have not had space to discuss in this brief response (e.g., see Killen, Mulvey, Hitti, \& Rutland [Killen et al.] on the importance of studying developmental processes and Vigil \& Venner on the role of "normative homophily" in discrimination).

Whether our perspective "signals a change in thinking about the 'nature of prejudice' that may turn out to be as significant as the identification of unconscious components of prejudicial attitudes" (Harrell \& Medford, intro.) 
remains to be seen. As we wrote this piece, a colleague somewhat cynically observed that debate is rare in psychology, but even rarer is debate that makes any difference. Usually what happens is that protagonists simply become more deeply entrenched in their existing positions. We hope not. We hope that both commentators and readers will appreciate how our position has evolved through the process of reading and responding to the commentaries. In turn, we hope that they will be as enthusiastic as us in pursuing the agenda we have outlined. That is, we hope that the overall process will move us all forward in understanding what remains, regrettably, the most pressing issue of our time: How can we reduce inequalities between groups?

\section{References}

[The letters " $a$ " and " $r$ " before author's initials stand for target article and response references, respectively]

Abrams, D. (2010) Processes of prejudice: Theory, evidence and intervention. Equality and Human Rights Commission. Research Report 56. EHRC. Retrieved from http://www.equalityhumanrights.com/uploaded_files/research/ 56_processes_of_prejudice.pdf. [DA]

Abrams, D. \& Grant, P. R. (2011) Testing the social identity relative deprivation (SIRD) model of social change: The political rise of Scottish nationalism. British Journal of Social Psychology. DOI: 10.1111/j.2044-8309.2011.02032.x. [DA]

Abrams, D. \& Hogg, M. A. (2004) Metatheory: Lessons from social identity research. Personality and Social Psychology Review 8:98-106. DOI: 10.1207/ s15327957pspr0802_2. [DA]

Abrams, D. \& Houston, D. M. (2006) Equality, diversity and prejudice in Britain: Results from the 2005 national survey. The Equalities Review. Cabinet Office. Retrieved from http://webarchive.nationalarchives.gov.uk/20100807034701/ http://archive.cabinetoffice.gov.uk/equalitiesreview/upload/assets/www.theequalitiesreview.org.uk/kentequality.pdf. [DA]

Abrams, D. \& Rutland, A. (2008) The development of subjective group dynamics. In: Intergroup relations and attitudes in childhood through adulthood, ed. S. R. Levy \& M. Killen, pp. 47-65. Oxford University Press. [MK]

Abrams, D., Viki, G. T. \& Masser, B. \& Bohner, G. (2003) Perceptions of stranger and acquaintance rape: The role of benevolent and hostile sexism in victim blame and rape proclivity. Journal of Personality and Social Psychology 84:11125. [aJD]

Abu-Nimer, M. (1999) Dialogue, conflict resolution and change: Arab-Jewish encounters in Israel. State University of New York Press. [IM]

Ackerman, P. \& Kruegler, C. (1994) Strategic nonviolent conflict: The dynamics of people power in the twentieth century. Praeger. [aJD]

Adorno, T. W., Frenkel-Brunswik, E., Levinson, D. J. \& Sanford, R. N. (1950) The authoritarian personality. Harper. [aJD]

Allport, G. W. (1951) Prejudice: A problem in social causation. Journal of Social Issues 6:4-23. [a]D]

Allport, G. (1954) The nature of prejudice. Addison-Wesley. [MB, RB, arJD, JTJ, IM, ELP]

Allport, G. W. \& Kramer, B. M. (1946) Some roots of prejudice. Journal of Psychology 22:9-39. [aJD]

Altemeyer, B. (1988a) Enemies of freedom: Understanding right-wing authoritarianism. Jossey-Bass. $\quad[\mathrm{CS}]$

Altemeyer, B. (1998b) The other "authoritarian personality." In: Advances in experimental social psychology, vol. 30, ed. M. P. Zanna, pp. 47-92. Academic Press. [CS $]$

Anderson, L. R., Mellor, J. M., \& Milyo, J. (2008) Inequality and public good provision: An experimental analysis. The Journal of Social Economics 37:101028. [JMV]

Aronson, E. \& Patnoe, S. (1997) The jigsaw classroom: Building cooperation in the classroom, 2nd ed. Longman. [aJD]

Ashburn-Nardo, L., Knowles, M. L. \& Monteith, M. J. (2003) Black Americans implicit racial associations and their implications for inter-group judgment. Social Cognition 21:61-87. [JTJ]

Austen-Smith, D. \& Fryer, R. (2005) An economic analysis of acting white. Quarterly Journal of Economics 120:551-83. [CDN]

Badgett, M. V. L., Donnelly, C. \& Kibbe. J. (1992) Pervasive patterns of discrimination against lesbians and gay men: Evidence from surveys across the United States. National Gay and Lesbian Task Force Policy Institute. [DL]
Bandura, A. (1999) Moral disengagement in the preparation of inhumanities. Personality and Social Psychology Review 3:193-209. [MB]

Barlow, F. K., Sibley, C. G. \& Hornsey, M. J. (2012) Rejection as a call to arms: Interracial hostility and support for political action as outcomes of race-based rejection in majority and minority groups. British Journal of Social Psychology 51(1):167-77. DOI: 10.1111/j.2044-8309.2011.02040.x. [aJD]

Barreto, M. \& Ellemers, N. (2005) The burden of benevolent sexism: How it contributes to the maintenance of gender inequalities. European Journal of Social Psychology 35:633-42. [aJD]

Bar-Tal, D. (2004) The necessity of observing real life situations: Palestinian-Israeli violence as a laboratory for learning about social behaviour. European Journal of Social Psychology 34:677-701. [ARF]

Bar-Tal, D. (2007) Sociopsychological foundations of intractable conflicts. American Behavioral Scientist 50:1430-53. DOI: 10.1177/ 0002764207302462 . [DA]

Bastian, B. \& Haslam, N. (2008) Immigration from the perspective of hosts and immigrants: The roles of psychological essentialism and social identity. Asian Journal of Social Psychology 11:127-40. [NH]

BBC (2001, Sept.) Bin Laden's warning: Full text. Retrieved from http://news.bbc.co. uk/2/hi/south_asia/1585636.stm. [ARF]

Becker, G. (1957) The economics of discrimination. University of Chicago Press. $[\mathrm{CDN}]$

Becker, J. C. \& Wright, S. C. (2011) Yet another dark side of chivalry: Benevolent sexism undermines and hostile sexism motivates collective action for social change. Journal of Personality and Social Psychology 101:62-77. [rJD, JTJ, NT]

Becker, J. C., Wright, S. C., Lubensky, M. E. \& Zhou, S. (under review) Friend or ally: Whether cross-group contact undermines collective action depends what advantaged group members say (or don't say). [rJD, NT]

Bekerman, Z. (2007) Rethinking intergroup encounters: Rescuing praxis from theory, activity from education, and peace/co-existence from identity and culture. Peace Education 4(1):29-41. [IM]

Biko, S. (1978) I write what I like. Bowerdean. [CH]

Bilewicz, M. \& Krzemiński, I. (2010) Anti-Semitism in Poland and Ukraine: The belief in Jewish control as a mechanism of scapegoating. International Journal of Conflict and Violence 4 234-43. [MB]

Bilewicz, M. \& Vollhardt, J. R. (2012) Evil transformations: Psychological processes underlying genocide and mass killing. In: Social psychology of social problems. The intergroup context, ed. A. Golec De Zavala \& A. Cichocka, pp. 280-307. Palgrave Macmillan. [MB]

Bilewicz, M., Winiewski, M., Kofta, M. \& Wojcik, A. (in press) Harmful ideas. The structure and consequences of anti-Semitic beliefs in Poland. Political Psychology. $[\mathrm{MB}]$

Billig, M. (1988) The notion of "prejudice": Some rhetorical and ideological aspects. Text 8:91-111. [aJD]

Blackburn, R. (2011) The overthrow of colonial slavery 1776-1848. Verso. [aJD]

Blanchard, F. A., Crandall, C. S., Brigham, J. C. \& Vaughn, L. A. (1994) Condemning and condoning racism: A social context approach to interracial settings. Journal of Applied Psychology 79:993-97. [ELP]

Blumer, H. (1958) Race prejudice as a sense of group position. Pacific Sociological Review 1:3-7. [aJD]

Bobo, L. \& Kluegel, J. R. (1993) Opposition to race-targeting: Self-interest, stratification ideology or racial attitudes? American Sociological Review 58:443-64. [aJD]

Bobo, L., Kluegel, J. R. \& Smith, R. A. (1997) Laissez-faire racism: The crystallization of a kinder, gentler, antiblack ideology. In: Racial attitudes in the 1990s: Continuity and change, ed. S. A. Tuch \& J. K. Martin, pp. 15-42. Praeger Publishers. [aJD]

Boccato, G., Cortes, B. P., Demoulin, S. \& Leyens, J. Ph. (2007) The automaticity of dehumanization. European Journal of Social Psychology 37:987-99. [aJD]

Bonilla-Silva, E. (2001) White supremacy and racism in the post-civil rights era. Lynne Rienner Publishers. [JPH]

Bonilla-Silva, E. (2006) Racism without racists: Color-blind racism and the persistence of racial inequality in the United States. Rowman and Littlefield Publishers, Inc. [JPH]

Bourdieu, P. (2000) The weight of the world-Social suffering in contemporary society. Stanford University Press. [CH]

Brewer, M. B. (1997) The social psychology of intergroup relations: Can research inform practice? Journal of Social Issues 53:197-211. [aJD]

Brewer, M. B. \& Miller, N. (1984) Beyond the contact hypothesis: Theoretical perspectives on desegregation. In: Groups in contact: The psychology of desegregation, ed. N. Miller \& M. B. Brewer, pp. 281-302, Academic Press. [RB, aJD]

Brown, C. L. (2006) Moral capital: Foundations of British abolitionism. University of North Carolina Press. [aJD]

Brown, R. (1995) Prejudice: Its social psychology. Basil Blackwell. [aJD]

Brown, R. (2010) Prejudice: Its social psychology, 2nd ed. Wiley-Blackwell. [RB]

Brown, R. \& Hewstone, M. (2005) An integrative theory of intergroup contact. In: Advances in experimental social psychology, vol. 37, ed. M. P. Zanna, pp. 255343. Elsevier Academic Press. [DA, RB, aJD, MH] 
Brown, R., Gonzalez, R., Zagefka, H., Manzi, J. \& Čehajić, S. (2008) Nuestra culpa: Collective guilt and shame as predictors of reparation for historical wrongdoing. Journal of Personality and Social Psychology 94:75-90. [RB]

Burgess, D. J. Warren, J, Phelan, S., Davidio, J. \& van Ryn, M. (2010) Stereotype threat and health disparities: What medical educators and future physicians need to know. Journal of General Internal Medicine 25(Suppl 2):169-77. [JMV]

Cakal, H., Hewstone, M., Schwär, G. \& Heath, A. (2011) An investigation of the social identity model of collective action and the "sedative" effect of intergroup contact among Black and White students in South Africa. British Journal of Social Psychology 50:606-27. [aJD]

Calogero, R. M. \& Jost, J. T. (2011) Self-subjugation among women: Exposure to sexist ideology, self-objectification, and the protective function of the need to avoid closure. Journal of Personality and Social Psychology 100:211-28. [JTJ]

Cameron, L. \& Rutland, A. (2006) Extended contact through story reading in school: Reducing children's prejudice toward the disabled. Journal of Social Issues 62:469-88. [ELP]

Camus, A. (1955/1961) Homage to an exile. In: Camus, A. Resistance, rebellion, death. trans. J. O’Brien, p. 101. Alfred A. Knopf. [aJD]

Cass, V. (1979) Homosexual identity formation: A theoretical model. Journal of Homosexuality 4:210-35. [DL]

Cass, V. (1984) Homosexual identity formation: Testing a theoretical model. The Journal of Sex Research 20:143-67. [DL]

Cehajic, S., Brown, R. J. \& Castano, E. (2008) Forgive and forget: Antecedents and consequences of intergroup forgiveness in Bosnia and Herzegovina. Political Psychology 29:351-67. [NH]

Chapleau, K. M., Oswald, D. L. \& Russell, B. L. (2007) How ambivalent sexism towards women and men supports rape myth acceptance. Sex Roles 57:13136. [aJD]

Chaplin, R., Flatley, J. \& Smith, K. (2011) Crime in England and Wales: Findings from the British Crime Survey and police recorded crime, 2nd ed. The Home Office. $[\mathrm{RB}]$

Cheung, R. M., Noel, S. \& Hardin, C. D. (2011) Adopting the system-justifying attitudes of others: Effects of trivial interpersonal connections in the context of social inclusion and exclusion. Social Cognition 29:255-69. [rJD, JTJ]

Chowkwanyun, M. (2011) The strange disappearance of history from health disparities research. Du Bois Review Social Science Research on Race 8:253-70. [JPH]

Cohen, G. L., Garcia, J., Apfel, N., \& Master, A. (2006) Reducing the racial achievement gap: A social-psychological intervention. Science 313:1307-10. [JMV]

Cohrs, J. C. \& Asbrock, F. (2009) Right-wing authoritarianism, social dominance orientation, and prejudice against threatening and competitive ethnic groups. European Journal of Social Psychology 39:270-89. [CS]

Coleman, E. (1981/1982) Developmental stages of the coming out process. Journal of Homosexuality 7:43. [DL]

Corr, P. J., ed. (2008) The reinforcement sensitivity theory of personality. Cambridge University Press. [CS]

Corr, P. J., ed. (2009) The reinforcement sensitivity theory of personality. In: The Cambridge handbook of personality psychology, ed. P. J. Corr and G. Matthews, pp. 347-76. Cambridge University Press. Retrieved from http://www.ueapsychology.net/uploads/downloads/15.pdf. [CS]

Corr, P. J., Hargreaves-Heap, S., Russell, A. \& Seger, C. R. (2012) Prejudice and personality: The role of basic motivational states and processes. Unpublished manuscript. [CS]

Cottrell, C. A. \& Neuberg, S. L. (2005) Differential emotional reactions to different groups: A sociofunctional threat-based approach to "prejudice." Journal of Personality and Social Psychology 88:770-89. [aJD]

Cottrell, C. A. \& Neuberg, S. L. (2005) Different emotional reactions to different groups: A sociofunctional threat-based approach to "prejudice." Journal of Personality and Social Psychology 88:770-89. [RB, MS]

Cottrell, C. A., Richards, D. A. R. \& Nichols, A. L. (2010) Predicting policy attitudes from general prejudice versus specific intergroup emotions. Journal of Experimental Social Psychology 46:247-54. [MS]

Coulter, J., Miller, S. \& Walker, M. (1984) State of siege: Politics and policing of the coalfields: The miners' strike 1984. Canary. [JD]

Craig, M. A. \& Richeson, J. A. (2012) Coalition or derogation? How perceived discrimination influences intra-minority relations. Journal of Personality and Social Psychology 102(4):759-77. [aJD]

Crandall, C. S., Eshleman, A. \& O'Brien, L. T. (2002) Social norms and the expression and suppression of prejudice: The struggle for internalization. Journal of Personality and Social Psychology 82:359-78. [MB]

Crandall, C. S. \& Stangor, C. (2005) Conformity and prejudice. In: On the nature of prejudice: Fifty years after Allport, ed. J. F. Dovidio, P. Glick \& L. A. Rudman, pp. 295-309. Blackwell. [ELP]

Crisp, R. J. \& Hewstone, M. (1999) Differential evaluation of crossed category groups: Patterns, processes, and reducing intergroup bias. Group Processes and Intergroup Relations 2:307-33. [aJD]

Crisp, R. J. \& Hewstone, M. (2007) Multiple social categorization. In: Advances in experimental social psychology, vol. 39, ed. M. P. Zanna, pp. 163-254,
Academic Press. Retrieved from http://dx.doi.org/10.1016/S0065-2601(06) 39004-1. [DA]

Crisp, R. J. \& Turner, R. N. (2011) Cognitive adaptation to the experience of social and cultural diversity. Psychological Bulletin 137:242-66. DOI: 10.1037/ a0021840. [DA]

Crosby, F. (1976) A model of egoistical relative deprivation. Psychological Review 83:85-113. [DAP]

Crystal, D., Killen, M. \& Ruck, M. (2008) It's who you know that counts: Intergroup contact and judgments about race-based exclusion. British Journal of Developmental Psychology 26:51-70. [MK]

Cuddy, A. J. C., Fiske, S. T. \& Glick, P. (2008) Warmth and competence as universal dimensions of social perception: The stereotype content model and the BIAS map. In: Advances in experimental social psychology, ed. M. P. Zanna, vol. 40 pp. 61-149. Academic Press. [aJD]

De Tezanos Pinto, P., Bratt, C. \& Brown, R. (2010) What will the others think? Ingroup norms as a mediator of the effects of intergroup contact. British Journal of Social Psychology 49:507-23. [RB]

De Wolf, A. \& Doosje, B. (2010) Aanpak van radicalisme: Een psychologische analyse [Dealing with radicalization: A psychological analysis]. SWP. [ARF]

Derks, B., Van Laar, C., Ellemers, N. \& De Groot, K. (2011) Gender bias primes elicit queen bee responses among senior police women. Psychological Science 22:1243-49. [NT]

Diekman, A. B., Eagly, A. H. \& Johnston, A. M. (2010) Social structure. In: The Sage handbook of prejudice, stereotyping, and discrimination, ed. J. F. Dovidio, M. Hewstone, P. Glick \& V. M. Esses, pp. 209-24. Sage. [AHE]

Diekman, A. B. \& Hirnisey, L. (2007) The effect of context on the silver ceiling: A role congruity perspective on prejudiced responses. Personality and Social Psychology Bulletin 33:1353-66. [AHE]

Dion, K. L. (2002) The social psychology of perceived prejudice and discrimination. Canadian Psychology 4:1-10. [aJD]

Dixon, J., Durrheim, K. \& Tredoux, C. (2005) Beyond the optimal strategy: A "reality check" for the contact hypothesis. American Psychologist 60(7):697-711. [IM]

Dixon, J., Durrheim, K. \& Tredoux, C. (2007) Intergroup contact and attitudes towards the principle and practice of racial equality. Psychological Science 18:867-72. [aJD, IM]

Dixon, J., Durrheim, K., Tredoux, C., Tropp, L. R., Clack, B. \& Eaton, E. (2010a) A paradox of integration? Interracial contact, prejudice reduction and black South Africans' perceptions of racial discrimination. Journal of Social Issues 66:40116. [aJD, NT]

Dixon, J., Durrheim, K., Tredoux, C. G., Tropp, L. R., Clack, B., Eaton, L. \& Quayle, M. (2010b) Challenging the stubborn core of opposition to equality: Racial contact and policy attitudes. Political Psychology 31:831-56. [aJD]

Dixon, J., Tropp, L. R., Durrheim, K. \& Tredoux, C. G. (2010c) "Let them eat harmony": Prejudice reduction and the political attitudes of historically disadvantaged groups. Current Directions in Psychological Science 19:76-80. [aJD]

Doise, W. (1998) Social psychology and human rights. European Review 6:341-47. DOI: $10.1017 / \mathrm{S} 1062798700003380 . \quad$ [DA]

Dollard, J., Doob, L., Miller, N. E., Mowrer, O. \& Sears, R. (1939) Frustration and aggression. Yale University Press. [aJD]

Doosje, B., Branscombe, N. R., Spears, R. \& Manstead, A. S. R. (1998) Guilty by association: When one's group has a negative history. Journal of Personality and Social Psychology 75:872-86. [ARF]

Dovidio, J. F. (2001) On the nature of contemporary prejudice: The third wave. Journal of Social Issues 57:829-49. [aJD]

Dovidio, J. F. \& Gaertner, S. L. (2004) Aversive racism. In: Advances in experimental social psychology, ed. M. P. Zanna, vol. 36, pp. 1-52. Academic Press. [aJD]

Dovidio, J. F., Brigham, J. C., Johnson, B. T. \& Gaertner, S. L. (1996) Stereotyping, prejudice, and discrimination: Another look. In: Stereotypes and stereotyping, ed. C. N. Macrae, C. Stangor \& M. Hewstone, pp. 276-319. Guilford Press. [MB]

Dovidio, J. F., Gaertner, S. L. \& Saguy, T. (2008) Another view of "we": Majority and minority group perspectives on a common ingroup identity. European Review of Social Psychology 18:296-330. [aJD]

Dovidio, J. F., Gaertner, S. L. \& Saguy, T. (2009) Commonality and the complexity of "we": Social attitudes and social change. Personality and Social Psychology Review 13:3-20. [aJD, JTJ]

Dovidio, J. F., Gaertner, S. L., Shnabel, N., Saguy, T. \& Johnson, J. D. (2010) Recategorization and prosocial behavior: Common identity and a dual identity. In: The psychology of pro-social behavior, ed. S. Stürmer \& M. Snyder, pp. 191-208. Wiley-Blackwell. [aJD]

Dovidio, J. F., Glick, P. \& Rudman, L. A. eds. (2005) On the nature of prejudice: Fifty years after Allport. Blackwell. [aJD]

Drescher, S. \& Emmer, P. C. (2010) Who abolished slavery?: Slave revolts and abolitionism. Berghahn Books. [aJD]

Drury, J. \& Reicher, S. (2000) Collective action and psychological change: The emergence of new social identities. British Journal of Social Psychology 39:579-604. [JD] 
Drury, J. \& Reicher, S. (2005) Explaining enduring empowerment: A comparative study of collective action and psychological outcomes. European Journal of Social Psychology 35:35-58. [JD]

Drury, J. \& Reicher, S. (2009) Collective psychological empowerment as a model of social change: Researching crowds and power. Journal of Social Issues 65: 707-25. DOI: 10.1111/j.1540-4560.2009.01622.x. [arJD, JD]

Drury, J., Reicher, S. \& Stott, C. (2003) Transforming the boundaries of collective identity: From the "local" anti-road campaign to "global" resistance? Social Movement Studies 2:191-212. DOI: 10.1080/1474283032000139779. [JD]

Du Bois, W. E. B. (1935) Black reconstruction in America 1860-1880. Harcourt Brace. $[\mathrm{JPH}]$

Duckitt, J. (1992) The social psychology of prejudice. Westport. [aJD]

Duncan, L. E. (1999) Motivation for collective action: Group consciousness as a mediator of personality, life experiences, and women's rights activism. Political Psychology 20:611-35. [CS]

Dunham, Y., Baron, A. S. \& Carey, S. (2011) Consequences of "minimal" group affiliations in children. Child Development 82:793-811. DOI: 10.1111/j.1467-8624.2011.01577.x. [MK]

Eagly, A. (2004) Prejudice: Towards a more inclusive definition. In: The social psychology of group identity and social conflict: Theory, application, and practice, ed. A. H. Eagly, R. M. Baron, \&. V. L. Hamilton, pp. 45-64. American Psychological Association. [aJD]

Eagly, A. H. \& Chaiken, S. (2007) The advantages of an inclusive definition of attitude. Social Cognition 25: 582-602. [AHE]

Eagly, A. H. \& Diekman, A. B. (2005) What is the problem? Prejudice as an attitude-in-context. In: On the nature of prejudice: Fifty years after Allport, ed. J. F. Dovidio, P. Glick \& L. A. Rudman, pp. 19-35. Blackwell. [AHE]

Eagly, A. H. \& Karau, S. J. (2002) Role congruity theory of prejudice toward female leaders. Psychological Review 109:573-98. [AHE]

Eagly, A. H. \& Mladinic, A. (1989) Gender stereotypes and attitudes toward women and men. Personality and Social Psychology Bulletin 15:543-58. [aJD]

Eagly, A. H. \& Mladinic, A. (1993) Are people prejudiced against women? Some answers from research on attitudes, gender stereotypes and judgments of competence. In: European review of social psychology, ed. W. Stroebe \& M. Hewstone, vol. 5, pp. 1-35. Wiley. [aJD]

Eagly, A. H. \& Wood, W. (1991) Explaining sex differences in social behavior: A meta-analytic perspective. Personality and Social Psychology Bulletin 17: 30615. [MA]

Eagly, A. H., Mladinic, A. \& Otto, S. (1991) Are women evaluated more favorably than men? An analysis of attitudes, beliefs, and emotions. Psychology of Women Quarterly 15:203-16. [AHE]

Edgell, P., Gertis, J. \& Hartmann, D. (2006) Atheists as "Other": Moral boundaries and cultural membership. American Sociological Review 71:211-34. [EPC]

EHRC (2010) How fair is Britain? Equality, human rights and good relations: The first triennial review. Equality and Human Rights Commission. Retrieved from http://www.equalityhumanrights.com/key-projects/how-fair-is-britain/. [DA]

Eibach, R. P. \& Keegan, T. (2006) Free at last? Social dominance, loss aversion, and white and black Americans' differing assessments of racial progress. Journal of Personality and Social Psychology 90:453-67. [DAP]

Eidelson, R. J. \& Eidelson, R. I. (2003) Dangerous ideas: Five beliefs that impel groups towards conflict. American Psychologist 58:182-92. [aJD]

Ekehammar, B., Akrami, N., Gylje, M. \& Zakrisson, I. (2004) What matters most to prejudice: Big five personality, social dominance orientation, or right-wing authoritarianism? European Journal of Personality 18:463-82. [CS]

Elcheroth, G., Doise, W. \& Reicher, S. (2011) On the knowledge of politics and the politics of knowledge: How a social representations approach helps us rethink the subject of political psychology. Political Psychology. 32(5):729-58. [CH]

Ellemers, N., Van Den Heuvel, H., De Gilder, D., Maass, A. \& Bonvini, A. (2004) The underrepresentation of women in science: Differential commitment or the queen bee syndrome? British Journal of Social Psychology 43:315-38. [NT]

Esses, V. M. \& Dovidio, J. F. (2002) The role of emotions in determining willingness to engage in intergroup contact. Personality and Social Psychology Bulletin 28:1202-14. [aJD]

EVS (2011) European Values Study 2008: Integrated Dataset (EVS 2008) GESIS Data Archive, Cologne. ZA4800 Data file Version 3.0.0, DOI: 10.4232/ 1.11004. [MB]

Fanon, F. (1965) The wretched of the earth. Grove Press. [aJD, CH]

Feddes, A. R., Noack, P. \& Rutland, A. (2009) Direct and extended friendship effects on minority and majority children's interethnic attitudes: A longitudinal study. Child Development 80:377-90. DOI: 10.1111/j.1467-8624.2009.01266.x. [MK]

Ferguson, E., Heckman, J. J. \& Corr, P. (2011) Personality and economics: Overview and proposed framework. Personality and Individual Differences 51:201209. [CS]

Fischer, A. H. (2011) Contempt: A hot feeling hidden under a cold jacket. In: Reconstructing emotional spaces: From experience to regulation, ed. R. Trnka, K Balcar \& M. Kuška, pp. 77-89. Prague College of Psychosocial Studies Press. $[\mathrm{ARF}]$
Fischer, A. H. \& Roseman, I. J. (2007) Beat them or ban them: The characteristics and social functions of anger and contempt. Journal of Personality and Social Psychology 93:103-15. [ARF]

Fiske, A. P. (1992) The four elementary forms of sociality: Framework for a unified theory of social relations. Psychological Review 99:689-723. [SW]

Fiske, A. P. (2004) Relational models theory 2.0. In: Relational models theory: A contemporary overview, ed. N. Haslam, pp. 3-25. Erlbaum. [SW]

Fiske, S. T. (1993) Controlling other people: The impact of power on stereotyping. American Psychologist 48:621-28. [MA]

Forbes, G. B., Jung, J. \& Haas, K. B. (2006) Benevolent sexism and cosmetic use: A replication with three college samples and one adult sample. Journal of Social Psychology 145:635-40. [aJD]

Forbes, H. D. (1997) Ethnic contact: Commerce, culture and the contact hypothesis. Yale University Press. [aJD]

Fordham, S. \& Ogbu, J. (1986) Black students school success: Coping with the burden of "acting white." Urban Review 18:176-206. [CDN]

Fox-Genovese, E. \& Genovese, E. D. (2005) The mind of the master class. Cambridge University Press. [aJD, JPH]

Franklin, J. H. (1965) The two worlds of race: A historical view. Daedelus 94:899920. [JPH]

Frith, C. D. \& Frith, U. (2012) Mechanisms of social cognition. Annual Review of Psychology 63:287-313. [GM]

Fryer, R. (2010) An empirical analysis of "Acting White." Journal of Public Economics 94:380-96. [CDN]

Gaertner, S. L. \& Dovidio, J. F. (2000) Reducing intergroup bias: The common ingroup identity model. Psychology Press. [RB, aJD]

Gaertner, S. L. \& Dovidio, J. F. (2009) Common ingroup identity: A categorizationbased approach for reducing intergroup bias. In: Handbook of prejudice, ed. T. Nelson, pp. 489-506. Taylor \& Francis. [aJD]

Gee, G. C. \& Ford, C. L. (2011) Structural racism and health inequities: Old issues, new directions. Du Bois Review Social Science Research on Race. 8:115-32. [JPH]

Gigerenzer, G. (2010) Moral satisficing: Rethinking moral behavior as bounded rationality. Topics in Cognitive Science 2:528-54.DOI: 10.1111/j.17568765.2010.01094.x. [GM]

Gillespie, A., Howarth C. \& Cornish, F. (forthcoming) Four problems for researchers using social categories. Culture and Psychology. $[\mathrm{CH}]$

Glasford, D. E. \& Calcagno, J. (2012) The conflict of harmony: Intergroup contact, commonality and political solidarity between disadvantaged groups. Journal of Experimental Social Psychology 48:323-28. [aJD]

Glick, P. \& Fiske, S. T. (1996) The ambivalent sexism inventory: Differentiating hostile and benevolent sexism. Journal of Personality and Social Psychology 70:491-512. [aJD, NT]

Glick, P. \& Fiske, S. T. (2001) An ambivalent alliance: Hostile and benevolent sexism as complementary justifications for gender inequality. American Psychologist 56:109-18. [arJD, JTJ]

Glick, P., Lameiras, M., Fiske, S. T., Eckes, T., Masser, B., Volpato, C., Manganelli, A. M., Pek, J., Huang, L., Sakalli-Uğurlu, N., Castro, Y. R., Luiza, M., Pereira D., Willemson, T. M., Brunner, A., Materna, I. \& Wells, R. (2004) Bad but bold: Ambivalent attitudes toward men predict gender inequality in 16 nations. Journal of Personality and Social Psychology 86:713-28. [aJD]

Godbole, M. (2006) The holocaust of Indian partition: An inquest. Rupa \& Co. [r]D]

Goff, P. A., Eberhardt, J. L., Williams, M. J. \& Jackson, M. (2008) Not yet human: Implicit knowledge, historical dehumanization, and contemporary consequences. Journal of Personality and Social Psychology 94:292-306. [aJD]

Goldberg, D. T. (1993) Racist culture. Blackwell. [aJD]

Goldsmith, W. W. \& Blakely, E. J. (2010) Separate societies: Poverty and inequality in U.S. cities, Temple University Press. [MB]

Grant, P. R. and Brown, R. (1995) From ethnocentricism to collective protestresponses to relative deprivation and threats to social identity. Social Psychology Quarterly 58:195-212. [aJD]

Green, P. (1990) The enemy without: Policing and class consciousness in the miners strike. Open University Press. [JD]

Greenaway, K. H., Quinn, E. A. \& Louis, W. R. (2011) Appealing to common humanity increases forgiveness but reduces collective action among victims of historical atrocities. European Journal of Social Psychology 41:569-73. [aJD]

Greenwald, A. G. \& Banaji, M. R. (1995) Implicit social cognition: Attitudes, selfesteem and stereotypes. Psychological Review 102:4-27. [JPH]

Halabi, R. \& Sonnenschein N. (2004) The Jewish-Palestinian encounter in a time of crisis. Journal of Social Issues 60(2):375-87. [IM]

Halabi, S., Dovidio, J. F. \& Nadler, A. (2008) When and how high status groups offer help: Effects of social dominance orientation and status threat. Political Psychology 29:841-58. [aJD]

Haller, J. (1971) Outcasts from evolution: Scientific attitudes of racial inferiority. University of Illinois Press. [aJD]

Halperin, E., Russell, A. G., Trzesniewski, K. H., Gross, J. J. \& Dweck, C. S. (2011) Promoting the Middle East peace process by changing beliefs about group malleability, Science 333:1767-69. [NH] 
Halpin, S. A. \& Allen, M. W. (2004) Changes in psychosocial well-being during stages of gay identity development. Journal of Homosexuality 47:109-26. [DL]

Hamilton, D. L. (1981) Illusory correlation as a basis for stereotyping. In: Cognitive processes in stereotyping and intergroup behavior, ed. D. L. Hamilton, pp. 563-71. Erlbaum. [MA]

Hamilton, W. D. (1971) Geometry for the selfish herd. Journal of Theoretical Biology 31(2):295-311. [GM]

Harrell, C. J. P., Burford, T. I., Cage, B. N., Nelson, T. M., Shearon, S., Thompson, A. \& Green, S. (2011) Multiple pathways linking racism to health outcomes. Du Bois Review Social Science Research on Race. 8:143-58. [JPH]

Harris, L. T. \& Fiske, L. T. (2006) Dehumanizing the lowest of the low: Neuroimaging

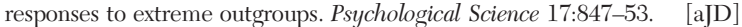

Hartling, L. M. \& Luchetta, T. (1999) Humiliation: Assessing the impact of derision, degradation, and debasement. The Journal of Primary Intervention 19:259-78. [ARF]

Harvey, R. (2003) The fall of apartheid. Palgrave Macmillan. [aJD]

Harwood, J., Hewstone, M., Hamburger, Y. \& Tausch, N. (2013) Intergroup contact: An integration of social psychological and communication perspectives. In: Communication yearbook 36, ed. C. Salomon, pp. 55-102. Routledge. [MH]

Haslam, N. (2006) Dehumanization: An integrative review. Personality and Social Psychology Review 10:252-64. [aJD]

Haslam, N. \& Holland, E. (2012) Attitudes towards asylum seekers: The Australian experience. In: Peace psychology in Australia, ed. D. Bretherton \& N. Balvin, pp. 107-20. Springer. [NH]

Haslam, N. \& Loughnan, S. (2012) Dehumanization and prejudice. In: Beyond prejudice: Extending the social psychology of intergroup conflict, inequality and social change, ed. J. Dixon \& M. Levine, pp. 89-104. Cambridge University Press. [aJD]

Haslam, N., Rothschild, L. \& Ernst, D. (2000) Essentialist beliefs about social categories. British Journal of Social Psychology 39:113-27. [NH]

Haslam, S. A., Reicher, S. D. \& Platow, M. J. (2011) The new psychology of leadership: Identity, influence and power. Psychology Press. [SAH]

Haslam, S. A., Turner, J. C., Oakes, P. J., McGarty, C. \& Reynolds, K. J. (1998) The group as a basis for emergent stereotype consensus. European Review of Social Psychology 8:203-39. [SAH]

Henrich, J., Heine, S. J. \& Norenzayan, A. (2010) The weirdest people in the world? Brain and Behavioral Sciences 33:61-135. [MB]

Henriques, J. Hollway, W., Urwin, C., Venn, C. \& Walkerdine, V. (1984) Changing the subject. Methuen. [aJD]

Henry, P. J. \& Hardin, C. D. (2006) The contact hypothesis revisited: Status bias in the reduction of implicit prejudice in the United States and Lebanon. Psychological Science 17:862-68. [JTJ]

Hewstone, M. (2009) Living apart, living together? The role of intergroup contact in social integration. Proceedings of the British Academy 162:243-300. [MH]

Hewstone, M., Cairns, E., Voci, A., Hamberger, J. \& Niens, U. (2006) Intergroup contact, forgiveness, and experience of "The Troubles" in Northern Ireland. Journal of Social Issues 62:99-120. [MH]

Hobsbawm, E. (1998) On history. Abacus. [rJD]

Hodson, G. (2011) Do ideologically intolerant people benefit from intergroup contact? Current Directions in Psychological Science 20:154-59. [rJD, MH]

Hodson, G., Hewstone, M. \& Swart, H. (2013) Advances in intergroup contact: Epilogue and future directions. In: Advances in intergroup contact, ed. G. Hodson \& M. Hewstone, pp. 262-305. Psychology Press. [MH]

Hopkins, N., Reicher, S. \& Levine, M. (1997) On the parallels between social cognition theory and the new racism. British Journal of Social Psychology 36:30529. [aJD]

Horowitz, J. L. \& Newcomb, M. D. (2001) A multidimensional approach to homosexual identity. Journal of Homosexuality 42:1-19. [DL]

Hovland, C. I. \& Sears, R. (1940) Minor studies of aggression: Correlation of lynchings with economic indices. Journal of Psychology 9:301-10. [MA]

Howarth, C. (2006) A social representation is not a quiet thing: Exploring the critical potential of social representations theory. British Journal of Social Psychology 45:65-86. [CH]

Howarth, C., Wagner, W., Magnusson, N. \& Sammut, G. (forthcoming) "It’s only other people who make me feel black": Acculturation, identity and agency in a multicultural community. Political Psychology. $\quad[\mathrm{CH}]$

Huang, J. Y., Sedlovskaya, A., Ackerman, J. M. \& Bargh, J. A. (2011) Immunizing against prejudice: Effects of disease protection on outgroup attitudes. Psychological Science 22:1550-56. [MS]

Ibanez, A., Haye, A., González, R., Hurtado, E. \& Henríquez, R. (2009) Multi-level analysis of cultural phenomena. Journal for the Theory of Social Behaviour 39:81-110. [aJD]

Imhoff, R., Bilewicz, M. \& Erb, H.-P. (2012) Collective regret versus collective guilt: Different emotional reactions to historical atrocities. European Journal of Social Psychology. 42:729-42. DOI:10.1002/ejsp.1886. [MB]

Insko, C. A. \& Schopler, J. (1998) Differential distrust of groups and individuals. In: Intergroup cognition and intergroup behavior, ed. C. Sedikides, J. Schopler \& C. A. Insko, pp. 75-107. Erlbaum. [MS]
Jackman, M. R. (1994) The velvet glove: Paternalism and conflict in gender, class, and race relations. University of California Press. [arJD, JTJ, NT]

Jackman, M. R. (2005) Rejection or inclusion of outgroups? In: On the nature of prejudice: 50 years after Allport, ed. J. F. Dovidio, P. Glick \& L. A. Rudman, Oxford. [aJD]

Jackman, M. R. \& Crane, M. (1986) "Some of my best friends are black...": Interracial friendship and whites' racial attitudes. Public Opinion Quarterly 50:459-86. [aJD]

Jackson, J. W. (1993) Realistic group conflict theory: A review and evaluation of the theoretical and empirical literature. Psychological Record 43:395-413. [MA]

Jasper, J. M. (2011) Emotions and social movements: Twenty years of theory and research. Annual Review of Sociology 37:285-303. [aJD]

Jeffries, V. \& Ransford, H. E. (1969) Interracial social contact and middle-class white reactions to the Watts riots. Social Problems 16:312-24. [MH]

Johns, M., Schmader, T. \& Martens, A. (2005) Knowing is half the battle: Teaching stereotype threat as a means of improving women's math performance. Psychological Science 16:175-79. [JMV]

Johnson, T., Dawes, C. T., Fowler, J. H., McElreath, R. \& Smirnov, O. (2009) The role of egalitarian motives in altruistic punishment. Economics Letters 102:192_ 94. [JMV]

Jones, J. M. (1972/1997) Prejudice and racism. McGraw-Hill. [JPH]

Jost, J. T. (2001) Outgroup favoritism and the theory of system justification: An experimental paradigm for investigating the effects of socio-economic success on stereotype content. In: Cognitive social psychology: The Princeton symposium on the legacy and future of social cognition, ed. G. Moskowitz, pp. 89-102. Erlbaum. [JTJ]

Jost, J. T., Banaji, M. R. \& Nosek, B. A. (2004) A decade of system justification theory: Accumulated evidence of conscious and unconscious bolstering of the status quo. Political Psychology 25:881-919. [JTJ]

Jost, J. T., Banaji, M. R. \& Nosek, B. A. (2004) A decade of system justification theory: Accumulated evidence of conscious and unconscious bolstering of the status quo. Political Psychology 25:881-919. [aJD]

Jost, J. T. \& Burgess, D. (2000) Attitudinal ambivalence and the conflict between group and system justification motives in low status groups. Personality and Social Psychology Bulletin 26:293-305. [CS]

Jost, J. T., Chaikalis-Petritsis, V., Abrams, D., Sidanius, J., van der Toorn, J. \& Bratt, C. (2012) Why men (and women) do and don't rebel: System justification on the willingness to protest. Personality and Social Psychology Bulletin 38:197208. [JTJ]

Jost, J. T. \& Hamilton, D. L. (2005) Stereotypes in our culture. In: On the nature of prejudice: Fifty years after Allport, ed. J. Dovidio, P. Glick \& L. Rudman, pp. 208-24. Blackwell. [JTJ]

Jost, J. T. \& Hunyady, O. (2002) The psychology of system justification and the palliative function of ideology. European Review of Social Psychology 13:111- 53. [JTJ]

Jost, J. T. \& Kay, A. C. (2005) Exposure to benevolent sexism and complementary gender stereotypes: Consequences for specific and diffuse forms of system justification. Journal of Personality and Social Psychology 88:498-509. [JTJ]

Jost, J. T., Kivetz, Y., Rubini, M., Guermandi, G. \& Mosso, C. (2005) System-justifying functions of complementary regional and ethnic stereotypes: Crossnational evidence. Social Justice Research 18:305-33. [JTJ]

Kalev, A., Dobbin, F. \& Kelly, E. (2006) Best practices or best guesses: Assessing the effectiveness of corporate affirmative action and diversity policies. American Sociological Review 71:589-617. [aJD, ELP]

Kanyangara, P., Rimé, B., Philippot, P. \& Yzerbyt, V. (2007) Collective rituals, emotional climate, and intergroup perception: Participation in "Gacaca" tribunals and assimilation of the Rwandan genocide. Journal of Social Issues 63:387-403. [MB]

Kay, A. C. \& Jost, J. T. (2003) Complementary justice: Effects of "poor but happy" and "poor but honest" stereotype exemplars on system justification and implicit activation of the justice motive. Journal of Personality and Social Psychology 85:823-37. [JTJ]

Kay, A. C., Jost, J. T. \& Young, S. (2005) Victim derogation and victim enhancement as \begin{tabular}{l} 
alternate routes to system justification. Psychological Science 16:240-46. [JTJ] \\
\hline
\end{tabular}

Kay, A. C., Jost, J. T., Mandisodza, A. N., Sherman, S. J., Petrocelli, J. V. \& Johnson, A. L. (2007) Panglossian ideology in the service of system justification: How complementary stereotypes help us to rationalize inequality. In: Advances in experimental social psychology, vol. 38, ed. M. P. Zanna, pp. 305-58. Academic Press. [JTJ]

Kenrick, A., \& Paluck, E. L. Extended contact with gay men through film. Unpublished data. $[\mathrm{ELP}]$

Kessi, S. (2011) Photovoice as a practice of re-presentation and social solidarity: Experiences from a youth empowerment project in Dar es Salaam and Soweto. In: Papers on social representations 20:1-27. [CH]

Killen, M., Lee-Kim, J., McGlothlin, H. \& Stangor, C. (2002) How children and adolescents evaluate gender and racial exclusion. Monographs of the Society for Research in Child Development, Serial No. 271, vol. 67, No. 4. Blackwell. [MK] 
Killen, M. \& Rutland, A. (2011) Children and social exclusion: Morality, prejudice, and group identity. Wiley/Blackwell. [MK]

Killen, M., Rutland, A., Abrams, D., Mulvey, K. L. \& Hitti, A. (2012) Development of intra- and intergroup judgments in the context of moral and social-conventional norms. Child Development. DOI: 10.1111/cdev.12011 [MK]

Kinder, D. R. \& Sears, D. O. (1981) Prejudice and politics: Symbolic racism versus racial threats to the good life. Journal of Personality and Social Psychology 40:414-31. [aJD]

Klandermans, B. (1997) The social psychology of protest. Blackwell. [aJD]

Klandermans, B. (2002) How group identification helps to overcome the dilemma of collective action. American Behavioral Scientist 45:887-900. [aJD]

Koenig, A. M., Eagly, A. H., Mitchell, A. A. \& Ristikari, T. (2011) Are leader stereotypes masculine? A meta-analysis of three research paradigms. Psychological Bulletin 137:616-42. [AHE]

Kosmin, B. A. \& Keysar, A. (2009) American religious identification survey, 2008 Summary report. Trinity College. [EPC]

Kramer, B. M. (1949) Dimensions of prejudice. Journal of Psychology 27:389-451. [aJD]

Krieger, N. (1994) Epidemiology and the web of causation: Has anyone seen the spider? Social Science \& Medicine 39:887-903. [JPH]

Krieger, N. (2011) Epidemiology and the people's health: Theory and context. Oxford University Press. [JPH]

Kring, A. M. \& Gordon, A. H. (1998) Sex differences in emotion: Expression, experience, and physiology. Journal of Personality and Social Psychology 74:686-783. [GM]

Küpper, B., Wolf, C. \& Zick, A. (2010) Social status and anti-immigrant attitudes in Europe: An examination from the perspective of social dominance theory. International Journal of Conflict and Violence 4:205-19. [MB]

Langdridge, D. (2008) Are you angry or are you heterosexual? A queer critique of lesbian and gay models of identity development. In: Feeling queer or queer feelings: Radical approaches to counselling sex, sexualities and gender, ed. L. Moon, pp. 23-35. Routledge. [DL]

Latané, B. (1980) The psychology of social impact. American Psychologist 36:34356. [ELP]

Laurin, K., Kay, A. \& Fitzsimons, G. (2012) Reactance versus rationalization: Divergent responses to policies that constrain freedom. Psychological Science 23:205-209. [ELP]

Leach, C. (2005) Against the notion of a "new racism." Journal of Community and Applied Social Psychology 15:432-45. [rJD]

Lecci, L. \& Johnson, J. D. (2008) Black anti-White attitudes: The influence of racial identity and the Big Five. Personality and Individual Differences 44:182-92. [JMV]

Lerner, M. J. (1980) The belief in a just world. Plenum. [MA]

Levin, J. \& Levin, W. C. (1982) The functions of prejudice and discrimination. Harper \& Row. [aJD]

Levine, M. \& Crowther, S. (2008) The responsive bystander: How social group membership and group size can encourage as well as inhibit bystander intervention. Journal of Personality and Social Psychology 96:1429-39. [aJD]

Levy, S. \& Killen, M. (2008) Intergroup attitudes and relations in childhood through adulthood. Oxford University Press. [MK]

Lewin, K. (1951) Field theory in social science, ed. D. Cartwright. Harper. [ELP]

Lewis, G. B. (2011) The friends and family plan: Contact with gays and support for gay rights. The Policy Studies Journal 39:217-38. [DL]

Leyens, J.-P., Cortes, B., Demoulin, S., Dovidio, J. F., Fiske, S. T., Gaunt, R. Paladino, M.-P., Rodriguez-Perez, A., Rodriguez-Torres, R. \& Vaes, J. (2003) Emotional prejudice, essentialism, and nationalism: The 2002 Tajfel lecture. European Journal of Social Psychology 33:703-17. [aJD]

Leyens, J.-P., Paladino, P. M., Rodriguez-Torres, R., Vaes, J., Demoulin, S., Rodriguez-Perez, A. \& Gaunt, R. (2000) The emotional side of prejudice: The attribution of secondary emotions to ingroups and outgroups. Personality and Social Psychology Review 4:186-97. [ARF]

Leyens, J. Ph., Demoulin, S., Vaes, J., Gaunt, R. \& Paladino, M. P. (2007) Infrahumanization: The wall of group differences. Social Issues and Policy Review 1:139-72. [aJD]

Leyens, J. Ph., Rodriguez, A. P., Rodriguez, R. T., Gaunt, R., Paladino, P. M., Vaes, J. \& Demoulin, S. (2001) Psychological essentialism and the attribution of uniquely human emotions to ingroups and outgroups. European Journal of Social Psychology 31:395-411. [aJD]

Lilienfeld, S. O., Ammirati, R. \& Landfield, K. (2009) Giving debiasing away. Can psychological research on correcting cognitive errors promote human welfare? Perspectives on Psychological Science 4:390-98. [aJD]

Lindner, E. G. (2001) Humiliation as the source of terrorism: A new paradigm. Peace Research 33:59-68. [ARF]

Lippa, R. (2010) Sex differences in personality traits and gender-related occupational preferences across 53 nations: Testing evolutionary and social-environmental theories. Archives of Sexual Behavior 39:619-36. [GM]

Lombardo, W. K., Crester, G. A. \& Roesch, S. C. (2001) For crying out loud-the differences persist into the '90s. Sex Roles 45:529-47. [GM]
Long, H. H. (1951) Race prejudice and social change. American Journal of Sociology 57:15-19. [aJD]

Mackie, D. M. \& Smith, E. R. (Eds.) (2002) From prejudice to intergroup emotions: Differentiated reactions to social groups. Psychology Press. [aJD]

Mackie, D. M., Smith, E. R. \& Ray, D. G. (2008) Intergroup emotions and intergroup relations. Personality and Social Psychology Compass 2:1866-80. $[\mathrm{rJD}, \mathrm{ARF}]$

Mallett, R. K., Huntsinger, J. R., Sinclair, S. \& Swim, J. K. (2008) Seeing through their eyes: When majority group members take collective action on behalf of an outgroup. Group Processes and Intergroup Relations 11:451-70. DOI: 10.1177/ 1368430208095400. [DA, aJD, MH]

Maoz, I. (2000a) Power relations in intergroup encounters: A case study of JewishArab encounters in Israel. International Journal of Intercultural Relations 24 (4):259-77. [IM]

Maoz, I. (2000b) Multiple conflicts and competing agendas: A framework for conceptualizing structured encounters between groups in conflict - The case of a coexistence project of Jews and Palestinians in Israel. Peace and Conflict: Journal of Peace Psychology 6(2):135-56. [IM]

Maoz, I. (2004) Coexistence is in the eye of the beholder: Evaluating intergroup encounter interventions between Jews and Arabs in Israel. Journal of Social Issues 60(2):437-52. [IM]

Maoz, I. (2006) Between coexistence and conflict: Jewish-Arab encounters in Israel In: Arab-Jewish Relations: From conflict to resolution? ed. E. Podeh \& A Kaufman, pp. 319-41. Sussex Academic Press. [IM]

Maoz, I. (2011) Does contact work in protracted asymmetrical conflict? Appraising 20 years of reconciliation-aimed encounters between Israeli Jews and Palestinians. Journal of Peace Research 48(1):115-25. [arJD, IM]

Marcu, A. \& Chryssochoou, X. (2005) Exclusion of ethnic groups from the realm of humanity: Prejudice against the Gypsies in Britain and in Romania. Psicologia Politica 30:41-56. [MB]

Marques, J. P. (2006) The sounds of silence: Nineteenth-century Portugal and the abolition of the slave trade. Berghahn Books. [aJD]

Marques, J. P. (2010a) Afterthoughts. In: Who abolished slavery?: Slave revolts and abolitionism, ed. S. Drescher \& P. C. Emmer, pp. 185-200. Berghahn Books. [aJD]

Marques, J. P. (2010b) Slave revolts and the abolition of slavery: An overinterpretation. In: Who abolished slavery?: Slave revolts and abolitionism, ed. S Drescher \& P. C. Emmer, pp. 3-89. Berghahn Books. [aJD]

Martens, A., Johns, M., Greenberg, J. \& Schimel, J. (2006) Combating stereotype threat: The effect of self-affirmation on women's intellectual performance. Journal of Experimental and Social Psychology 42:236-43. [JMV]

Martin, J. (1986) The tolerance of injustice. In: Relative deprivation and social comparison: The Ontario Symposium, vol. 4, ed. J. M. Olson, C. P. Herman \& M. P. Zanna, pp. 217-42. Erlbaum. [ARF]

McCauley, C. R. \& Stitt, C. (1978) An individual and quantitative measure of stereotypes. Journal of Personality and Social Psychology 36:929-40. [GM]

McDonald, M. M., Navarrete, C. D. \& Van Vugt, M. (2012) Evolution and the psychology of intergroup conflict: The male warrior hypothesis. Philosophical Transactions of the Royal Society B 367:670-79. [MS]

McGrane, J. A. \& White, F. A. (2007) Differences in Anglo and Asian Australians' explicit and implicit prejudice and the attenuation of their in-group bias. Asian Journal of Social Psychology 10:204-10. [MB]

McLaren, L. (2003) Anti-immigrant prejudice in Europe: Contact, threat perception, and preferences for the exclusion of migrants. Social Forces 81:909-36. [RB]

McPherson, J. M. (2003) Battle cry of freedom: The Civil War era. Oxford University Press. [MA]

McPherson, M., Smith-Lovin, L. \& Cook, J. M. (2001) Birds of a feather: Homophily in social networks. Annual Review of Sociology 27:415-44. [JMV]

Miles, R. (1989) Racism. Routledge \& Kegan Paul. [JD]

Montagu, M. F. (1949) Some psychodynamic factors in race prejudice. Journal of Social Psychology 30:175-87. [aJD]

Mullen, B., Brown, R. \& Smith, C. (1992) Ingroup bias as a function of salience, relevance, and status: An integration. European Journal of Social Psychology 22:103-22. [MA]

Murray, S. L. \& Holmes, J. G. (2011) Interdependent minds: The dynamics of close relationships. The Guildford Press. [DAP]

Nadler, A. (2002) Inter-group helping relations as power relations: Helping relations as affirming or challenging inter-group hierarchy. Journal of Social Issues 58:487-503. [MB, aJD]

Nadler, A. (2010) Interpersonal and intergroup helping relations as power relations Implications for real-world helping. In: The psychology of prosocial behavior, ed. S. Sturmer \& M. Synder, pp. 269-87. Wiley Blackwell. [aJD]

Nadler, A. \& Halabi, S. (2006) In tergroup helping as status relations: Effects of status stability, identification, and type of help on receptivity to high status group's help. Journal of Personality and Social Psychology 91:97-110. [aJD]

Nadler, A., Halabi, S. \& Harpaz-Gorodeisky, G. (2007) Inter-group helping as status organizing processes: Implications for inter-group misunderstandings. 
Unpublished paper. Recovered 08/15/2008 from http://www.humiliationstudies.org/documents/NadlerIntergrougHelping2007revisedversion.pdf. [aJD]

Nagda, B. \& Gurin, P. (2006) “Just a friend? Or a just friend?" Paper presented at the 6th Biennial Convention of the Society for the Psychological Study of Social Issues. Social Justice: Research, Action and Policy, Long Beach, California, June 2006. [NT]

Nelson, T. D., ed. (2009) Handbook of prejudice, stereotyping and discrimination. Psychology Press. [aJD]

Nepstad, S. E. (2007) Oppositional consciousness amongst the privileged: Remaking religion in the central America solidarity movement. Critical Sociology 33:661-88. [aJD]

Nesdale, D. \& Lawson, M. J. (2011) Social groups and children's intergroup attitudes: Can school norms moderate the effects of social group norms? Child Development 82:1594-606. [MK]

Neuberg. S. L. \& Cottrell, C. A. (2006) Evolutionary bases of prejudices. In: Evolution and social psychology, ed. M. Schaller, J. A. Simpson \& D. T. Kenrick, pp. 163-87. Psychology Press. [aJD]

Neuberg, S. L., Kenrick, D. T. \& Schaller, M. (2011) Human threat management systems: Self-protection and disease-avoidance. Neuroscience \& Biobehavioral Reviews 35:1042-51. [aJD]

Nier, J. A., Gaertner, S. L., Dovidio, J. F., Banker, B. S. \& Ward, C. M. (2001) Changing interracial evaluations and behavior: The effects of a common group identity. Group Processes and Intergroup Relations 4:299-316. [aJD]

No, S., Hong, Y. Y., Liao, H., Lee, K., Wood, D. \& Chao, M. M. (2008) Lay theory of race affects and moderates Asian Americans' responses toward American culture. Journal of Personality and Social Psychology 95:991-1004. [NH]

Oakes, P. (2001) The root of all evil? Unearthing the categorization process. In: Blackwell handbook of social psychology, ed. R. Brown \& S. Gaertner, chapter 1. Blackwell. [aJD]

Oakes, P. J., Haslam, S. A. \& Turner, J. C. (1994) Stereotyping and social reality. Blackwell. [JD, SAH]

O'Gorman, R. (2010) The evolutionary logic of terrorism. In: The Psychology of Counter-Terrorism, ed. A. Silke, pp. 62-75. Routledge. [ARF]

Öhman, A. (2009) Of snakes and faces: An evolutionary perspective on the psychology of fear. Scandinavian Journal of Psychology 50:543-52. [GM]

Olson, M. A. \& Fazio, R. H. (2006) Reducing automatically-activated racial prejudice through implicit evaluative conditioning. Personality and Social Psychology Bulletin 32:421-33. [aJD]

Opotow, S. (1990) Moral exclusion and injustice: An introduction. Journal of Social Issues 46:1-20. [aJD]

Oppenheimer D. B. (1994-1995) Kennedy, King, Shuttleswoth and Walker: The events leading to the introduction of the Civil Rights Act of 1964. University of San Francisco Law Review 29:645-79. [aJD]

Paluck, E. L. (2009a) Reducing intergroup prejudice and conflict using the media: A field experiment in Rwanda. Journal of Personality and Social Psychology 96:574-87. [ELP]

Paluck, E. L. (2009b) What's in a norm? Sources and processes of norm change. Journal of Personality and Social Psychology 96:594-600. [ELP]

Paluck, E. L. \& Green, D. P. (2009) Prejudice reduction: What works? A review and assessment of resarch and practice. Anmual Review of Psychology 60:339-67. [aJD, MH]

Paluck, E. L. \& Shepherd, H. (under review) The salience of social referents: A field experiment on collective norms and harassment behavior in a school social network. [ELP]

Paolini, S., Hewstone, M., Cairns, E. \& Voci, A. (2004) Effects of direct and indirect cross-group friendships on judgments of Catholics and Protestants in Northern Ireland: The mediating role of an anxiety-reduction mechanism. Personality and Social Psychology Bulletin 30:770-86. [aJD]

Paradies, Y. (2006) Defining, conceptualizing and characterizing racism in health research. Critical Public Health 16:143-57. [JPH]

Park, J. H., Schaller, M. \& Crandall, C. S. (2007) Pathogen-avoidance mechanisms and the stigmatization of obese people. Evolution and Human Behavior 28:41014. [MS]

Perruchet, P. \& Pacton, S. (2006) Implicit learning and statistical learning: One phenomenon, two approaches. Trends in Cognitive Sciences 10:233-38. $[\mathrm{GM}]$

Pettigrew, T. (1991) Normative theory in intergroup relations: Explaining both harmony and conflict. Psychology and Developing Societies 3:3-16. [ELP]

Pettigrew, T. (1998) Intergroup contact theory. Annual Review of Psychology 49 (1):65-85. [IM]

Pettigrew, T. F. (1996) How to think like a social scientist. Harper-Collins. [MH]

Pettigrew, T. F. (2010) Commentary: South African contributions to the study of intergroup relations. Journal of Social Issues 66:417-30. [aJD, NT]

Pettigrew, T. F., Christ, O., Wagner, U. \& Stellmacher, J. (2007) Direct and indirect intergroup contact effects on prejudice: A normative interpretation. International Journal of Intercultural Relations 31:411-25. [RB, MH]

Pettigrew, T. F. \& Meertens, R. W. (1995) Subtle and blatant prejudice in Western Europe. European Journal of Social Psychology 57:57-75. [aJD]
Pettigrew, T. F. \& Tropp, L. (2006) A meta-analytic test of intergroup contact theory. Journal of Personality and Social Psychology 90:751-83. [RB, aJD, MH, JTJ, DL $]$

Pettigrew, T. F., \& Tropp, L. R. (2008) How does intergroup contact reduce prejudice? Meta-analytic tests of three mediators. European Journal of Social Psychology 38:922-34. [aJD]

Pettigrew, T. F. \& Tropp, L. R. (2011) When groups meet: The dynamics of intergroup contact. Psychology Press. [RB]

Pettigrew, T. F., Tropp, L. R., Wagner, U. \& Christ, O. (2011) Recent advances in intergroup contact theory. International Journal of Intercultural Relations $35: 271-80$. [aJD]

Pew Research Center (2008) The Pew Global Attitudes Report: Unfavorable attitudes of Jews and Muslims on the increase in Europe. Washington: Pew Research Center. [RB]

Phelps, E. A., O’Connor, K. J., Cunningham, W. A., Funayama, E. S., Gatenby, J. C., Gore, J. C. \& Banaji, M. R. (2000) Performance on indirect measures of race evaluation predicts amygdala activation. Journal of Cognitive Neuroscience 12:729-38. [aJD]

Piven, F. F. (2008) Challenging authority: How ordinary people change America. Rowman \& Littlefield. [aJD]

Piven, F. F. \& Cloward, R. A. (1977) Poor people's movements: Why they succeed, how they fail. Vintage. [aJD, JD]

Poore, A. G., Gagne, F., Barlow, K. M., Lydon, J. E., Taylor, D. M. \& Wright, S. C. (2002) Contact and the person/group discrimination discrepancy in an Inuit community. Journal of Psychology 136:371-82. [aJD]

Pratto, F., Sidanius, J., Stallworth, L. M. \& Malle, B. F. (1994) Social dominance orientation: A personality variable predicting social and political attitudes. Journal of Personality and Social Psychology 67:741-63. [CS]

Quattrone, G. A. \& Jones, E. E. (1980) The perception of variability within ingroups and outgroups: Implications for the law of small numbers. Journal of Personality and Social Psychology 38:141-52. [MA]

Quillian, L. (2006) New approaches to understanding prejudice and discrimination. Annual Review of Sociology 32:299-338. [aJD]

Quintana, S., \& McKown, C. (2007) The handbook of race, racism, and the developing child. Wiley. [MK]

Rees, J., Allpress, J. A. \& Brown, R. (in press) Nie wieder: Group-based emotions about wrongdoing to one outgroup affect attitudes toward an unrelated minority. Political Psychology. [RB]

Reicher, S. D. (2007) Rethinking the paradigm of prejudice. South African Journal of Psychology 37:820-34. [aJD, NT]

Reicher, S. D. \& Haslam, S. A. (2006) Rethinking the psychology of tyranny: The BBC Prison Study. British Journal of Social Psychology 45:1-40. $[\mathrm{NT}]$

Reynolds, K. J., Haslam, S. A. \& Turner, J. C. (2012) Prejudice, social identity and social change: Resolving the Allportian problematic. In: Beyond the prejudice problematic: Extending the social psychology of conflict, inequality and social change, ed. J. Dixon \& R. M. Levine, pp. 48-69. Cambridge University Press. [SAH]

Ridgeway, C. (2001) The emergence of status beliefs: From structural inequality to legitimizing ideology. In: The psychology of legitimacy: Emerging perspectives on ideology, justice, and intergroup relations, ed. J. Jost \& B. Major, pp. 257-77. Cambridge University Press. [rJD, SCW]

Rimé, B., Kanyangara, P., Yzerbyt, V. \& Paezt, D. (2011) The impact of Gacaca tribunals in Rwanda: Psychosocial effects of participation in a truth and reconciliation process after a genocide. European Journal of Social Psychology 41:695-706. [ARF]

Riordan, C. (1978) Equal status interracial contact: A review and revision of the concept. International Journal of Intercultural Relations 2:161-85. [aJD]

Roberts, A. \& Ash, T. G. (2009) Civil resistance and power politics: The experience of non-violent action from Ghandi to the present. Oxford University Press. [aJD]

Roccas, S. \& Brewer, M. B. (2002) Social identity complexity. Personality and Social Psychology Review 6:88-106. DOI: 10.1207/ S15327957PSPR0602_01. [DA]

Rose, A. M. (1956) Intergroup relations vs. prejudice: Pertinent theory for the study of social change. Social Problems 4:173-76. [aJD, SCW]

Rowland, N. J., Long, B. \& Yarrison, F. (in press) "Imagined recursivity" and stigma management among American Atheists. In: Recursion in human systems, ed. M. Orozco \& Z. Beckstead. Transaction Press. [EPC]

Rude, G. (1981) The crowd in history: A study of popular disturbances in France and England, 1730-848. Lawrence and Wishart. [aJD]

Rye, B. J. \& Meaney, G. J. (2010) Self-defense, sexism, and etiological beliefs: Predictors of attitudes toward gay and lesbian adoption. Journal of GLBT Family Studies 6:1-24. [aJD]

Sadanius, J., Pratto, F., van Laar, C. \& Levin, S. (2004) Social dominance theory: Its agenda and method. Political Psychology 25:845-80. [JPH]

Saenger, G. (1953) The social psychology of prejudice. Harper. [aJD]

Saguy, T. \& Chernyak-Hai, L. (2012) Intergroup contact can undermine disadvantaged group members' attributions to discrimination. Journal of Experimental Social Psychology 48:714-20. [rJD, JTJ] 
Saguy, T., Tausch, N., Dovidio, J. F. \& Pratto, F. (2009) The irony of harmony: Intergroup contact can produce false expectations for equality. Psychological Science 20:114-21. [MB, aJD, JTJ, NT]

Said, E. (1993) Culture and imperialism. Knopf. [aJD]

Salt, C. \& Layzell, J. (1985) Here we go! Women's memories of the 1984/85 miners' strike. Co-operative Retail Services. [JD]

Salter, F. (2007) On genetic interests: Family, ethnicity, and humanity in an age of mass migration. Transaction. [GM]

Samelson, F. (1978) From "race psychology" to "studies in prejudice": Some observations on the thematic reversal in social psychology. Journal of the History of the Behavioral Sciences 14:265-78. [aJD]

Saminaden, A., Loughnan, S. \& Haslam, N. (2010) Afterimages of savages: Implicit associations between "primitive" peoples, animals, and children. British Journal of Social Psychology 49:91-105. [aJD]

Sampson, E. E. (1999) Dealing with differences: An introduction to the social psychology of prejudice. Harcourt Brace. [aJD]

Scarman, L. (1981) The Brixton disorders, 10-12 April, 1981: Report of an inquiry by the Rt. Hon. The Lord Scarman, O.B.E. H.M.S.O. [JD]

Schaller, M. \& Abeysinghe, A. M. N. D. (2006) Geographical frame of reference and dangerous intergroup attitudes: A double-minority study in Sri Lanka. Political Psychology 27:615-31. [MS]

Schaller, M. \& Neuberg, S. L. (2012) Danger, disease, and the nature of prejudice(s). Advances in Experimental Social Psychology 46:1-54. [MS]

Shnabel, N. \& Nadler, A. (2008) A needs-based model of reconciliation: Satisfying the differential needs of victim and perpetrator. Journal of Personality and Social Psychology 94:116-32. [MB]

Schuman, H., Steeh, C., Bobo, L. \& Krysan, M. (1997) Racial attitudes in America: Trends and interpretations (revised edition). Harvard University Press. [aJD]

Sears, D. O., van Laar, C., Carrillo, M. \& Kosterman, R. (1997) Is it really racism? The origins of white Americans' opposition to race targeted policies. Public Opinion Quarterly 61:16-53. [aJD]

Secord, P. F. \& Backman, C. W. (1961) Personality change and the problem of stability and change in individual behavior: An interpersonal approach. Psychological Review 68:21-32. [DL]

Seligman, M. E. P. (1970) On the generality of the laws of learning. Psychological Review 77:406-18. [GM]

Semyonov, M., Raijman, R. \& Gorodzeisky, A. (2006) The rise of anti-immigrant sentiment in European societies, 1988-2000. American Sociological Review 71:426-49. [RB]

Sengupta, N. K., Barlow, F. K. \& Sibley, C. G. (2012) Intergroup contact and postcolonial ideology: Outgroup contact ameliorates symbolic exclusion but not historical negation. International Journal of Intercultural Relations 36:50617. [rJD]

Shanahan, M. J. \& Flaherty, B. P. (2001) Dynamic patterns of time use in adolescence. Child Development 72:385-401. [GM]

Shanks, D. R. (2005) Implicit learning. In: Handbook of cognition, ed. K. Lamberts \& R. Goldstone, pp. 202-20. Sage Publications. [GM]

Shelton, J. N. (2000) A reconceptualization of how we study issues of racial prejudice. Personality and Social Psychology Review 4:374-90. [aJD]

Shelton, J. N. \& Richeson, J. A. (2006) Interracial interactions: A relational approach. Advances in experimental social psychology 38:121-81. [aJD, DAP]

Sherif, M., Harvey, O. J., White, B. J., Hood, W. R. \& Sherif, C. (1961) Intergroup conflict and cooperation: The robber's cave experiment. University of Oklahoma. [aJD]

Sibley, C. G. \& Duckitt, J. (2008) Personality and prejudice: A meta-analysis and theoretical review. Personality and Social Psychology Review 12:248-79. [CS]

Sibley, C. G., Overall, N. C. \& Duckitt, J. (2007) When women become more hostilely sexist toward their gender: The system-justifying effect of benevolent sexism. Sex Roles 57:743-54. [aJD]

Sigelman, L. \& Welch, S. (1993) The contact Hypothesis revisited: Black-white interaction and positive racial attitudes. Social Forces 71:781-95. [aJD]

Simmel, G. (1955) Conflict and the web of group affiliations. Free Press. [DA]

Sinclair, S., Hardin, C. D., Lowery, B. S. \& Colangelo, A. (2005) Social tuning of automatic racial attitudes: The role of affiliative motivation. Journal of Personality and Social Psychology 89:583-92. [SCW]

Smelser, N. J. (1962) Theory of collective behaviour. Routledge and Kegan Paul. [aJD]

Smetana, J. G. (2006) Social-cognitive domain theory: Consistencies and variations in children's moral and social judgments. In: Handbook of moral development, ed. M. Killen \& J. G. Smetana, pp. 119-54. Erlbaum. [MK]

Smith, A. M. (1994) New right discourse on race and sexuality: Britain 1968-1990. Cambridge University Press. [DL]

Smith, D. (2008) Globalization, degradation and the dynamics of humiliation. Current Sociology 56:371-79. [ARF]

Smith, E. R. (1993) Social identity and social emotions: Toward new conceptualizations of prejudice. In: Affect, cognition and stereotyping, ed. D. M. Mackie \& D. L. Hamilton, pp. 297-315, Academic Press. [RB]
Son Hing, L. S., Bobocel, D. R., Zanna, M. P. \& McBride, M. V. (2007) Authoritarian dynamics and unethical decision making: High social dominance orientation leaders and high right-wing authoritarianism followers. Journal of Personality and Social Psychology 92:67-81. [CS]

Sorensen, G. (1992) Utopianism in peace research: The Ghandian heritage. Journal of Peace Research 29:135-44. [aJD]

Spence, M. (1973) Job market signaling. Quarterly Journal of Economics 87 (3):355-74. [CDN]

Staub, E. (1989) The roots of evil: The origins of genocide and other group violence. Cambridge University Press. [aJD, ARF]

Steele, C. M. \& Aronson, J. (1995) Stereotype threat and the intellectual test performance of African Americans. Journal of Personality and Social Psychology 69:797-811. [JMV]

Stephan, W. G. (1983) Intergroup relations. In: Social psychology, ed. D. Perlman \& P. Cozby, pp. 414-41. Holt, Rinehart \& Winston. [aJD]

Stephan, W. G \& Finlay, K. (1999) The role of empathy in improving intergroup relations. Journal of Social Issues 55:729-43. [aJD]

Sternberg, R. J. (2003) A duplex theory of hate: Development and application to terrorism, massacres, and genocide. Review of General Psychology 7:299328. [ARF]

Stott, C., Drury, J. \& Reicher, S. (2012) From prejudice to collective action. In: Beyond prejudice: Extending the social psychology of conflict, inequality and social change, ed. J. Dixon \& M. Levine, pp. 286-303, Cambridge University Press. [JD]

Sugrue, T. J. (2010) Stories and legends. The Nation, June 7th, http://www.thenation.com/article/stories-and-legends. [aJD]

Surace, S. J. \& Seeman, M. (1968) Some correlates of civil rights activism. Social Forces 46:197-207. [aJD]

Tajfel, H. (1981) Social stereotypes and social groups. In: Intergroup behaviour, ed J. C. Turner \& H. Giles, pp. 144-67. Blackwell. [SAH]

Tajfel, H. \& Turner, J. C. (1979) An integrative theory of intergroup conflict. In: The social psychology of intergroup relations, ed. W. G. Austin \& S. Worchel, pp. 33-47. Brooks/Cole. [DA, rJD, JD, SAH, NT]

Tajfel, H. \& Turner J. (1986) The social identity theory of intergroup behavior. In Psychology of intergroup relations, ed. S. Worchel \& W. Austin, pp. 7-24. Nelson-Hall. [aJD, IM]

Talaska, C. A., Fiske, S. T. \& Chaiken, S. (2008) Legitimating racial discrimination: Emotions, not beliefs, best predict discrimination in a metaanalysis. Social Justice Research 21:263-96. [aJD]

Tam, T., Hewstone, M., Cairns, E., Tausch, N., Maio, G. \& Kenworthy, J. (2007) The impact of intergroup emotions on forgiveness in Northern Ireland. Group Processes \& Intergroup Relations 10:119-35. [ [NH, MH]

Tam, T., Hewstone, M., Kenworthy, J. \& Cairns, E. (2009) Intergroup trust in Northern Ireland. Personality and Social Psychology Bulletin 35:45-59. [MH]

Tam, T., Hewstone, M., Kenworthy, J., Cairns, E., Marinetti, C., Geddes, L. \& Parkinson, B. (2008) Post-conflict reconciliation: Intergroup forgiveness, trust, and implicit biases in Northern Ireland. Journal of Social Issues 64:303-20. [ [MH]

Tarrow, S. G. (2011) Power in movement: Social movements and contentious politics. 3rd ed. Cambridge University Press. [aJD]

Tausch, N., Becker, J. C., Spears, R., Christ, O., Saab, R., Singh, P. \& Siddiqui, R. N (2011) Explaining radical group behavior: Developing emotion and efficacy routes to normative and nonnormative collective action. Journal of Personality and Social Psychology 101:129-48. [ARF]

Tausch, N., Hewstone, M., Kenworthy, J. B., Psaltis, C., Schmid, K., Popan, J. R. \& Hughes, J. (2010) Secondary transfer effects of intergroup contact: Alternative accounts and underlying processes. Journal of Personality and Social Psychology 99:282-302. [MH]

Tausch, N., Saguy, T. \& Singh, P. (2009) Contact between Muslims and Hindus: Benefits and limitations. Unpublished Manuscript. [aJD]

Tausch, N., Saguy, T., Singh, P., Bryson, J. \& Siddiqui, R. N. (2012) The implications of intergroup contact for collective action and individual mobility orientations. Manuscript in preparation. [NT]

Thompson, E. P. (1991) Customs in common. Penguin. [aJD]

Tilcsik, A. (2011) Pride and prejudice: Employment discrimination against openly gay men in the United States. American Journal of Sociology 117:586-626. [DL]

Tileagă, C. (2007) Ideologies of moral exclusion: A critical discursive reframing of depersonalization, delegitimization and dehumanization. British Journal of Social Psychology. 46:717-37. [MB]

Tilly, C. (1998) Durable inequality. University of California Press. [DAP]

Tilly, C., Tilly, L. \& Tilly, R. (1975) The rebellious century, 1830-1930. Harvard University Press. [a]D]

Tropp, L. R., Hawi, D., van Laar, C. \& Levin, S. (2012) Perceived discrimination, cross ethnic friendships and their effects on ethnic activism over time: A longitudinal investigation of three ethnic minority groups. British Journal of Social Psychology 51(2):257-72. DOI: 10.1111/j.2044-8309.2011.02050.x. [aJD]

Tuch, S. A. \& Hughes, M. (1996) Whites' racial policy attitudes. Social Science Quarterly 77:723-41. [aJD] 
References/Dixon et al.: Beyond prejudice

Turiel, E. (1998) The development of morality. In: Handbook of child psychology 5th ed., vol. 3: Social, emotional, and personality development, ed. W. Damon, pp. 863-932. Wiley. [MK]

Turiel, E. (2002) The culture of morality: Social development, context, and conflict. Cambridge University Press. [MK]

Turner, R. H. \& Killian, L. M. (1987) Collective behaviour. Prentice-Hall. [aJD]

Turner, R. N., Hewstone, M., Voci, A., Paolini, S. \& Christ, O. (2007) Reducing prejudice via direct and extended cross-group friendship. In: European review of social psychology, vol. 18, ed. W. Stroebe \& M. Hewstone, pp. 212-55. Psychology Press. $[\mathrm{MH}]$

Uchida, A. (1992) When difference is dominance: A critique of the anti-powerbased cultural approach to gender differences. Language in Society 21:547-68. [rJD]

Ulfelder, J. (2005) Contentious collective action and the breakdown of authoritarian regimes. International Political Science Review 26:311-34. [aJD]

van Zomeren, M., Postmes, T. \& Spears, R. (2008) Toward an integrative social identity model of collective action: A quantitative research synthesis of three socio-psychological perspectives. Psychological Bulletin 134: 504-35. [aJD]

van Zomeren, M., Spears, R., Fischer, A. \& Leach, C. W. (2004) Put your money where your mouth is! Explaining collective action tendencies through groupbased anger and group efficacy. Journal of Personality and Social Psychology 87:649-64. [aJD]

Vasiljevic, M. \& Crisp, R. J. (2010) Thinking about surprising social pairings reduces discrimination and increases tolerance between social groups. Paper presented at the International Conference on Discrimination and Tolerance in Intergroup Relations, Jena, Germany, June 30-July 3. [DA]

Verkuyten, M. (2003) Ethnic in-group bias among minority and majority early adolescents: The perception of negative peer behaviour. British Journal of Developmental Psychology 21: 543-64. [MK]

Vigil, J. M. (2007) Asymmetries in the social styles and friendship preferences of men and women. Human Nature 18:143-61. [JMV]

Vigil, J. M. (2009) A socio-relational framework of sex differences in the expression of emotion. Behavioral and Brain Sciences 32:375-428. [JMV]

Wagner, U. \& Hewstone, M. (2012) Intergroup contact. In: The Oxford handbook of intergroup conflict, ed. L. R. Tropp, pp. 193-209. Oxford University Press. [MH]

Wagner, W., Sen, R., Permanadeli, R. \& Howarth, C. (forthcoming) The veil and Muslim women's identity: Cultural pressures and resistance to stereotyping. Culture \& Psychology. [CH]

Waldzus, S. \& Fiske, A. P. (in preparation) Social identities beyond comparisons: A relational models approach to intergroup relations. [r]D, SW]

Wenzel, M. (2001) Justice and identity: The significance of inclusion for perceptions of entitlement and the justice motive. Personality and Social Psychology Bulletin 26:157-76. [aJD]
Wetherell, M. \& Potter, J. (1992) Mapping the language of racism: Discourse and the legitimation of exploitation. Harvester Wheatsheaf. [aJD]

Wheeler, M. E. \& Fiske, S. T. (2005) Controlling racial prejudice: Socio-cognitive goals affect amygdala and stereotype activation. Psychological Science 16:56-63. [aJD]

White, J. B. \& Langer, E. J. (1999) Horizontal hostility: Relations between similar minority groups. Journal of Social Issues 55:537-59. [aJD]

Whitley, B. E., Jr. (1999) Right-wing authoritarianism, social dominance orientation, and prejudice. Journal of Personality and Social Psychology 77:126-34. [CS]

Williams, M. J. \& Eberhardt, J. L. (2008) Biological conceptions of race and the motivation to cross racial boundaries. Journal of Personality and Social Psychology 94:1033-47. [NH]

Winiewski, H. M. (2010) Warmth and competence as a structure of stereotype content. Modification and application of BIAS map model to individual-level cognitions. Unpublished doctoral dissertation. University of Warsaw. [MB]

Woodman, N. J. \& Lena, H. R. (1980) Counseling with gay men and women: A guide for facilitating positive lifestyles. Jossey Bass. [DL]

Wright, S. C. (2001) Strategic collective action: Social psychology and social change. In: Intergroup processes: Blackwell handbook of social psychology, ed. R. Brown \& S. L. Gaertner, Vol. 4, pp. 409-30. Blackwell. [aJD]

Wright, S. C., Aron, A., Mclaughlin-Volpe, T. \& Ropp, S. A. (1997) The extended contact effect: Knowledge of cross-group friendships and prejudice. Journal of Personality and Social Psychology 73:73-90. [RB, MH]

Wright, S. C. \& Baray, G. (2012) Models of social change in social psychology: Collective action or prejudice reduction, conflict or harmony. In: Beyond the "prejudice problematic": Extending the social psychology of intergroup conflict, inequality and social change, ed. J. Dixon \& M. Levine, pp. 225-47. Cambridge University Press. [aJD, SCW]

Wright, S. C. \& Lubensky, M. (2009) The struggle for social equality: Collective action vs. prejudice reduction. In: Intergroup misunderstandings: Impact of divergent social realities, ed. S. Demoulin, J. P. Leyens \& J. F. Dovidio, pp. 291-310. Psychology Press. [MB, arjD, NT, SCW]

Wright, S. C., Taylor, D. M. \& Moghaddam, F. M. (1990) Responding to membership in a disadvantaged group: From acceptance to collective protest. Journal of Personality and Social Psychology 58:994-1003. [ARF, JTJ, NT]

Zawadzki, B. (1948) Limitations of the scapegoat theory of prejudice. Journal of Abnormal and Social Psychology 43(2):127-41. [MB, aJD, GM]

Zimmermann, A., Abrams, D., Doosje, B. \& Manstead, A. (2011) Causal and moral responsibility: Antecedents and consequences of group-based guilt. European Journal of Social Psychology 41:825-39. DOI: 10.1002/ejsp.826. [DA]

Zunes, S. (1999) The role of non-violent action in the downfall of apartheid. The Journal of Modern African Studies 37:137-69. [aJD] 